\title{
Nuclear Aurora-A kinase-induced hypoxia signaling drives dissemination and metastasis in breast cancer.
}

Kristina Marinak Whately

kmmarinak@mix.wvu.edu

Follow this and additional works at: https://researchrepository.wvu.edu/etd

Part of the Cancer Biology Commons, and the Cell Biology Commons

\section{Recommended Citation}

Whately, Kristina Marinak, "Nuclear Aurora-A kinase-induced hypoxia signaling drives dissemination and metastasis in breast cancer." (2021). Graduate Theses, Dissertations, and Problem Reports. 10163.

https://researchrepository.wvu.edu/etd/10163

This Dissertation is protected by copyright and/or related rights. It has been brought to you by the The Research Repository @ WVU with permission from the rights-holder(s). You are free to use this Dissertation in any way that is permitted by the copyright and related rights legislation that applies to your use. For other uses you must obtain permission from the rights-holder(s) directly, unless additional rights are indicated by a Creative Commons license in the record and/ or on the work itself. This Dissertation has been accepted for inclusion in WVU Graduate Theses, Dissertations, and Problem Reports collection by an authorized administrator of The Research Repository @ WVU.

For more information, please contact researchrepository@mail.wvu.edu. 
Nuclear Aurora-A kinase-induced hypoxia signaling drives dissemination and metastasis in breast cancer.

\author{
Kristina Marinak Whately
}

Dissertation submitted to the School of Medicine at West Virginia University

in partial fulfillment of the requirements for the degree of

Doctor of Philosophy

in

Cancer Cell Biology

Lori Hazlehurst, PhD, Chair

Scott Weed, PhD

Mike Ruppert, PhD

Tim Eubank, PhD

Sijin Wen, PhD

Elena Pugacheva, PhD, Mentor

Department of Biochemistry

Morgantown, West Virginia

2021

Keywords: AURKA, aurora-a kinase, metastasis, dissemination, breast cancer, tumors, hypoxia, HIF1A, HIF1B

Copyright 2021 Kristina M. Whately 


\section{ABSTRACT}

\section{Nuclear Aurora-A kinase-induced hypoxia signaling drives dissemination and metastasis in breast cancer.}

\section{Kristina M. Whately}

Metastatic breast cancer causes the vast majority of cancer-associated deaths, especially in triple negative breast cancers (TNBC). TNBC is still poorly understood and has no effective treatment. Here we reveal that presence of Aurora-A Kinase (AURKA) in the nucleus and metastatic dissemination are molecularly connected through HIF1 (Hypoxia induced factor-1) signaling. The nuclear AURKA in the complex with constitutively expressed HIF-1 $1 \beta$ subunit activates transcription of "hypoxia induced genes" under normoxic conditions (the phenomenon called pseudohypoxia) without upregulation of oxygen-sensitive HIF-1 1 a subunit. We uncover that AURKA preferentially binds to and phosphorylates HIF-1 $\beta$, and co-localizes with HIF complex on DNA. The mass spectrometry analysis of AURKA complex further confirmed presence of CBP and p300 along with other TFIIB/RNApol II components. Importantly, expression of multiple HIF-dependent genes including migration/invasion, survival/death and stemness induced by nuclear AURKA promote early cancer dissemination. These results indicate that nuclear pool of AURKA, but not cytoplasmic, is a novel driver of early metastatic dissemination. Analysis of clinical tumor specimens revealed a correlation between HIF$1 \alpha$ and AURKA levels and an association of their co-expression to decreased patient survival. Our results establish a mechanistic linkage between two key pathways in cancer metastasis, identifying nuclear AURKA as a critical upstream regulator of HIF-1 transcription complex, and a target for anti-metastatic therapy. 


\section{DEDICATION}

This work is dedicated to my husband, Chester Whately, who has given me his constant support. You are my best friend. Your love, friendship, humor, and patience has gotten me through this period in our life and I am excited for what is to come. 


\section{ACKNOWLEDGEMENTS}

First I would like to thank my Husband and my family for their support and always believing in me. Chester, you have seen me at my highest and lowest of days, and you never let me quit. Mom and Dad, thank you for all the sacrifices you have made to give me the most in life and for guiding me into the person I am today. Andrew, thank you for all the miles traveled, frequent visits to Morgantown, and always making me feel closer to home. Memaw and Papa, thank you for all the phone calls with encouraging words and motivation to push through and stay focused.

Thank you to all my extended family, all of your support means the world to me. The entire Whately family, my Grandparents, Aunts, Uncles, cousins, and family friends. You all have been to all of my ceremonies and graduations and this is the last one, I promise!

Next, to all of my friends, who I consider my second family. Ashley, Hyeran, Dylan, Brittney, Jessica, Sila, Abha, Russ, Abby, Lindsey, Michelle, Tanya, Keyana, Skye, Katie, Dudley, Tayvia, the Boehm family, the Matthey family, and the Nijakowski family. Thank you for all the laughter, fun, and cherished moments.

To my lab mates, past and present, thank you for your encouraging words, laughter in the lab, and for giving me more than the allotted daily time for crying.

To my mentor, Elena, thank you for always pushing me to go further. Thank you for teaching me how to think critically about science and always asking the next question. Thank you for all the opportunities to travel and experience new places. Lastly, thank you for helping me grow into an independent scientist. 


\section{TABLE OF CONTENTS}

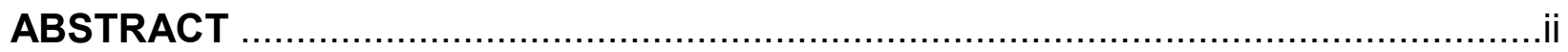

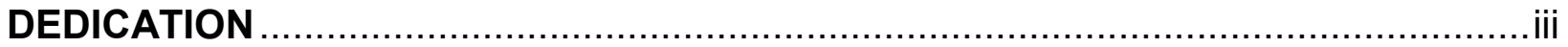

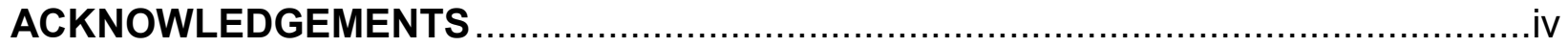

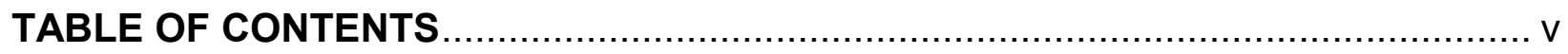

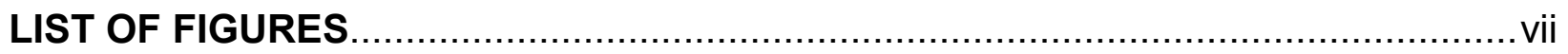

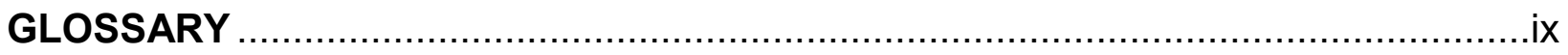

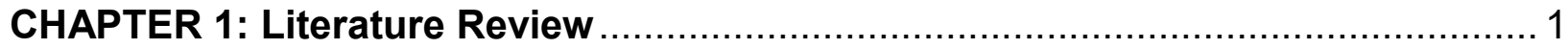

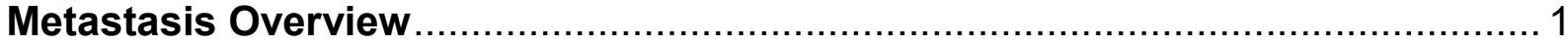





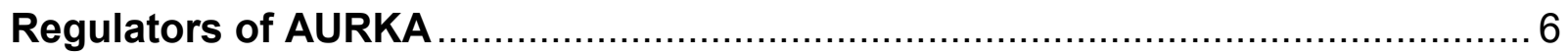







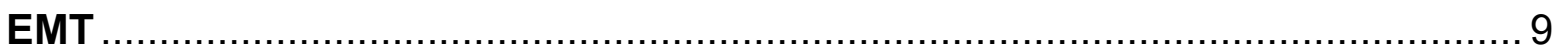

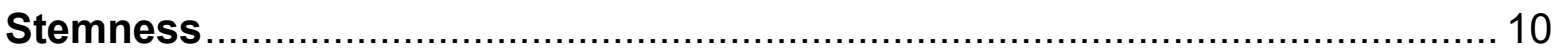





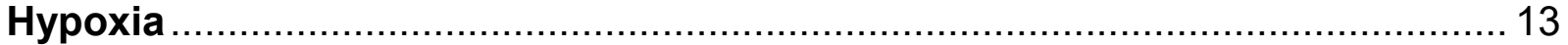



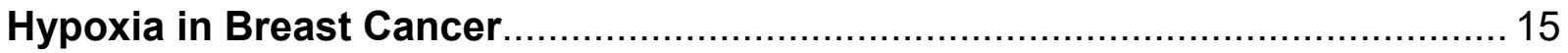

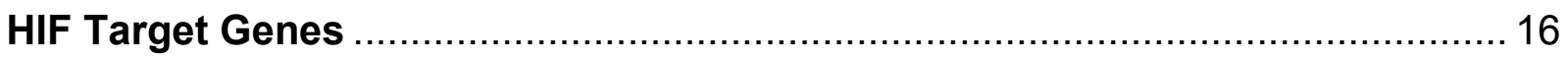

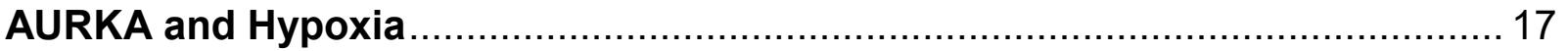

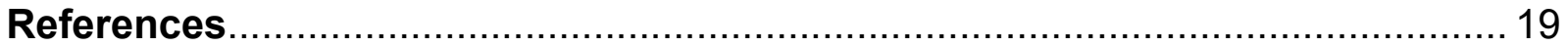

CHAPTER 2: Nuclear Aurora-A kinase-induced hypoxia signaling drives dissemination and metastasis in breast cancer: implications for treatment of

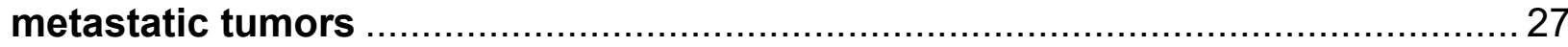

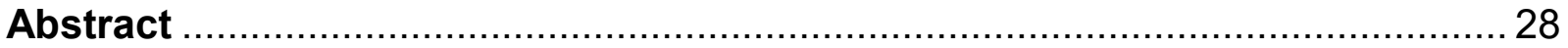

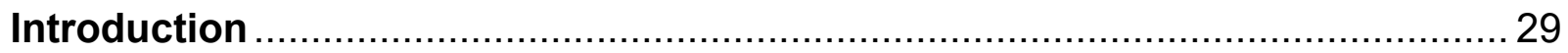




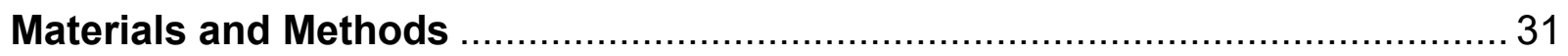

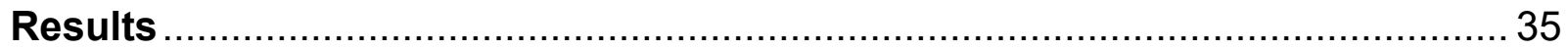

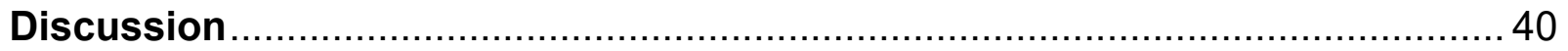

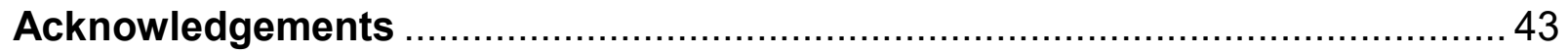





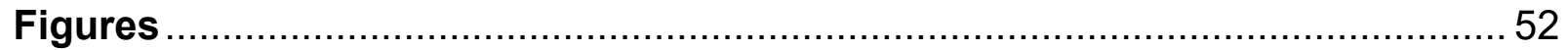

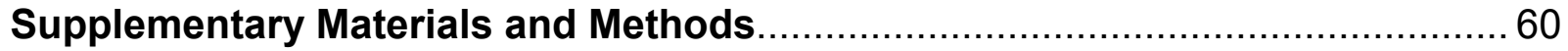

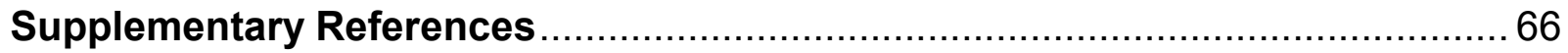

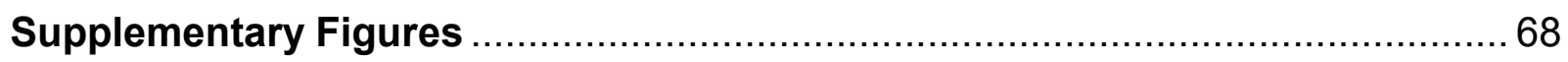

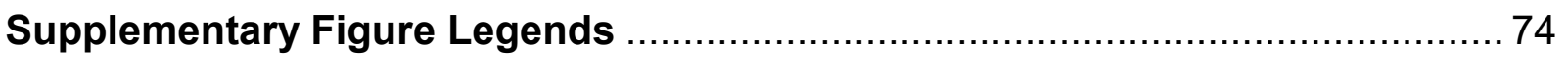

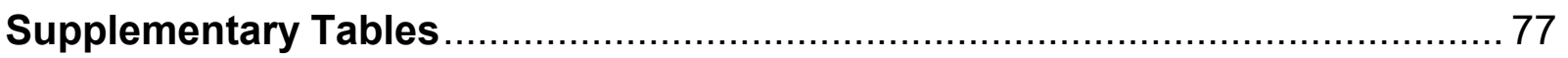

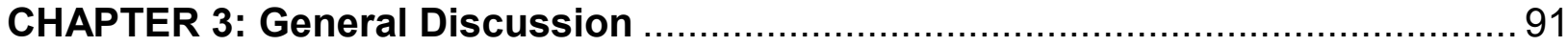

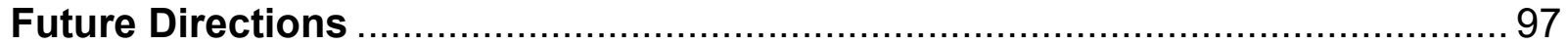

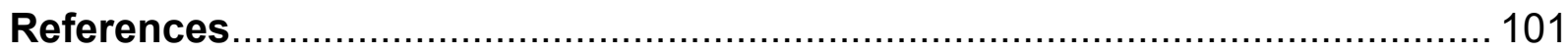

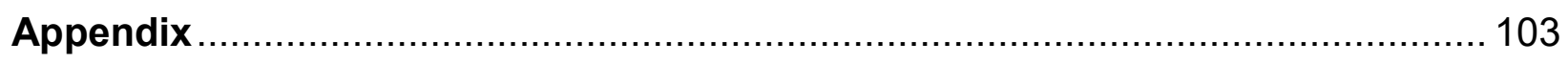




\section{LIST OF FIGURES}

\section{Chapter 1- Introduction}

Figure 1. The Metastatic Cascade

Figure 2. Positive regulators of AURKA regulate transcription, protein stability, and kinase activity.

Figure 3. AURKA interactors leading to increased invasion and migration.

Figure 4. Normoxia and Hypoxia signaling in cells.

Figure 5. HIF targeted genes.

\section{Chapter 2- Nuclear Aurora-A kinase-induced hypoxia signaling drives dissemination and metastasis in breast cancer: implications for treatment of metastatic tumors}

Figure 1. Nuclear AURKA positivity correlates with metastasis and more aggressive breast cancer subtypes.

Figure 2. N-AURKA drives cancer migration/invasion but does not affect proliferation.

Figure 3. N-AURKA induces hypoxia in xenograft models of breast cancer.

Figure 4. N-AURKA expressing tumors are highly metastatic.

Figure 5. RNA-seq profile of N-AURKA cells.

Figure 6. N-AURKA binds to HIF1A/B and promotes transactivation of hypoxiaresponse genes.

Figure 7. HIF1A/B is required for N-AURKA-driven invasion.

Figure 8. Inhibition of N-AURKA kinase activity decreases breast cancer metastasis.

Supplementary Figure 1. Nuclear AURKA is present in breast cancer metastatic cells.

Supplementary Figure 2. Depletion of FOXM1 does not change stem cell phenotype in NLS-AURKA cells.

Supplementary Figure 3. Final tumor measurements.

Supplementary Figure 4. Lymph node IVIS analysis. 
Supplementary Figure 5. NLS-AURKA gene expression changes are reproduced in BT549 and MDA-MB-231 tumors.

Supplementary Figure 6. HIF expression in BT549 and MDA-MB-231 tumors.

\section{Chapter 3- General Discussion}

Figure 1. Known Nuclear AURKA functions. 


\section{GLOSSARY}

PMN- pre-metastatic niche

CTCs- circulating tumor cells

ECM- extracellular matrix

EMT- epithelial to mesenchymal transition

MMPs- matrix metalloproteinases

TGFb- transforming growth factor beta

VEGF- vascular endothelial growth factor

BC- breast cancer

ER- estrogen receptor

PR-progesterone receptor

HER2- human epidermal growth factor receptor

TNBC- triple negative breast cancer

AURKA- Aurora Kinase A

AURKB- Aurora Kinase B

AURKC- Aurora Kinase C

TPX2- targeting protein for Xklp2

NEDD9- neural precursor cell expressed, developmentally down-regulated 9

PAK1- p21 activated kinase 1

PP1- protein phosphatase 1

APC/C- anaphase-promoting complex/cyclosome

ARID3A- AT-rich interaction domain 3A

PUF60- poly(u) binding splicing factor 60

E4TF1- GA binding transcription factor alpha subunit

TRAP220- thyroid hormone receptor associated protein 220

MED1- mediator complex subunit 1

EGFR- epidermal growth factor receptor

STAT5- Signal transducer and activator of transcription 5

TCF4- transcription factor 4

Myc- MYC proto-oncogene 
FOXM1- forkhead box m1

hnRNP Q1- Heterogenous nuclear ribonucleoprotein Q1

PUM2- Pumilio RNA Binding Family Member 2

LIMK2- lim domain kinase 2

ALDH1A1- Aldehyde Dehydrogenase 1 Family Member A1

YBX1- y-box binding protein 1

USP2a- ubiquitin-specific protease-2a

PKC- protein kinase $c$

KCTD12- Potassium Channel Tetramerization Domain Containing 12

RASSF1A- Ras Association Domain Family Member 1

AKI- aurora kinase inhibitor

FAK- focal adhesion kinase

PLD2- Phospholipase D2

Src- SRC Proto-Oncogene

Akt- protein kinase $b$

MET- mesenchymal to epithelial transition

CD44- homing cell adhesion molecule

MAPK- mitogen-activated protein kinase

GSK-3ß- Glycogen synthase kinase 3

PI3K- Phosphoinositide 3-Kinase

Wnt- Wingless-related integration site

NFkB- Nuclear Factor kappa-light-chain-enhancer of activated B cells

GICs- glioma initiating cells

CD24- cluster of differentiation 24

WT- wild-type

NES- nuclear exclusion signal

NLS- nuclear localization signal

hnRNPk- Heterogenous nuclear ribonucleoprotein $\mathrm{k}$

HIFs- hypoxia inducible factors

PHDs- HIF prolyl hydroxylase

FIH- Hypoxia Inducible Factor 1 Subunit Alpha Inhibitor 
VHL- Von Hippel-Lindau Tumor Suppressor

HRE- hypoxia response element

CBP- CREB Binding Protein

P300- Histone acetyltransferase p300

Tie2- Angiopoietin-1 receptor

PDGF- platelet-derived growth factor

ITGA6- integrin alpha-6

CXCR4- C-X-C Motif Chemokine Receptor 4

ADM- Adrenomedullin 


\section{CHAPTER 1: Literature Review}

\section{Metastasis Overview}

Metastatic disease is responsible for $90 \%$ of cancer-related deaths. Metastasis is the process of cancer cells escaping their primary site and traveling through the body to a different secondary site. The metastatic process consists of multiple steps: establishing a pre-metastatic niche (PMN), invasion, intravasation, extravasation, and colonization (1) (Figure 1). The PMN is microenvironment changes that occur in the secondary organ before circulating tumor cells (CTCs) arrive to form the metastatic niche. Early PMN changes like vascular leakiness and recruitment of special cells are caused by secreted factors and extracellular vesicles from tumor cells (2). The second step is invasion and enhanced motility of the tumor cells. Invasion involves changes to the extracellular matrix (ECM), allowing cells to move through tight, and constricting spaces. Many changes occur to cell morphology and internal signaling, allowing cells to use different types of migration and detach or adhere from other cells and matrices $(1,3)$. The invasion step is directly involved with intravasation, as it is the process of cells entering into a vascular or lymphatic compartment. At this point, cells need to develop plasticity to adapt to the different environments and forces they will be exposed to in a vascular compartment. It is known that some cells require the genetic switch to a mesenchymal phenotype, using the epithelial to mesenchymal transition (EMT). Still, once entering the vascular compartment, they may switch back to epithelial (4). The EMT process may not be required for all cancer cells to metastasize, but cells usually display plasticity as they are going through this process (1, 4). Cells also must be able to enhance survival mechanisms during this stressful process 
to circulate through the vasculature and ultimately extravasate into the new tissue/organ environment. Extravasation requires activation of multiple cytoskeleton processes to aid in adhesion of the tumor cell to the endothelial cells, disruption of the endothelial layer, and migration (5). Platelets, neutrophils, and macrophages also help promote tumor cell extravasation by releasing certain factors (MMPs, TGFb, VEGF) that mediate the interaction between tumor and endothelial cells (5). The final step of the metastatic cascade is colonization and growth. This new environment, called premetastatic niche (PMN), must support the tumor cell survival even before its arrival. The tumor cells may need immune cells and/or secreted factors in the environment to allow for colonization and growth (1); without such factors, tumor cells are subjected to a long-term dormancy period. There are specific patterns of metastasis across different cancer types; this is supported by Dr. Paget's "seed and soil" hypothesis (6). This hypothesis states that tumor cells that are successfully metastatic, the "seed," interact with the microenvironment, the "soil". The crosstalk of the cell and microenvironment will influence the metastatic site (7). 


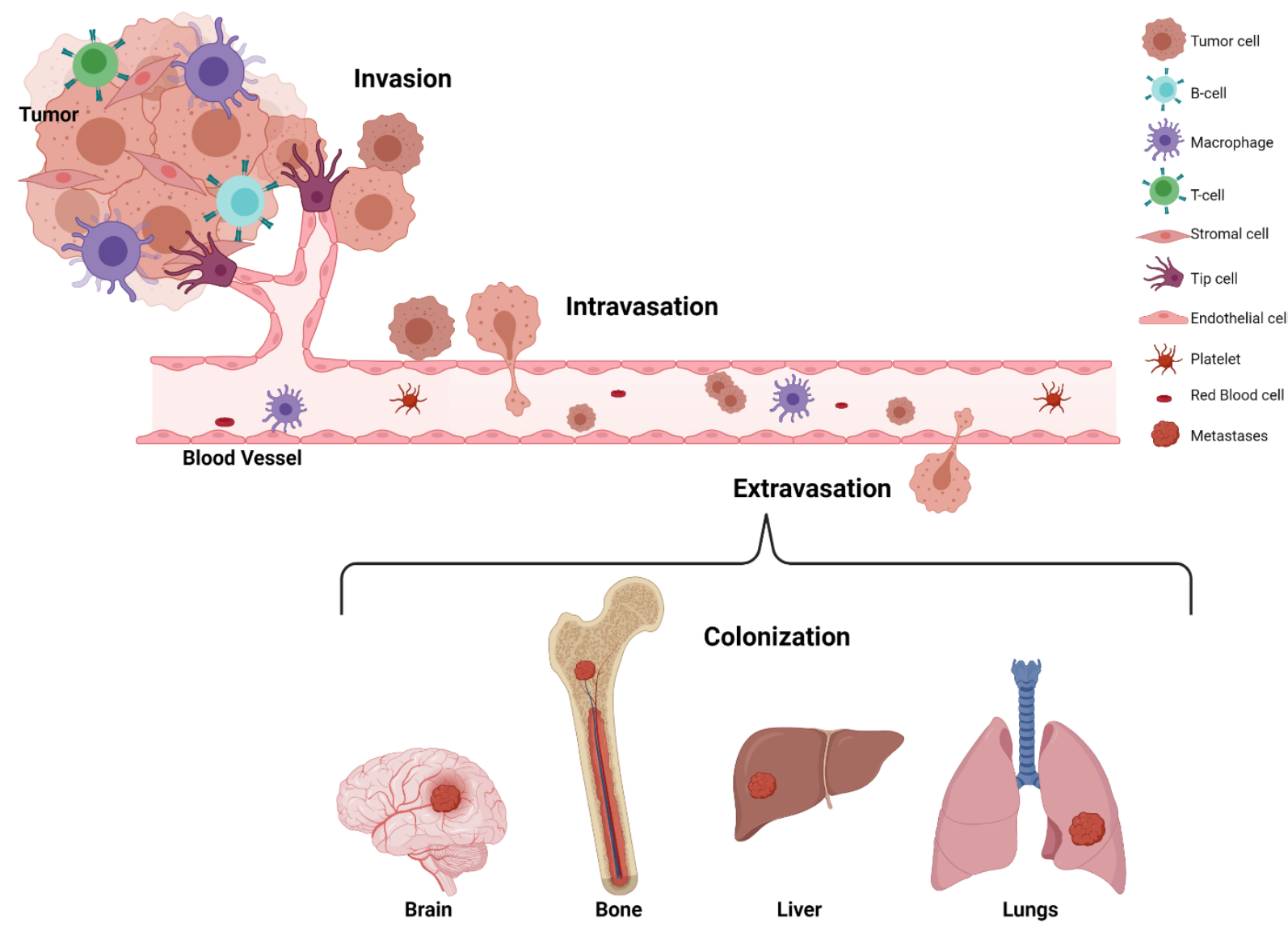

Figure 1. The Metastatic Cascade. A process is consisting of invasion, intravasation, extravasation, and colonization. There are immune cells and stromal cells in the tumor, which help to inhibit immune response and facilitate angiogenesis and stromagenesis. Tumor cells will invade and migrate to leave the primary tumor and intravasate into the blood vessel. Interaction with other immune/blood cells in the vessel allows for survival of disseminating tumor cells in suspension under sheer pressure; the tumor cell will leave by extravasation and form colonies at distant organs- brain, bone, liver, or lungs. The figure was created with BioRender.com.

\section{Breast Cancer Metastasis}

Breast cancer (BC) is classified into different subtypes based on molecular and histological characteristics, essential for determining therapy treatments. Tumors are grouped based on the expression of estrogen receptor (ER), progesterone receptor (PR), and/or human epidermal growth factor receptor (HER2), and also the lack of 
overexpression of those receptors, which is triple-negative breast cancer (TNBC). The clinic uses five classification groups currently: Luminal A (ER+,PR+,HER2-), Luminal BHER2- (low ER+, PR+, HER2-), Luminal B-HER2+ (low ER+, PR+, HER2+), HER2enriched (ER-, PR-, HER2+), and Triple Negative (ER-, PR-, HER2-) (8). The HER2enriched and Triple Negative subtypes are most aggressive with increased proliferation, higher grade, and genetic stability. Tumors that overexpress ER, PR, or HER2 generally respond well to receptor-targeted therapies, have an intermediate to good prognosis, and a 5 -year survival rate above $80 \%$ for regional disease. TNBC tends to have a poor prognosis due to the aggressive phenotype, lack of targeted therapies, and a 5-year survival rate of $65 \%$ for regional disease (SEER data).

Metastatic breast cancer is an incurable disease that is the ultimate cause of death in $\mathrm{BC}$ patients. The 5-year survival rate for patients with distant metastases significantly decreases to $30-40 \%$ for Luminal or HER2 expressing tumors and $11 \%$ for TNBC (SEER data). The most common metastatic sites for breast cancer include bone $(67 \%)$, lymph nodes $(30-50 \%)$, liver $(40 \%)$, lungs $(36 \%)$, brain $(12 \%)$, peritoneal cavity $(10 \%)$, and contralateral breast $(6 \%)(8)$. It is interesting to note that the different subtypes of BC have different patterns of metastasis; due to their genetic alterations, not all subtypes have the same percentage of metastasizing to the bone (8). Metastatic disease recurrence occurs at different time points with Luminal or HER2 tumor occurrence at 5-10 years; however, TNBC occurrence is within two years (8).

Metastasis research is ultimately asking the question of what causes a tumor cell to metastasize. Even though extensive research is being done, there is still no exact answer to this question. The metastatic process is very complex, as described above. The 
molecular tumor classifications bring additional complexity to the process. Identifying factors that could determine if a tumor cell will metastasize and what makes them metastatic is the goal of this field.

\section{Aurora Kinase A in Cancer}

Aurora Kinase A (AURKA) is a mitotic kinase among family members Aurora $B$ and Aurora C. Its canonical functions include: regulation of centrosome maturation and separation, mitotic entry, bipolar spindle assembly, chromosome alignment, and cytokinesis (9). Under non-pathological conditions, AURKA localization is only documented at the centrosomes. In mitosis, AURKA can also be detected on the microtubules of mitotic spindles. AURKA protein and its activity gradually increase as the cell progresses from the S phase to $\mathrm{G} 2$ to Mitosis in the cell cycle. Still, the decrease and inactivation of AURKA is required for mitotic exit (9). The autophosphorylation of T288 residue is necessary for AURKA activation. This autophosphorylation is activated by binding partners (TPX2, NEDD9, Ajuba, and PAK1) via a conformational change in AURKA (10). AURKA inactivation is done by protein phosphatase 1 (PP1). The PP1 dephosphorylates AURKA enabling ubiquitination by anaphase-promoting complex/cyclosome (APC/C) and proteasomal degradation (10).

AURKA was identified as an oncogene in 1998 after two studies showed AURKA amplification, overexpression, and transformation activity in colorectal cancers and breast cancer cell lines $(11,12)$. Amplification of AURKA DNA on chromosome 20q13 has been documented in multiple cancer types, including breast (13), bladder (14), and ovarian (15) tumors. There is also evidence of increased protein expression and mRNA expression in tumors and cell types $(12,16)$. High AURKA expression positively correlates with 
proliferation marker, Ki67, poor overall survival, and recurrence of TNBC patients (17). It was also shown to correlate with increased pathological states and predicts poorer prognosis in lung cancer (18) and glioblastoma (19). The amplification and overexpression of AURKA leads to chromosomal instability, aneuploidy and transformation of normal cells $(12,20)$. The oncogenic AURKA is not restricted to localize at the centrosomes but has a diffuse cytoplasmic localization $(16,21)$. There is also more recent evidence showing AURKA localization in the nucleus (22-24).

\section{Regulators of AURKA}

Many positive and negative regulators of AURKA contribute to transcriptional, translational, protein stability, and kinase activity regulation (25). Because overexpression and amplification of AURKA is needed for its oncogenic role, the regulators summarized below are positive regulators of AURKA. Regulators that promote AURKA transcription include ARID3A (26), PUF60 (27), E4TF1 (28), TRAP220/MED1 (29), EGFR/STAT5 (30), $\beta$-catenin/TCF4 (31), Myc (32), and FOXM1 (33). These transcriptional regulators bind to the designated regions in the AURKA promoter and increase AURKA transcription (mRNA). The translation of AURKA was shown to be upregulated by hnRNP Q1 through binding to AURKA's 5'-UTRs (34). Multiple proteins protect AURKA from degradation, increasing its stability, including NEDD9 (35), TPX2 (36), PUM2 (37), LIMK2 (38), Twist (39), ALDH1A1 (40), YBX1 (41), and USP2a (42). The kinase activity of AURKA is regulated through autophosphorylation of Thr-288 (9). Several proteins assist AURKA in this process, including NEDD9 (35), TPX2 (43), PUM2 (37), PKC (44), PAK1 (45), Ajuba (46), KCTD12 (47), and RASSF1A (48). There are 432 unique AURKA interactors currently documented in the literature (BioGrid). The list is growing, supporting the 
fundamental role this protein plays in cellular physiology under normal and pathological conditions. Regulators of AURKA are summarized in Figure 2.
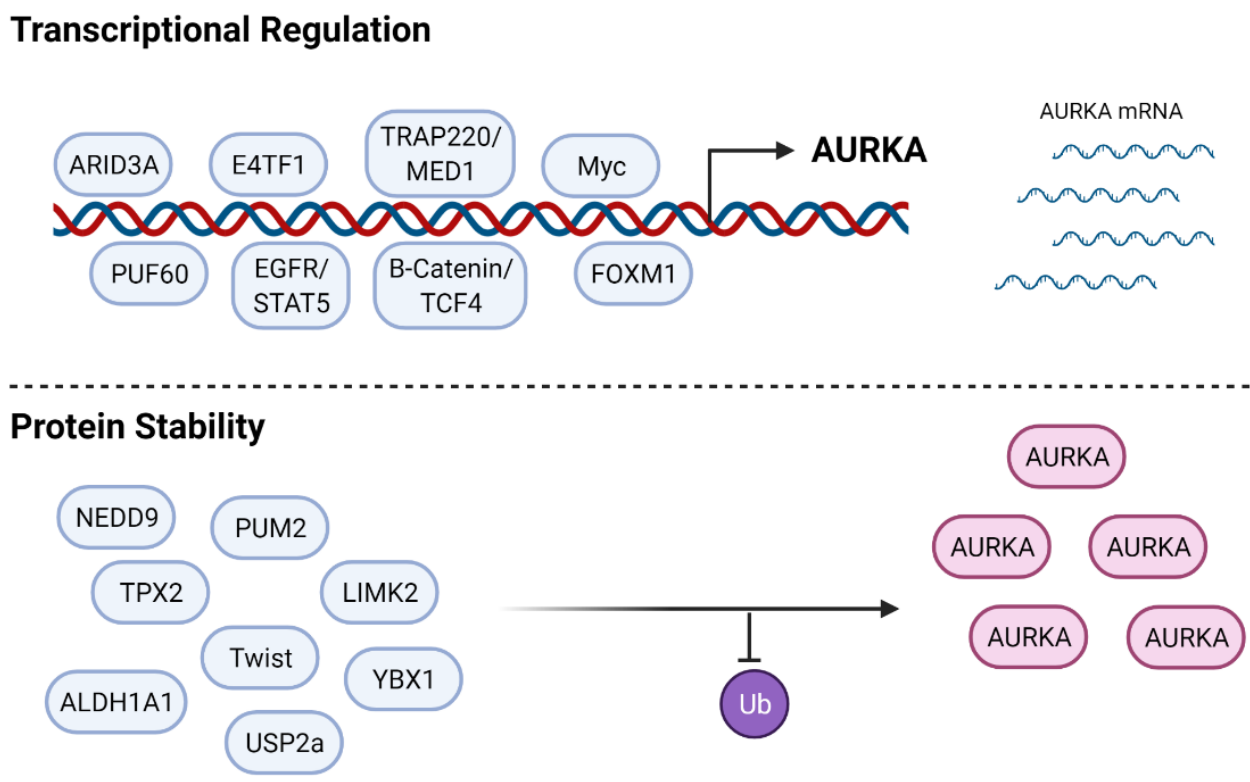

Kinase Activity

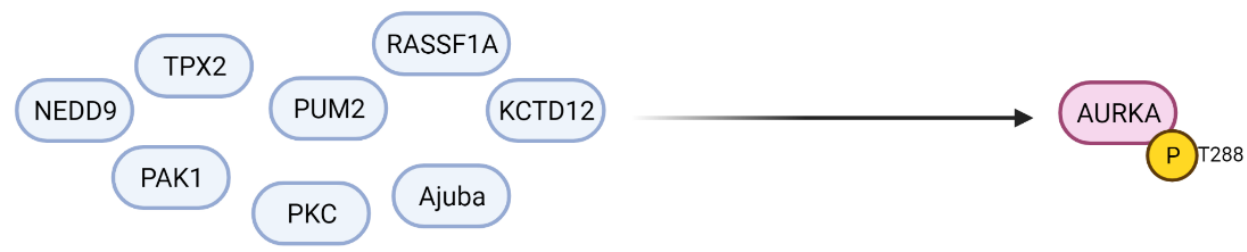

Figure 2. Positive regulators of AURKA regulate transcription, protein stability, and kinase activity. Figure adapted from $\mathrm{Du}$ et al. (25). Figure was created with BioRender.com.

\section{Inhibition of AURKA kinase activity}

Several small-molecule compounds have been discovered to inhibit the kinase activity of AURKA (25). Some are specific to AURKA, but others have pan-specific effects on the Aurora kinase family (AURKA/AURKB/AURKC). These molecules are termed Aurora Kinase Inhibitors or AKls. One of the most extensively studied AKIs with strong 
specificity to AURKA is MLN8237 (Alisertib) (49). MLN8237 was shown to be 200-fold more selective to AURKA than AURKB kinase and very effective at reducing tumor growth in multiple xenograft models (49). MLN8237 is currently in multiple clinical trials for various cancer types (clinicaltrials.gov), and the majority of these studies are in combination with other drugs. The AKIs enhance the efficiency of other drugs when used in combination (5053). Due to the importance of AURKA in mitosis, the AKIs in the clinic cause significant adverse side effects in patients. Among reported adverse effects, the most common were fatigue, nausea, and neutropenia (54). Hence, there is ongoing research to use nanoparticle technology to encapsulate AKIs for targeted tumor delivery to decrease adverse side effects (55).

\section{Non-Canonical Cytoplasmic AURKA}

The cytoplasmic (non-centrosomal) localization of oncogenic AURKA allows interaction with and phosphorylation of numerous cytoplasmic proteins, leading to its noncanonical cytoplasmic functions: migration and invasion, stem-like phenotype, EMT, proliferation, and survival (25). Note that these studies did not consider the presence of nuclear AURKA. Thus, it is possible that observed phenotypes at least partly were driven by the nuclear and not cytoplasmic pool of AURKA.

Invasion/Migration: AURKA was shown to enhance migration and invasion through phosphorylation of key cytoskeleton substrates. In immortalized fibroblasts, AURKA expression was shown to increase migration by phosphorylation of FAK, PLD2, and interaction with Src leading to increased tubulin polymerization (56). In head and neck cancer, AURKA increased migration and invasion through phosphorylation of Akt and FAK (57). Other mechanisms of AURKA-driven increase in migration and invasion involve 
phosphorylation/activation of cortactin (58), Akt1 (59), Src (60), and the cofilin-F-actin pathway (61). Phosphorylation of targets is summarized in Figure 3.

\section{Kinase activity dependent:}
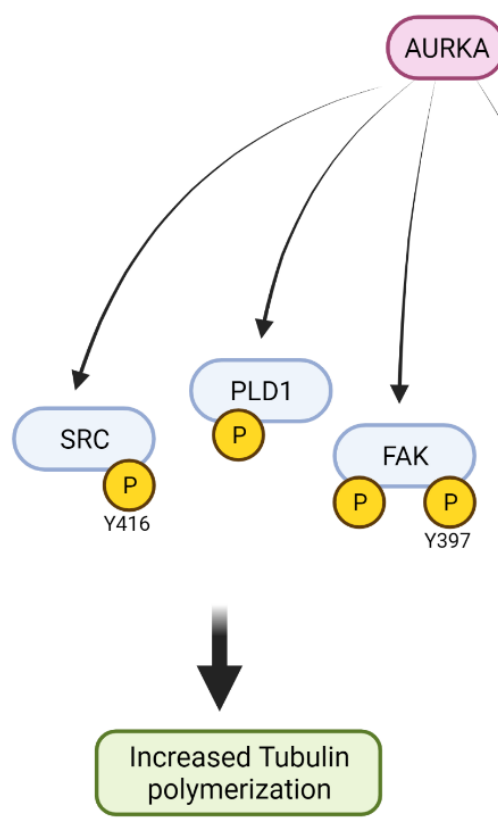

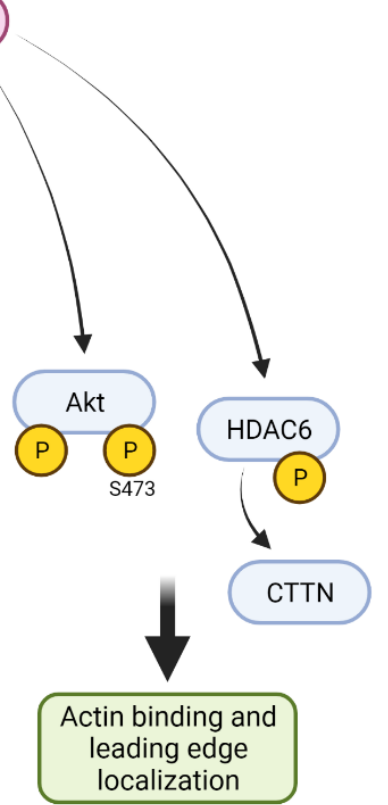

Protein interaction:

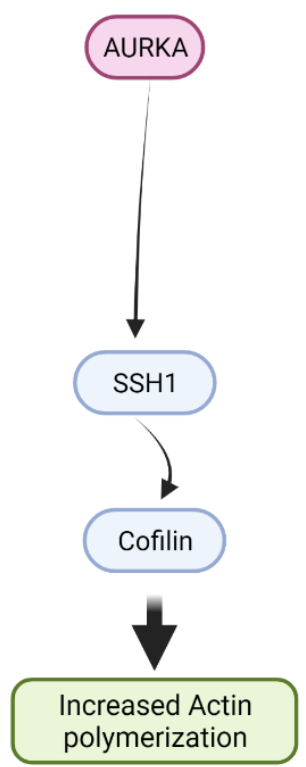

\section{Increased Invasion and Migration}

Figure 3. AURKA interactors leading to increased invasion and migration. They are either dependent on AURKA phosphorylation or protein interaction to become activated. This Figure was created with BioRender.com.

EMT: The epithelial to mesenchymal transition (EMT) and mesenchymal to epithelial (MET) are important processes that allow cells to have the plasticity to switch from epithelial to mesenchymal molecular pathways (62). This is important in metastasis to enable cells to leave the primary tumor, enter the vasculature, survive, and exit to other distant organs. Those steps require different molecular pathways to be active/repressed to be successful (62). AURKA was shown to phosphorylate Twist at three different residues, further 
increasing the expression of other EMT markers: CD44, Slug, and Snail (39). Alternatively, AURKA can induce EMT through MAPK phosphorylation leading to the upregulation of EMT signature genes in multiple models $(63,64)$. Inhibition of AURKA was shown to reduce expression of key transcription factors regulating EMT such as Twist, Snail/Slug and markers of EMT such as N-cadherin and increase E-cadherin, suggesting a transition from EMT to MET. This group also showed that AURKA inhibition led to decreased Akt and GSK-3 $\beta$ phosphorylation (decreased PI3K/Akt and Wnt/ $\beta$-catenin pathways) and led to increased histone methylation at the Twist promoter (65). Induction of EMT also leads to increased invasion and metastasis, indicating that AURKA can regulate these processes directly via phosphorylation of FA, Src, Cofillin, tubulin etc., or indirectly via activation of EMT transcription factors.

Stemness: The expression of AURKA positively correlates with cancer recurrence (17), which is often driven by the presence of cancer stem cells (CSCs) (66). In ovarian CSCs, therapy resistance and recurrence were shown to be dependent on AURKA-driven NFKB signaling. The inhibition of AURKA led to cell death and an increase in nuclear IKBa, which sequesters NFKB inhibiting its activity (67). In glioma initiating cells (GICs), AURKA regulates their self-renewal by phosphorylation/stabilization of $\beta$-catenin, leading to Wnt pathway activation (68). In breast cancer cells, overexpression of AURKA led to an increase in CD44+/CD24- cell population and increased mammosphere formation (33). Similarly, with the depletion of AURKA, there was a decrease in CD44+/CD24- population and mammospheres (33). In colorectal CSCs, AURKA is overexpressed and regulates the tumorigenic ability of these cells due to genomic instability (69). Silencing AURKA expression led to growth inhibition and sensitivity to chemotherapeutic agents (69), 
indicating the significant therapeutic potential of AURKA targeting in combination with chemotherapy.

AURKA is also known to interact with oncogene Myc - a transcription factor that contributes to many oncogenic processes, including stemness (70). AURKA-dependent phosphorylation was shown to stabilize N-Myc via inhibition of its degradation $(71,72)$, resulting in the continued proliferation of Myc-addicted cancer cells. The protein and transcript expression of AURKA and Myc has been shown to correlate in certain cancers (71), indicative of a positive feedback loop and regulation on the transcriptional level (32, 73). Due to the feedback loop and stability of the AURKA-Myc complex, the two oncogenes seem to enhance tumorigenesis, which led to studies investigating the inhibition of this complex (74). Cancer stem cells have self-renewal, tumor-initiating, and colonizing capabilities due to their stem cell-like gene signatures, including genes involved with EMT. AURKA's vast regulation in stemness, EMT, migration, and invasion show the importance of AURKA in the metastatic cascade.

\section{Non-canonical Nuclear AURKA}

More recently, AURKA localization in the nucleus was reported in biopsies across multiple types of cancer, including oral squamous cell carcinoma (24), esophageal squamous cell carcinoma (22), ovarian carcinoma (75), and lung cancer (23). It is important

to note that in these samples, along with nuclear AURKA, there is also a diffuse cytoplasmic AURKA staining. In ovarian cancer, it was shown that overexpression of nuclear AURKA led to worse overall survival and correlated with higher stage, higher grade, and larger tumor size (75). There have been only a few studies evaluating the role of nuclear AURKA, and those point towards nuclear AURKA being more oncogenic than cytoplasmic AURKA 
(76). The authors used a functional Ras-induced transformation assay to determine the oncogenic potential of WT-AURKA (nuclear and cytoplasmic) or NES-AURKA (nuclear exclusion signal, cytoplasmic). The results suggested that only cells with nuclear AURKA but not cytoplasmic AURKA possess the cell transformation activity and cooperate with Ras (76). Following this initial observation, a few more studies had been conducted using AURKA overexpression models and documented the function of nuclear AURKA promotion/activation of transcription $(33,73,77)$. Recalling the Myc-AURKA relationship, Myc was shown to transcriptionally upregulate AURKA (32), while AURKA was shown to transcriptionally upregulate Myc (73). In a model of hepatocellular carcinoma (HCC) in which cells have nuclear AURKA, depletion of AURKA led to decreases in Myc mRNA and protein levels. Chromatin immunoprecipitation (ChIP) assays further revealed that AURKA binds to Myc promoter regions (73), suggesting for the first time that AURKA possesses transcriptional functions and transcriptional domains. These results were confirmed in breast cancer cells discovering the hnRNPk protein as the necessary DNA-binding partner of AURKA at the Myc promoter (77). In a similar model of BC, AURKA transactivates transcription factor FOXM1 (33), which in turn positively re-enforces AURKA transcription, creating yet another positive feedback loop. AURKA and FOXM1 were shown to co-localize in the nucleus by immunofluorescence and interact with each other by coimmunoprecipitation (33).

These recent studies have shown that nuclear AURKA regulates and augments breast cancer stemness $(33,77)$. The study done by Zheng et al. $(77)$ establishes the importance of nuclear AURKA expression in supporting the stem cell population. The depletion of AURKA resulted in a decreased population of stem cells (CD24 low/CD44 ${ }^{\text {high }}$ 
cells). When utilizing the model of inducible AURKA in the cytoplasm by an NES tag or WTAURKA found in both compartments, researchers found that cells with only cytoplasmic AURKA had lost stem-like properties as manifested by the decrease in mammosphere size and number are decreased. Having AURKA in both nuclear and cytoplasmic compartments is needed to increase the stem cell population and mammosphere forming ability, suggesting that the nuclear pool of AURKA enhanced stem cell function (77).

\section{Gaps in Nuclear AURKA Research}

A significant gap in nuclear AURKA research is the mechanisms of nuclear translocation of AURKA are currently unknown. It was shown that amino acids 333-383 of AURKA in the catalytic domain (amino acids 133-383) (78) are required for nuclear targeting (77). Although no NLS has been identified, suggesting that the nuclear localization is due to protein-protein interaction/s within this region. The authors also claim that amino acids 1-333 are responsible for cytoplasmic localization/retention (77). More research is needed to fill this gap in the nuclear AURKA field.

\section{$\underline{\text { Hypoxia }}$}

Hypoxia is a state of low oxygen, around $1-2 \% \mathrm{O}_{2}$ and below, compared to its normal oxygen level, termed normoxia (79). The normal oxygen levels of different tissues vary; for example, the breast has a median oxygen level of $\sim 7 \%$, but the brain is $\sim 4 \%(80,81)$. However, the tumor counterpart is much lower, with breast cancer $\sim 1.3 \% \mathrm{O}_{2}$ and brain cancer $\sim 1.7 \% \mathrm{O}_{2}(80,81)$. In the literature, it is widely accepted that $20 \% \mathrm{O}_{2}$ is considered normoxia levels for in vitro studies, even though normoxia levels in tissues are well below this (82). Hypoxia is one of the hallmarks of cancer and is associated with disease progression and dissemination $(82,83)$. 


\section{Hypoxia Transcriptional Regulation}

As cells in the tumor become deprived of oxygen, they activate the hypoxia response signaling cascade to alleviate/compensate for this deficit. The induction of the hypoxia signaling cascade depends on hypoxia-inducible factors (HIFs), a family of transcription regulators. This family consists of alpha subunits (HIF1a, HIF2a, HIF3a) in which protein stability and degradation are dependent on oxygen sensors, prolyl hydroxylases (PHDs), and factor inhibiting HIF1 (FIH1) (84). The beta subunits (HIF1 $\beta$ and HIF2 $\beta$ ) are oxygenindependent but required for heterodimerization and transactivation (85). In normoxia, HIFa subunits are hydroxylated by PHDs and FIH1 (84). The hydroxylated HIFs are then ubiquitinated by the E3 ubiquitin ligase, von-Hippel Lindau (VHL), and degraded by the proteasome (86). Due to HIF- $\alpha$ subunits being constantly degraded, the HIF- $\beta$ subunits cannot heterodimerize, ultimately leading to a lack of gene transcription. In the hypoxia settings, the PHDs and FIH1 enzymes become inactive due to the low oxygen needed for their function and thus unable to hydroxylate the HIF- $\alpha$ subunits (84). The HIF- $\alpha$ protein accumulation results in heterodimerization of $\mathrm{HIF \alpha} / \beta$ subunits and translocation into the nucleus $(85,87)$. In the nucleus, HIFa/ $\beta$ dimer binds to hypoxia response elements (HREs) on DNA/promoter regions in cooperation with other cofactors CBP/P300, initiating transcription of hypoxia target genes (88) (Figure 4). 


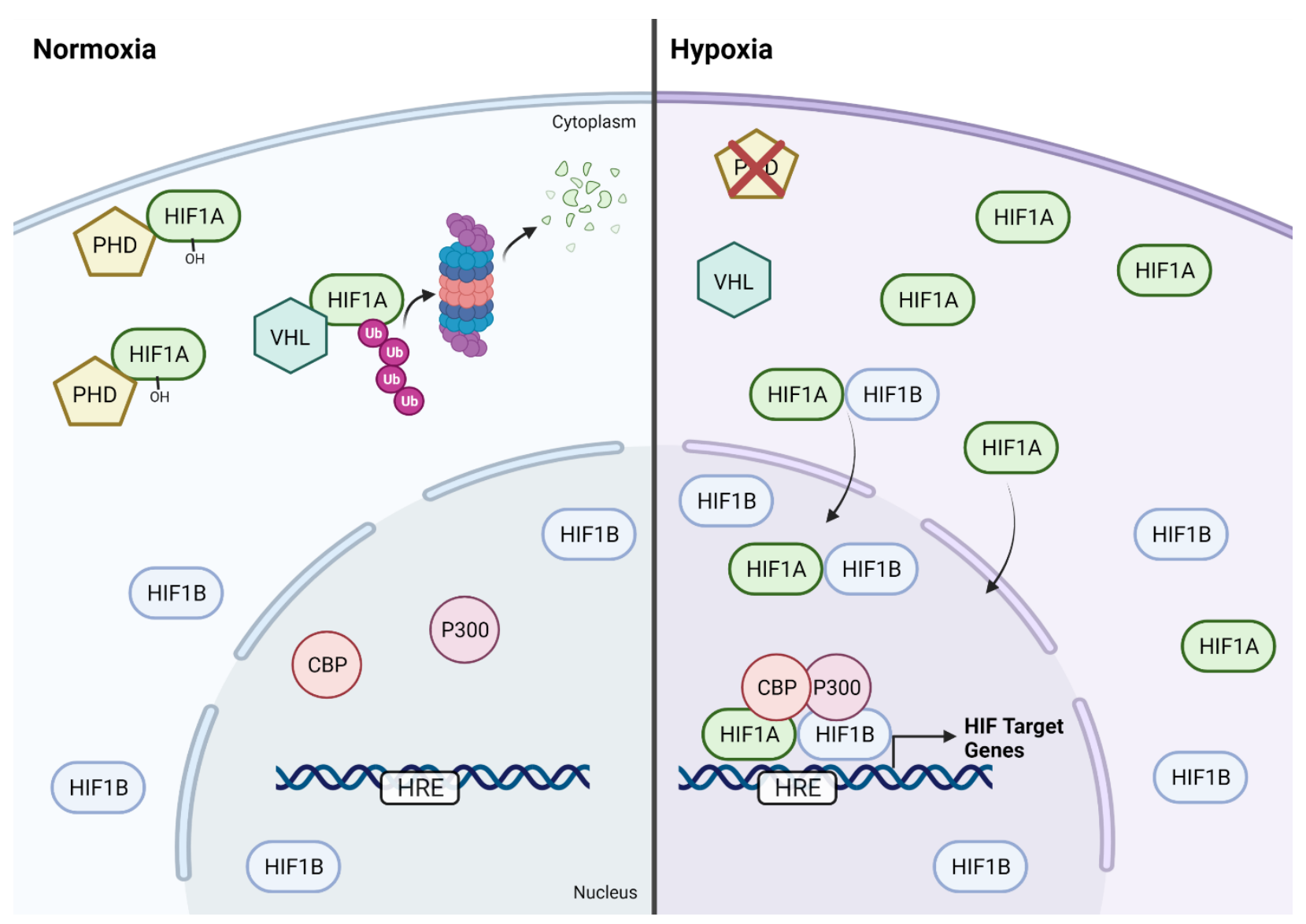

Figure 4. Normoxia and Hypoxia signaling in cells. In normoxia, PHD's hydroxylate HIF1A, which is then recognized by VHL to promote ubiquitination and degradation. HIF1B is not able to bind with HIF1A, resulting in no transcriptional complex. In hypoxia, PHDs become inactive, meaning HIF1A is not hydroxylated, thus increasing protein levels. HIF1A is able to bind HIF1B and translocate into the nucleus. HIF1B has NLS targeting it to the nucleus. The heterodimer binds to HRE regions and forms a complex with other cofactors $C B P / P 300$, and transcription of HIF target genes is activated. The Figure was created with BioRender.com.

\section{$\underline{\text { Hypoxia in Breast Cancer }}$}

The HIF1a expression levels in cells and tissues are the most common read-out for hypoxia and activation of hypoxia signaling. It has been shown in multiple cancer types, including breast cancer, in which HIF1a expression correlates with cancer progression (89). It was also demonstrated that overexpression of HIF1a leads to poorer patient survival (89, 
90). Interestingly, patients with elevated HIF1 1 levels show a faster onset of metastasis and metastases outgrowth. The HIF1 $1 \alpha$ overexpression was detected in BC metastases more often than the primary tumor $(89,91)$, suggesting a strong involvement of HIFs in tumor progression and metastasis.

\section{HIF Target Genes}

Hypoxia is an important mechanism for cancer progression and metastasis, as it induces genes involved in angiogenesis, metabolism, invasion, transcriptional regulators, EMT, stemness, and more (92-94) (Figure 5). These genes, when activated, promote tumor cells to adapt to harsh (low oxygen/nutrients) conditions within the tumor microenvironment. Angiogenesis is an essential part of metastasis as it provides routes for tumor cells to escape and disseminate to other organs (95) and supply oxygen. Essential genes involved in angiogenesis and are regulated by HIF signaling include VEGF (96), angiopoietin1/2, Tie2 (97), and PDGF (98). HIF-induced genes that are involved with increasing invasion and stemness include adhesion molecules like ITGA6 (99), matrix-degrading enzymes like MMPs (100), cytokines like CXCR4 (101, 102), and ADM (103). These genes were shown to be induced by HIFs and contribute to inducing the metastatic cascade. 




Figure 5.HIF targeted genes. Hypoxia-inducible factor (HIF) targets various genes affecting tumor progression and metastasis. Figure adapted from Dengler et al. (93), Semenza (104), Tsai and Wu (92) and created with BioRender.com.

\section{AURKA and Hypoxia}

There have been few studies showing a relationship between AURKA and hypoxia/HIF1 $\alpha$. The AURKA and HIF1 $\alpha$ coexpression better correlate with worse overall survival than the single expression counterpart $(105,106)$. In neuroblastoma and hepatocellular carcinoma patients, induction of hypoxia was shown to increase AURKA protein and mRNA expression (106-108). However, opposite results were reported in one model of breast cancer where induction of hypoxia was shown to decrease AURKA mRNA expression and AURKA promoter activity. Knockdown of HIF1 $\alpha$ leads to increased AURKA 
mRNA expression (109). These results suggest that regulation of AURKA by hypoxia may differ between cancer models/types. The role of nuclear AURKA in hypoxia/HIF signaling is currently unknown. 


\section{References}

1. Welch DR, Hurst DR. Defining the Hallmarks of Metastasis. Cancer Res. 2019;79(12):3011-27.

2. Peinado H, Zhang H, Matei IR, Costa-Silva B, Hoshino A, Rodrigues G, et al. Premetastatic niches: organ-specific homes for metastases. Nat Rev Cancer. 2017;17(5):302-17.

3. Friedl $\mathrm{P}$, Wolf $\mathrm{K}$. Tumour-cell invasion and migration: diversity and escape mechanisms. Nat Rev Cancer. 2003;3(5):362-74.

4. Gupta PB, Pastushenko I, Skibinski A, Blanpain C, Kuperwasser C. Phenotypic Plasticity: Driver of Cancer Initiation, Progression, and Therapy Resistance. Cell Stem Cell. 2019;24(1):65-78.

5. Strilic B, Offermanns S. Intravascular Survival and Extravasation of Tumor Cells. Cancer Cell. 2017;32(3):282-93.

6. Paget S. The distribution of secondary growths in cancer of the breast. 1889 . Cancer Metastasis Rev. 1989;8(2):98-101.

7. Fidler IJ. The pathogenesis of cancer metastasis: the 'seed and soil' hypothesis revisited. Nat Rev Cancer. 2003;3(6):453-8.

8. Harbeck N, Penault-Llorca F, Cortes J, Gnant M, Houssami N, Poortmans P, et al. Breast cancer. Nat Rev Dis Primers. 2019;5(1):66.

9. Marumoto T, Zhang D, Saya H. Aurora-A - a guardian of poles. Nat Rev Cancer. 2005;5(1):42-50.

10. Nikonova AS, Astsaturov I, Serebriiskii IG, Dunbrack RL, Jr., Golemis EA. Aurora A kinase (AURKA) in normal and pathological cell division. Cell Mol Life Sci. 2013;70(4):661-87.

11. Bischoff JR, Anderson L, Zhu Y, Mossie K, Ng L, Souza B, et al. A homologue of Drosophila aurora kinase is oncogenic and amplified in human colorectal cancers. EMBO J. 1998;17(11):3052-65.

12. Zhou H, Kuang J, Zhong L, Kuo WL, Gray JW, Sahin A, et al. Tumour amplified kinase STK15/BTAK induces centrosome amplification, aneuploidy and transformation. Nat Genet. 1998;20(2):189-93.

13. Kallioniemi A, Kallioniemi OP, Piper J, Tanner M, Stokke T, Chen L, et al. Detection and mapping of amplified DNA sequences in breast cancer by comparative genomic hybridization. Proc Natl Acad Sci U S A. 1994;91(6):2156-60.

14. Reznikoff CA, Belair CD, Yeager TR, Savelieva E, Blelloch RH, Puthenveettil JA, et al. A molecular genetic model of human bladder cancer pathogenesis. Semin Oncol. 1996;23(5):571-84. 
15. Iwabuchi $H$, Sakamoto $M$, Sakunaga $H$, Ma $Y Y$, Carcangiu ML, Pinkel D, et al. Genetic analysis of benign, low-grade, and high-grade ovarian tumors. Cancer Res. 1995;55(24):6172-80.

16. Tanaka T, Kimura M, Matsunaga K, Fukada D, Mori H, Okano Y. Centrosomal kinase AlK1 is overexpressed in invasive ductal carcinoma of the breast. Cancer Res. 1999;59(9):2041-4.

17. Xu J, Wu X, Zhou WH, Liu AW, Wu JB, Deng JY, et al. Aurora-A identifies early recurrence and poor prognosis and promises a potential therapeutic target in triple negative breast cancer. PLoS One. 2013;8(2):e56919.

18. Zeng B, Lei Y, Zhu H, Luo S, Zhuang M, Su C, et al. Aurora-A is a novel predictor of poor prognosis in patients with resected lung adenocarcinoma. Chin $\mathrm{J}$ Cancer Res. 2014;26(2):166-73.

19. Barton VN, Foreman NK, Donson AM, Birks DK, Handler MH, Vibhakar R. Aurora kinase $A$ as a rational target for therapy in glioblastoma. J Neurosurg Pediatr. 2010;6(1):98-105.

20. Zhu J, Abbruzzese JL, Izzo J, Hittelman WN, Li D. AURKA amplification, chromosome instability, and centrosome abnormality in human pancreatic carcinoma cells. Cancer Genet Cytogenet. 2005;159(1):10-7.

21. Gritsko TM, Coppola D, Paciga JE, Yang L, Sun M, Shelley SA, et al. Activation and overexpression of centrosome kinase BTAK/Aurora-A in human ovarian cancer. Clin Cancer Res. 2003;9(4):1420-6.

22. Tanaka E, Hashimoto Y, Ito T, Okumura T, Kan T, Watanabe G, et al. The clinical significance of Aurora-A/STK15/BTAK expression in human esophageal squamous cell carcinoma. Clin Cancer Res. 2005;11(5):1827-34.

23. Xu HT, Ma L, Qi FJ, Liu Y, Yu JH, Dai SD, et al. Expression of serine threonine kinase 15 is associated with poor differentiation in lung squamous cell carcinoma and adenocarcinoma. Pathol Int. 2006;56(7):375-80.

24. Kao SY, Chen YP, Tu HF, Liu CJ, Yu AH, Wu CH, et al. Nuclear STK15 expression is associated with aggressive behaviour of oral carcinoma cells in vivo and in vitro. $\mathrm{J}$ Pathol. 2010;222(1):99-109.

25. Du R, Huang C, Liu K, Li X, Dong Z. Targeting AURKA in Cancer: molecular mechanisms and opportunities for Cancer therapy. Mol Cancer. 2021;20(1):15.

26. Tang J, Yang L, Li Y, Ning X, Chaulagain A, Wang T, et al. ARID3A promotes the development of colorectal cancer by upregulating AURKA. Carcinogenesis. 2021;42(4):578-86.

27. Long Q, An X, Chen M, Wang N, Sui S, Li Y, et al. PUF60/AURKA Axis Contributes to Tumor Progression and Malignant Phenotypes in Bladder Cancer. Front Oncol. 2020;10:568015. 
28. Tanaka M, Ueda A, Kanamori H, Ideguchi H, Yang J, Kitajima S, et al. Cell-cycledependent regulation of human aurora $A$ transcription is mediated by periodic repression of E4TF1. J Biol Chem. 2002;277(12):10719-26.

29. Udayakumar TS, Belakavadi M, Choi KH, Pandey PK, Fondell JD. Regulation of Aurora-A kinase gene expression via GABP recruitment of TRAP220/MED1. J Biol Chem. 2006;281(21):14691-9.

30. Hung LY, Tseng JT, Lee YC, Xia W, Wang YN, Wu ML, et al. Nuclear epidermal growth factor receptor (EGFR) interacts with signal transducer and activator of transcription 5 (STAT5) in activating Aurora-A gene expression. Nucleic Acids Res. 2008;36(13):4337-51.

31. Chou CH, Yang NK, Liu TY, Tai SK, Hsu DS, Chen YW, et al. Chromosome instability modulated by BMI1-AURKA signaling drives progression in head and neck cancer. Cancer Res. 2013;73(2):953-66.

32. den Hollander J, Rimpi S, Doherty JR, Rudelius M, Buck A, Hoellein A, et al. Aurora kinases $A$ and $B$ are upregulated by Myc and are essential for maintenance of the malignant state. Blood. 2010;116(9):1498-505.

33. Yang N, Wang C, Wang Z, Zona S, Lin SX, Wang X, et al. FOXM1 recruits nuclear Aurora kinase $A$ to participate in a positive feedback loop essential for the self-renewal of breast cancer stem cells. Oncogene. 2017;36(24):3428-40.

34. Lai CH, Huang YC, Lee JC, Tseng JT, Chang KC, Chen YJ, et al. Translational upregulation of Aurora-A by hnRNP Q1 contributes to cell proliferation and tumorigenesis in colorectal cancer. Cell Death Dis. 2017;8(1):e2555.

35. Ice RJ, McLaughlin SL, Livengood RH, Culp MV, Eddy ER, Ivanov AV, et al. NEDD9 depletion destabilizes Aurora A kinase and heightens the efficacy of Aurora A inhibitors: implications for treatment of metastatic solid tumors. Cancer Res. 2013;73(10):3168-80.

36. Giubettini M, Asteriti IA, Scrofani J, De Luca M, Lindon C, Lavia P, et al. Control of Aurora-A stability through interaction with TPX2. J Cell Sci. 2011;124(Pt 1):113-22.

37. Huang $\mathrm{YH}, \mathrm{Wu} \mathrm{CC}$, Chou $\mathrm{CK}$, Huang $\mathrm{CY}$. A translational regulator, PUM2, promotes both protein stability and kinase activity of Aurora-A. PLoS One. 2011;6(5):e19718.

38. Johnson EO, Chang KH, Ghosh S, Venkatesh C, Giger K, Low PS, et al. LIMK2 is a crucial regulator and effector of Aurora-A-kinase-mediated malignancy. J Cell Sci. 2012;125(Pt 5):1204-16.

39. Wang J, Nikhil K, Viccaro K, Chang L, Jacobsen M, Sandusky G, et al. The AuroraA-Twist1 axis promotes highly aggressive phenotypes in pancreatic carcinoma. J Cell Sci. 2017;130(6):1078-93.

40. Wang J, Nikhil K, Viccaro K, Chang L, White J, Shah K. Phosphorylationdependent regulation of ALDH1A1 by Aurora kinase A: insights on their synergistic relationship in pancreatic cancer. BMC Biol. 2017;15(1):10. 
41. Nikhil K, Raza A, Haymour HS, Flueckiger BV, Chu J, Shah K. Aurora Kinase AYBX1 Synergy Fuels Aggressive Oncogenic Phenotypes and Chemoresistance in Castration-Resistant Prostate Cancer. Cancers (Basel). 2020;12(3).

42. Shi Y, Solomon LR, Pereda-Lopez A, Giranda VL, Luo Y, Johnson EF, et al. Ubiquitin-specific cysteine protease 2a (USP2a) regulates the stability of Aurora-A. J Biol Chem. 2011;286(45):38960-8.

43. Bayliss R, Sardon T, Vernos I, Conti E. Structural basis of Aurora-A activation by TPX2 at the mitotic spindle. Mol Cell. 2003;12(4):851-62.

44. Mori D, Yamada M, Mimori-Kiyosue Y, Shirai Y, Suzuki A, Ohno S, et al. An essential role of the aPKC-Aurora A-NDEL1 pathway in neurite elongation by modulation of microtubule dynamics. Nat Cell Biol. 2009;11(9):1057-68.

45. Zhao ZS, Lim JP, Ng YW, Lim L, Manser E. The GIT-associated kinase PAK targets to the centrosome and regulates Aurora-A. Mol Cell. 2005;20(2):237-49.

46. Hirota T, Kunitoku N, Sasayama T, Marumoto T, Zhang D, Nitta M, et al. Aurora$A$ and an interacting activator, the LIM protein Ajuba, are required for mitotic commitment in human cells. Cell. 2003;114(5):585-98.

47. Zhong Y, Yang J, Xu WW, Wang Y, Zheng CC, Li B, et al. KCTD12 promotes tumorigenesis by facilitating $\mathrm{CDC} 25 \mathrm{~B} / \mathrm{CDK} 1 /$ Aurora A-dependent $\mathrm{G} 2 / \mathrm{M}$ transition. Oncogene. 2017;36(44):6177-89.

48. Liu L, Guo C, Dammann R, Tommasi S, Pfeifer GP. RASSF1A interacts with and activates the mitotic kinase Aurora-A. Oncogene. 2008;27(47):6175-86.

49. Manfredi MG, Ecsedy JA, Chakravarty A, Silverman L, Zhang M, Hoar KM, et al. Characterization of Alisertib (MLN8237), an investigational small-molecule inhibitor of aurora A kinase using novel in vivo pharmacodynamic assays. Clin Cancer Res. 2011;17(24):7614-24.

50. Kozyreva VK, Kiseleva AA, Ice RJ, Jones BC, Loskutov YV, Matalkah F, et al. Combination of Eribulin and Aurora A Inhibitor MLN8237 Prevents Metastatic Colonization and Induces Cytotoxic Autophagy in Breast Cancer. Mol Cancer Ther. 2016;15(8):1809-22.

51. DuBois SG, Mosse YP, Fox E, Kudgus RA, Reid JM, McGovern R, et al. Phase II Trial of Alisertib in Combination with Irinotecan and Temozolomide for Patients with Relapsed or Refractory Neuroblastoma. Clin Cancer Res. 2018;24(24):6142-9.

52. Kelly KR, Friedberg JW, Park SI, McDonagh K, Hayslip J, Persky D, et al. Phase I Study of the Investigational Aurora A Kinase Inhibitor Alisertib plus Rituximab or Rituximab/Vincristine in Relapsed/Refractory Aggressive B-cell Lymphoma. Clin Cancer Res. 2018;24(24):6150-9.

53. Brunner AM, Blonquist TM, DeAngelo DJ, McMasters M, Fell G, Hermance NM, et al. Alisertib plus induction chemotherapy in previously untreated patients with high-risk, acute myeloid leukaemia: a single-arm, phase 2 trial. Lancet Haematol. 2020;7(2):e122e33. 
54. Dees EC, Cohen RB, von Mehren M, Stinchcombe TE, Liu H, Venkatakrishnan K, et al. Phase I study of aurora A kinase inhibitor MLN8237 in advanced solid tumors: safety, pharmacokinetics, pharmacodynamics, and bioavailability of two oral formulations. Clin Cancer Res. 2012;18(17):4775-84.

55. Inchanalkar S, Deshpande NU, Kasherwal V, Jayakannan M, Balasubramanian N. Polymer Nanovesicle-Mediated Delivery of MLN8237 Preferentially Inhibits Aurora Kinase A To Target RalA and Anchorage-Independent Growth in Breast Cancer Cells. Mol Pharm. 2018;15(8):3046-59.

56. Mahankali M, Henkels KM, Speranza F, Gomez-Cambronero J. A non-mitotic role for Aurora kinase $A$ as a direct activator of cell migration upon interaction with PLD, FAK and Src. J Cell Sci. 2015;128(3):516-26.

57. Wu J, Yang L, Shan Y, Cai C, Wang S, Zhang H. AURKA promotes cell migration and invasion of head and neck squamous cell carcinoma through regulation of the AURKA/Akt/FAK signaling pathway. Oncol Lett. 2016;11(3):1889-94.

58. Kozyreva VK, McLaughlin SL, Livengood RH, Calkins RA, Kelley LC, Rajulapati A, et al. NEDD9 regulates actin dynamics through cortactin deacetylation in an AURKA/HDAC6-dependent manner. Mol Cancer Res. 2014;12(5):681-93.

59. Guan Z, Wang XR, Zhu XF, Huang XF, Xu J, Wang LH, et al. Aurora-A, a negative prognostic marker, increases migration and decreases radiosensitivity in cancer cells. Cancer Res. 2007;67(21):10436-44.

60. Do TV, Xiao F, Bickel LE, Klein-Szanto AJ, Pathak HB, Hua X, et al. Aurora kinase A mediates epithelial ovarian cancer cell migration and adhesion. Oncogene. 2014;33(5):539-49.

61. Wang LH, Xiang J, Yan M, Zhang Y, Zhao Y, Yue CF, et al. The mitotic kinase Aurora-A induces mammary cell migration and breast cancer metastasis by activating the Cofilin-F-actin pathway. Cancer Res. 2010;70(22):9118-28.

62. Heerboth S, Housman G, Leary M, Longacre M, Byler S, Lapinska K, et al. EMT and tumor metastasis. Clin Transl Med. 2015;4:6.

63. Wan XB, Long ZJ, Yan M, Xu J, Xia LP, Liu L, et al. Inhibition of Aurora-A suppresses epithelial-mesenchymal transition and invasion by downregulating MAPK in nasopharyngeal carcinoma cells. Carcinogenesis. 2008;29(10):1930-7.

64. D'Assoro AB, Liu T, Quatraro C, Amato A, Opyrchal M, Leontovich A, et al. The mitotic kinase Aurora--a promotes distant metastases by inducing epithelial-tomesenchymal transition in ERalpha(+) breast cancer cells. Oncogene. 2014;33(5):599610.

65. Liu X, Li Z, Song Y, Wang R, Han L, Wang Q, et al. AURKA induces EMT by regulating histone modification through $\mathrm{Wnt} /$ beta-catenin and PI3K/Akt signaling pathway in gastric cancer. Oncotarget. 2016;7(22):33152-64.

66. Peitzsch C, Tyutyunnykova A, Pantel K, Dubrovska A. Cancer stem cells: The root of tumor recurrence and metastases. Semin Cancer Biol. 2017;44:10-24. 
67. Chefetz I, Holmberg JC, Alvero AB, Visintin I, Mor G. Inhibition of Aurora-A kinase induces cell cycle arrest in epithelial ovarian cancer stem cells by affecting NFkB pathway. Cell Cycle. 2011;10(13):2206-14.

68. Xia Z, Wei P, Zhang H, Ding Z, Yang L, Huang Z, et al. AURKA governs selfrenewal capacity in glioma-initiating cells via stabilization/activation of beta-catenin/Wnt signaling. Mol Cancer Res. 2013;11(9):1101-11.

69. Cammareri P, Scopelliti A, Todaro M, Eterno V, Francescangeli F, Moyer MP, et al. Aurora-a is essential for the tumorigenic capacity and chemoresistance of colorectal cancer stem cells. Cancer Res. 2010;70(11):4655-65.

70. Dang CV. MYC on the path to cancer. Cell. 2012;149(1):22-35.

71. Otto T, Horn S, Brockmann M, Eilers U, Schuttrumpf L, Popov N, et al. Stabilization of $\mathrm{N}-\mathrm{Myc}$ is a critical function of Aurora $\mathrm{A}$ in human neuroblastoma. Cancer Cell. 2009;15(1):67-78.

72. Dauch D, Rudalska R, Cossa G, Nault JC, Kang TW, Wuestefeld T, et al. A MYCaurora kinase $A$ protein complex represents an actionable drug target in p53-altered liver cancer. Nat Med. 2016;22(7):744-53.

73. Lu L, Han H, Tian Y, Li W, Zhang J, Feng M, et al. Aurora kinase A mediates CMyc's oncogenic effects in hepatocellular carcinoma. Mol Carcinogen. 2015;54(11):146779.

74. Richards MW, Burgess SG, Poon E, Carstensen A, Eilers M, Chesler L, et al. Structural basis of N-Myc binding by Aurora-A and its destabilization by kinase inhibitors. Proc Natl Acad Sci U S A. 2016;113(48):13726-31.

75. Lassus H, Staff S, Leminen A, Isola J, Butzow R. Aurora-A overexpression and aneuploidy predict poor outcome in serous ovarian carcinoma. Gynecol Oncol. 2011;120(1):11-7.

76. Tatsuka M, Sato S, Kanda A, Miki T, Kamata N, Kitajima S, et al. Oncogenic role of nuclear accumulated Aurora-A. Mol Carcinogen. 2009;48(9):810-20.

77. Zheng F, Yue C, Li G, He B, Cheng W, Wang X, et al. Nuclear AURKA acquires kinase-independent transactivating function to enhance breast cancer stem cell phenotype. Nat Commun. 2016;7:10180.

78. Naso FD, Boi D, Ascanelli C, Pamfil G, Lindon C, Paiardini A, et al. Nuclear localisation of Aurora-A: its regulation and significance for Aurora-A functions in cancer. Oncogene. 2021;40(23):3917-28.

79. McKeown SR. Defining normoxia, physoxia and Hypoxia in tumours-implications for treatment response. Br J Radiol. 2014;87(1035):20130676.

80. Vaupel P, Mayer A, Briest S, Hockel M. Oxygenation gain factor: a novel parameter characterizing the association between hemoglobin level and the oxygenation status of breast cancers. Cancer Res. 2003;63(22):7634-7.

81. Vaupel $\mathrm{P}$, Hockel M, Mayer A. Detection and characterization of tumor hypoxia using pO2 histography. Antioxid Redox Signal. 2007;9(8):1221-35. 
82. Muz B, de la Puente P, Azab F, Azab AK. The role of in cancer progression, angiogenesis, metastasis, and resistance to therapy. Hypoxia (Auckl). 2015;3:83-92.

83. Rankin EB, Giaccia AJ. Hypoxic control of metastasis. Science. 2016;352(6282):175-80.

84. Bruick RK, McKnight SL. A conserved family of prolyl-4-hydroxylases that modify HIF. Science. 2001;294(5545):1337-40.

85. Jiang BH, Rue E, Wang GL, Roe R, Semenza GL. Dimerization, DNA binding, and transactivation properties of hypoxia-inducible factor $1 . \mathrm{J}$ Biol Chem. 1996;271(30):17771-8.

86. Jaakkola P, Mole DR, Tian YM, Wilson MI, Gielbert J, Gaskell SJ, et al. Targeting of HIF-alpha to the von Hippel-Lindau ubiquitylation complex by O2-regulated prolyl hydroxylation. Science. 2001;292(5516):468-72.

87. Wang GL, Jiang BH, Rue EA, Semenza GL. Hypoxia-inducible factor 1 is a basichelix-loop-helix-PAS heterodimer regulated by cellular $\mathrm{O} 2$ tension. Proc Natl Acad Sci U S A. 1995;92(12):5510-4.

88. Hu CJ, Wang LY, Chodosh LA, Keith B, Simon MC. Differential roles of hypoxiainducible factor 1alpha (HIF-1alpha) and HIF-2alpha in hypoxic gene regulation. Mol Cell Biol. 2003;23(24):9361-74.

89. Zhong H, De Marzo AM, Laughner E, Lim M, Hilton DA, Zagzag D, et al. Overexpression of hypoxia-inducible factor 1 alpha in common human cancers and their metastases. Cancer Res. 1999;59(22):5830-5.

90. Vleugel MM, Greijer AE, Shvarts A, van der Groep P, van Berkel M, Aarbodem Y, et al. Differential prognostic impact of hypoxia induced and diffuse HIF-1alpha expression in invasive breast cancer. J Clin Pathol. 2005;58(2):172-7.

91. Gruber G, Greiner RH, Hlushchuk R, Aebersold DM, Altermatt HJ, Berclaz G, et al. Hypoxia-inducible factor 1 alpha in high-risk breast cancer: an independent prognostic parameter? Breast Cancer Res. 2004;6(3):R191-8.

92. Tsai YP, Wu KJ. Hypoxia-regulated target genes implicated in tumor metastasis. J Biomed Sci. 2012;19:102.

93. Dengler VL, Galbraith M, Espinosa JM. Transcriptional regulation by hypoxia inducible factors. Crit Rev Biochem Mol Biol. 2014;49(1):1-15.

94. Mole DR, Blancher C, Copley RR, Pollard PJ, Gleadle JM, Ragoussis J, et al. Genome-wide association of hypoxia-inducible factor (HIF)-1alpha and HIF-2alpha DNA binding with expression profiling of hypoxia-inducible transcripts. J Biol Chem. 2009;284(25):16767-75.

95. Bielenberg DR, Zetter BR. The Contribution of Angiogenesis to the Process of Metastasis. Cancer J. 2015;21(4):267-73.

96. Oladipupo S, Hu S, Kovalski J, Yao J, Santeford A, Sohn RE, et al. VEGF is essential for hypoxia-inducible factor-mediated neovascularization but dispensable for endothelial sprouting. Proc Natl Acad Sci U S A. 2011;108(32):13264-9. 
97. Augustin HG, Koh GY, Thurston G, Alitalo K. Control of vascular morphogenesis and homeostasis through the angiopoietin-Tie system. Nat Rev Mol Cell Biol. 2009;10(3):165-77.

98. Bos R, van Diest PJ, de Jong JS, van der Groep P, van der Valk P, van der Wall E. Hypoxia-inducible factor-1alpha is associated with angiogenesis, and expression of bFGF, PDGF-BB, and EGFR in invasive breast cancer. Histopathology. 2005;46(1):31-6. 99. Brooks DL, Schwab LP, Krutilina R, Parke DN, Sethuraman A, Hoogewijs D, et al. ITGA6 is directly regulated by hypoxia-inducible factors and enriches for cancer stem cell activity and invasion in metastatic breast cancer models. Mol Cancer. 2016;15:26.

100. Munoz-Najar UM, Neurath KM, Vumbaca F, Claffey KP. Hypoxia stimulates breast carcinoma cell invasion through MT1-MMP and MMP-2 activation. Oncogene. 2006;25(16):2379-92.

101. Guo M, Cai C, Zhao G, Qiu X, Zhao H, Ma Q, et al. Hypoxia promotes migration and induces CXCR4 expression via HIF-1alpha activation in human osteosarcoma. PLoS One. 2014;9(3):e90518.

102. Micucci C, Matacchione G, Valli D, Orciari S, Catalano A. HIF2alpha is involved in the expansion of CXCR4-positive cancer stem-like cells in renal cell carcinoma. $\mathrm{Br} \mathrm{J}$ Cancer. 2015;113(8):1178-85.

103. Keleg S, Kayed H, Jiang X, Penzel R, Giese T, Buchler MW, et al. Adrenomedullin is induced by hypoxia and enhances pancreatic cancer cell invasion. Int $\mathrm{J}$ Cancer. 2007;121(1):21-32.

104. Semenza GL. Hypoxia-inducible factors: mediators of cancer progression and targets for cancer therapy. Trends Pharmacol Sci. 2012;33(4):207-14.

105. Wan XB, Fan XJ, Huang PY, Dong D, Zhang Y, Chen MY, et al. Aurora-A activation, correlated with hypoxia-inducible factor-1alpha, promotes radiochemoresistance and predicts poor outcome for nasopharyngeal carcinoma. Cancer Sci. 2012;103(8):1586-94.

106. Cui SY, Huang JY, Chen YT, Song HZ, Huang GC, De W, et al. The role of Aurora A in hypoxia-inducible factor 1alpha-promoting malignant phenotypes of hepatocelluar carcinoma. Cell Cycle. 2013;12(17):2849-66.

107. Romain CV, Paul P, Lee S, Qiao J, Chung DH. Targeting aurora kinase A inhibits hypoxia-mediated neuroblastoma cell tumorigenesis. Anticancer Res. 2014;34(5):226974.

108. Klein A, Flugel D, Kietzmann T. Transcriptional regulation of serine/threonine kinase-15 (STK15) expression by hypoxia and HIF-1. Mol Biol Cell. 2008;19(9):3667-75. 109. Fanale D, Bazan V, Corsini LR, Caruso S, Insalaco L, Castiglia M, et al. HIF-1 is involved in the negative regulation of AURKA expression in breast cancer cell lines under hypoxic conditions. Breast Cancer Res Treat. 2013;140(3):505-17. 


\section{CHAPTER 2: Nuclear Aurora-A kinase-induced hypoxia signaling drives dissemination and metastasis in breast cancer: implications for treatment of metastatic tumors}

Kristina M. Whately ${ }^{1,4}$, Maria A. Voronkova ${ }^{1,4}$, Abha Maskey ${ }^{1,4}$, Jasleen Gandhi ${ }^{3}$, Juergen Loskutov $^{1,4}$, Hyeran Choi ${ }^{1}$, Sila Yanardag ${ }^{1,4}$, Dongquan Chen ${ }^{6}$, Sijin Wen ${ }^{4,5}$, Naira V. Margaryan ${ }^{1}$, Matthew B. Smolkin ${ }^{2}$, Marc L. Purazo ${ }^{1,4}$, Gangqing $\mathrm{Hu}^{3,4}$, and Elena N. Pugacheva ${ }^{1,4 \#}$

${ }^{1}$ Department of Biochemistry, ${ }^{2}$ Department of Pathology, ${ }^{3}$ Department of Microbiology, Immunology \& Cell Biology and ${ }^{4}$ WVU Cancer Institute, School of Medicine, ${ }^{5}$ Department of Biostatistics, School of Public Health, West Virginia University, Morgantown, WV, 26506, ${ }^{6}$ Department of Medicine, Division of Preventive Medicine, UAB Comprehensive Cancer Center, Birmingham, AL, USA.

Accepted for publication in Oncogene on July 19th, 2021.

Corresponding author:

Elena N. Pugacheva,

Department of Biochemistry, PO Box 9142, 1 Medical Center Drive, West Virginia University School of Medicine, Morgantown, WV 26506.

Phone: 304-293-5295

Fax: 304-293-4667

E-mail: epugacheva@hsc.wvu.edu 


\section{Abstract}

Metastatic breast cancer causes most breast cancer-associated deaths, especially in triple negative breast cancers (TNBC). The metastatic drivers of TNBCs are still poorly understood, and effective treatment non-existent. Here we reveal that the presence of Aurora-A Kinase (AURKA) in the nucleus and metastatic dissemination are molecularly connected through HIF1 (Hypoxia-Inducible Factor-1) signaling. Nuclear AURKA activates transcription of "hypoxia-induced genes" under normoxic conditions (pseudohypoxia) and without upregulation of oxygen-sensitive HIF1A subunit. We uncover that AURKA preferentially binds to HIF1B and co-localizes with the HIF complex on DNA. The mass spectrometry analysis of the AURKA complex further confirmed the presence of CBP and p300 along with other TFIIB/RNApol II components. Importantly, the expression of multiple HIF-dependent genes induced by nuclear AURKA (N-AURKA), including migration/invasion, survival/death, and stemness, promote early cancer dissemination. These results indicate that nuclear, but not cytoplasmic, AURKA is a novel driver of early metastasis. Analysis of clinical tumor specimens revealed a correlation between N-AURKA presence and decreased patient survival. Our results establish a mechanistic link between two critical pathways in cancer metastasis, identifying nuclear AURKA as a crucial upstream regulator of the HIF1 transcription complex and a target for anti-metastatic therapy. 


\section{Introduction}

AURKA is a serine/threonine kinase responsible for centrosome maturation, separation, and spindle formation during mitosis (1). Normal localization of AURKA is at the centrosomes/cytoplasm (2). AURKA is also involved in the regulation of migration and invasion (3).

AURKA has recently been reported to localize in the nucleus in various cancers, such as colon (4), lung (5), and breast (6). Few reports demonstrate the oncogenic potential of nuclear (N-AURKA), but not cytoplasmic, AURKA in cooperation with Ras (7) and Myc (6) oncogenes. AURKA phosphorylates multiple nuclear proteins that promote carcinogenesis, including p53 (8), Akt (9), and NFkB (10), suggesting that these might be targets of nuclear AURKA.

High expression of AURKA was shown to correlate with earlier recurrence of TNBC in patients (11) and indicative of disease progression. The increased AURKA expression was established to promote metastasis by enhancing epithelial to mesenchymal transition (12), stemness (6), and invasion (3). Although expression of AURKA in the nucleus correlates with poor overall survival (13), the mechanism driving cancer progression associated with N-AURKA is currently unknown.

Hypoxia is a physical state of lower oxygen compared to normal oxygen levels (normoxia). When a cell experiences hypoxia, the hypoxia-inducible factors (HIFs) consisting of alpha/beta subunits (HIF1/2A, HIF1/2B) are stabilized. The HIFA/B heterodimer then translocates into the nucleus, where it binds to DNA on hypoxiaresponsive elements (HREs) (14), regulating transcription of genes involved in proliferation, apoptosis, angiogenesis, and metabolism (15). The association between HIF1 expression, hypoxia genes/signaling, and metastatic breast cancer has been previously documented (15-17).

Here we report, that N-AURKA via binding to HIF complexes activates hypoxia transcriptional programs independent of HIF1/2A stabilization in cells exposed to atmospheric oxygen (18). Transactivation of hypoxia genes leads to increased migration/invasion and stemness, enabling dissemination and metastases at distant organs without significant delay or dormancy. Inhibiting N-AURKA kinase activity with 
Alisertib/MLN8237, AURKA specific inhibitor, significantly reduces metastatic colonization but does not block dissemination. Hence, using nuclear AURKA-targeting compounds in combination with HIF inhibitors might prove beneficial in treating metastases in TNBCs and other cancers. The presence of cells with N-AURKA could serve as a surrogate for metastatic cells and indicate early dissemination. 


\section{Materials and Methods}

Cell Culture, plasmids, and reagents. Cell lines MDA-MB-231, BT-549, HCC1143, Hs578t, MCF7, MCF10A, SK-BR-3, and BT-474 were purchased from and authenticated by American Type Culture Collection. MDA-MB-231LN (PerkinElmer) were grown based on manufacturer's recommendations, low passage cells were used in the study. The sgRNAs, siRNAs, primers for site-directed mutagenesis is outlined in Suppl.Table S1. Details about lentivirus constructs/production/infection and reagents are outlined in Supplementary Methods.

Western blotting (WB). Cells/tumors were either lysed in Laemmli or M-PER lysis buffer (ThermoFisher) and processed as previously described(19). Proteins are normalized to loading controls (GAPDH or tubulin), $n=2$ biological/clones, $n=2-3$ experiments. Antibodies and dilutions are listed in Suppl.Table S2.

Immunofluorescent cell analysis. Immunofluorescence was performed as previously described (20). Images were captured using a Zeiss/LSM-510 confocal microscope with 63X Plan-Apochromat/NA1.4, oil objective. 3D-confocal images were processed using Zen and ImageJ/NIH software. Images inside each data set were collected with the same microscopy/image capture settings. Antibodies used are listed in Suppl.Table S2.

Immunohistochemistry (IHC). The detailed protocol for processing and analysis of Fluorescent-IHC and DAB-IHC is outlined in the Supplementary Methods.

Tissue Microarray and Patient Data. Breast cancer survival data were evaluated using the breast cancer gene chip data of the online databases Kaplan-Meier Plotter (21, 22), the best cutoff values were selected according to the defined high or low expression of AURKA, HIF1A/B, N-AURKA-signature genes. High-density breast cancer TMA BR2082 (US Biomax Suppl.Tables S3 and S4) were collected with full donor consent under the approved IRB protocol. The detailed protocol is outlined in the Supplementary Methods. 
Nuclear/Cytoplasmic Fractionation. The detailed protocol is outlined in the Supplementary Methods.

Cell viability analysis. Guava/Viacount (Luminex) reagent and Guava Eascyte-HT Flow Cytometer (Millipore) were used for analysis of cell viability per manufacturer's instructions. $1 \times 10^{5}$ cells/well in a 12 -well plate were collected $24-120 \mathrm{hr}$ post-plating. Parameters for the flow cytometer were set using positive (live) and negative (dead) cells/controls. $n=2$ experiments with $n=2$ biological, $n=2$ technical replicates.

Cell elongation and nuclear size analysis. $1 \times 10^{4}$ attached cells/well were stained with Hoechst33342 (ThermoFisher) and bright field images captured using Zeiss-Axio ImagerZ2 microscope, 20x Plan-Apochromat/0.80NA objective. Cell elongation was measured as a function of cell length divided by cell width in ImageJ software. 50 cells/condition quantified in 3-4 random fields with $n=2$ biological/clones, $n=2$ technical replicates.

Live-cell imaging of individual cell invasion/migration. Protocol and quantification methods were previously reported (23). $2.5 \times 10^{5}$ cells were imaged with confocal microscopy, $2 \mu \mathrm{m} /$ steps. $n=3$ experiments with $n=2$ biological, $n=2$ technical replicates, and $\geq 50$ cells traced/per condition.

Anoikis assay. The detailed protocol is outlined in Supplementary Methods.

Flow cytometry analysis. The staining, collection and gating protocols outlined in Supplementary Methods. Antibodies used are listed in Suppl.Table S2.

Mammosphere Assay. Mammosphere assay was done as described (6). At day 10, mammospheres were imaged on ECHO Rebel microscope (VWR) at $4 \mathrm{X}$ and 10X. Analysis of sphere's diameter and number was done in ImageJ. $n=2$ experiments, $n=2$ biological/clones, $n=3$ technical replicates per group with 100 cells counted in 6-10 random field/condition. 
Orthotopic xenograft models of breast cancer. Orthotopic injections, bioluminescent imaging, and ultrasound of xenografts were performed as described (24). All procedures were approved by the WVU Institutional Animal Care and Use Committee and followed guidelines established by the $\mathrm{NIH}$. Details for the orthotopic experiments are outlined in the Supplementary Methods.

RNA Sequencing and Bioinformatics. Total RNA was isolated from cells (2 clones/construct) with RNeasy Mini-kit (Qiagen). The RNA sequencing data were generated by the WVU Genomics core facility and deposited to GEO with accession number GSE154494. The detailed protocol is outlined in the Supplementary Methods.

Quantitative RT-PCR. RNA (RNeasy Mini-Kit) was used for cDNA generation with MaximaH-Minus First-Strand cDNA-Synthesis kit (ThermoFisher). Custom Taqman-Array in 96-well format (AppliedBiosciences \#4391524) was created based on RNA sequencing. The detailed protocol is outlined in the Supplementary Methods. Primer assays and sequences are listed in Suppl.Table S5.

Mass Spectrometry. The $6 \times 10^{6}$ cells (MDA-MB-231-NES/or NLS-AURKA) were used (2 clones combined/cell line). The detailed protocol is outlined in Supplementary Methods.

Immunoprecipitation (IP) assay. The detailed protocol for immunoprecipitation of AURKA is outlined in Supplementary Methods.

Chromatin Immunoprecipitation Assay. Chromatin immunoprecipitation (ChIP) was performed using ChIP-grade antibodies against human AURKA (BethylLabs, \#IHC00062) and the SimpleChIP Enzymatic ChromatinIP Kit (CellSignaling) according to manufacturer's instructions. The detailed protocol is outlined in Supplementary Methods. The primers used for ChIP qPCR analysis are listed in Suppl.Table S6.

Statistical analysis. Statistical comparisons were made using two-tailed Student's t-test, one-way or two-way analysis of variance (ANOVA). $P \leq 0.05$ was considered to be 
significant $\left(^{*}\right)$. All groups were compared to empty-vector control/s unless mentioned otherwise. Experimental values were reported as the means with +/-S.E.M (standard error of mean), p-values are reported as adjusted, and calculations of statistical significance were made using Prism7 software (Graphpad Software). All experimental data sets reported here were collected from multiple independent experiments with multiple technical and biological replicas. The analyses were performed by staff on numbered, deidentified samples. 


\section{$\underline{\text { Results }}$}

Nuclear localization of AURKA correlates with disease progression and metastasis.

AURKA overexpression in TCGA BC cohort correlates with poorer overall survival (Suppl.Fig.1A-C), but this dataset does not allow stratifying patients based on subcellular localization of AURKA. To fill this gap, a BC tissue microarray with over 200 patient samples (Suppl.Table-S3) was analyzed for AURKA localization and correlated with pathological stage and subtype (Fig.1A-C). The positivity of normal tissue and ductal carcinoma in-situ (DCIS) for N-AURKA is $0-3 \%$. There is a ten-fold increase in positivity in invasive ductal (IDC), lobular (ILC) carcinomas, and metastases (MIDC-LN) (Fig.1AB). The TNBC and HER2+ tumors show up to $12-20 \%$ of cells in the tumors with $\mathrm{N}$ AURKA compared to $5 \%$ of ER/PR+ cases (Fig.1C). To evaluate the association between $\mathrm{N}$-AURKA positivity in clinical samples and metastasis, we have procured a set of matched breast tumor-metastases biopsies along with biopsies from patients who had no metastases at the time of biopsy (IRB\#WVU011113, Suppl.Fig.1D, Suppl.Table-S4). Spearman's rank correlation coefficient analysis indicated a strong correlation between N-AURKA positivity and metastatic outcomes (Suppl.Fig.1E, $r=0.8051, p<0.0001$ ). Eleven of these biopsies were previously used to produce patient-derived xenograft (PDX) models (25). Similar to the original biopsy, the low/negative N-AURKA PDXs (PEN_060, PEN_061, PEN_175, PEN_181, PEN_025) had no distant metastases, while N-AURKA high (PEN_014, PEN_056, PEN_76, PEN_116) developed metastases (Suppl.Table-S4), indicating that N-AURKA correlates with metastasis. The AURKA localization/expression in BC cell lines shows a correlation between nuclear AURKA positivity and metastatic potential of the cells (Fig.1D-E, Suppl.Fig.1F-G).

\section{N-AURKA drives cancer migration/invasion but does not affect proliferation.}

To define the impact of N-AURKA on metastasis, cells with nuclear or cytoplasmic AURKA were produced. The cell lines (MDA-MB-231 and BT549) were made using CRISPR/Cas9 to knockout endogenous AURKA and replace with exogenous AURKA targeted to the nucleus (NLS), cytoplasm (NES), or no-localization signal (WT) (Fig.1FH, Suppl.Methods). The cells expressing non-targeting sgRNAs and empty vectors were 
used as controls. In vitro cell proliferation/viability assay and mixed modeling analysis show no statistically significant differences in cell growth or death between NLS- and NES-AURKA cells (Fig.2A). The morphometric analysis of NLS-AURKA cells shows reduced cell elongation index and nuclei (Fig.2B-D). The 3D invasion assay in collagen shows that NLS-AURKA cells travel a significantly longer distance and are faster than other cells (Fig.2E-H). In agreement with previously published reports, the MDA-MB-231 cell viability was not compromised due to attachment loss (Fig.2I). Interestingly, all cells expressing exogenous AURKA were more resistant to anoikis, but no differences were observed between sublines. The analysis of the number and size of multi-cellular clusters at $48 \mathrm{~h}$ post-seeding shows a significant decrease in the clumping/clustering potential of NLS-AURKA cells without effecting cell viability (Fig.2J-K), suggesting that clumping may not be necessary for the survival of these cells. These results indicate that cells with $\mathrm{N}$ AURKA are highly invasive but do not possess enhanced proliferation or anchorageindependent capabilities.

\section{N-AURKA drives cancer cell stemness.}

The cell-surface antigens, CD24, CD44, and CD104, are used as cancer stem cell (CSC) markers $(26,27)$. Similar to previous reports, there is a decrease in the CD24+/CD44+, CD24+/CD104+ cells and a significant increase in CD24-/CD44+, CD24/CD104- cells in NLS-AURKA cells, showing a shift to more stem-like (Fig.2L-O). A decrease was observed in the number of stained cells for CD24 and the mean fluorescent intensity (Suppl.Fig.2A), while CD44 mean fluorescent intensity was increased (Suppl.Fig.2B-C). Previously, FOXM1 transcription factor was reported to mediate the AURKA driven stemness (28). The analysis of stem cell markers shows no changes in CD24, CD44, or CD104 upon depletion of FOXM1 (Suppl.Fig.2D-H), suggesting that this activity of N-AURKA is FOXM1 independent. Similarly, analysis of mammosphere formation shows a significant increase in the number and diameter in NLS-AURKA cells (Fig.2P-R). Still, this activity was not affected by the depletion of FOXM1 (Supp.Fig.2I).

\section{N-AURKA induces hypoxia in xenograft models of breast cancer.}


To evaluate the effect of N-AURKA on tumor invasion and metastasis in vivo, the cells were injected into the mammary gland of immunocompromised mice (Fig.3A). There were no significant differences in the growth of mammary tumors between groups (Fig.3B, Suppl.Fig.3A-B). Even though tumors were of similar size/volume, there was a significant difference in tumor necrosis and vascularization (Fig.3C-G). Immunohistochemistry analysis of the tumors showed no significant difference in proliferation (Ki67) (Suppl.Fig.3C-E). The NLS-AURKA group showed a significant decrease in CD31 staining compared to the control (Fig.3F-G). To assess oxygenation of tumors, the hypoxia marker-pimonidazole was injected in mice before collection. Tumor analysis shows that over $40 \%$ of NLS-AURKA tumors were hypoxic (Fig. $3 \mathrm{H}-\mathrm{I})$.

\section{N-AURKA expressing tumors are highly metastatic.}

The induction of hypoxia often results in metastasis (29). The analysis of distant organs shows over ten-fold increase in the number and size of metastases in mice bearing NLS-AURKA tumors compared to other groups (Fig.4A-E, Suppl.Fig.4A-B). The bone and liver metastases were present in all NLS-AURKA mice (100\% penetrance rate) (Fig.4C), suggesting that NLS-AURKA cells have an increased proficiency to disseminate/grow at multiple distant sites.

\section{N-AURKA induces hypoxia signaling via upregulation of HIF-responsive genes.}

To identify the processes responsible for the increased metastatic potential, the gene expression profiles of cells were generated (GSE154494). The presence of AURKA in the nucleus was associated with a global transcriptional response (Fig.5A). Principal component analysis of RNA-seq data separated the samples into three groups (Fig.5B) with a significant number of genes differentially expressed in NLS-AURKA cells (Fig.5C, Suppl.Fig.5A-B). The expression of some targets was evaluated by western blotting and qPCR in MDA-MB-231 and BT-549 cells (Fig.5E-F, Suppl.Fig.5D-F). The N-AURKA gene-signature was confirmed by qPCR in tumors showing a similar gene expression profile (Suppl.Fig.5G-I). The Gene Ontology terms analyzed with the REViGO tool show that NLS-AURKA upregulates genes related to differentiation, motility/adhesion, hypoxia/oxygen, and protein phosphorylation (Fig.5D, Suppl.Fig.5C). Gene Set 
Enrichment Analysis (GSEA) showed enrichment for genes involved in mammary stem cell development, EMT, and hypoxia (Fig.5G). The NLS-AURKA cells show upregulation of genes associated with the hypoxia-response, such as CXCR4, MMP1, ANGPT1, ARNT/HIF1B, MMP14, ITGA6/CD49f, and ARNT2/HIF2B (Fig.5H). The IPA analysis of RNA-seq identified multiple upstream regulators of hypoxia signaling, including HypoxiaInducible Factor-1 alpha (HIF1A), NFKB, and tumor necrosis factor (TNF) to be activated in NLS-AURKA cells (Fig.5I). The N-AURKA-driven hypoxia gene signature correlates with a worse prognosis and high risk of relapse (Suppl.Fig.5J-K), suggesting that hypoxia genes identified in our study influence the disease progression.

\section{N-AURKA binds to HIF1A/B and transactivates hypoxia response genes.}

To understand how N-AURKA enables the transcription of hypoxia-response genes, protein expression of Hypoxia-Inducible Factors (HIFs) was examined. DMOG (dimethyloxalyl glycine) treatment was used as a positive control, leading to upregulation and stabilization of HIF1/2A. In normoxia, there were no differences in protein levels of HIF1/2A between the sublines (Fig.6A-B, Suppl.Fig.6A-B). The DMOG treatment led to increased HIF1A protein independently of AURKA localization. In contrast, HIF2A was not upregulated in DMOG-treated NLS-AURKA cells, suggesting differential action of AURKA on these proteins during hypoxia, but not normoxia. Consistent with RNA-seq results, a significant increase in HIF1/2B proteins was detected (Fig.6A-B, Suppl.Fig.6AE). To determine if N-AURKA interacts with HIFs, we immunoprecipitated AURKA from cell lysates. The AURKA complex contained HIF1A and HIF1B proteins; NLS-AURKA expressing cells preferentially precipitated AURKA in a complex with HIF1B (Fig.6C-D). Next, the binding of AURKA to hypoxia-response gene promoters was assessed using chromatin immunoprecipitation (ChIP) assay. The CD49f/ITGA6, EPO, and CXCR4 genes were selected as they contain Hypoxia Response Elements (HREs) (30-32). ChIP for HIF1B was used as the positive control. The GPCR with FOXM1 promoter was used as a positive control for AURKA (28). ChIP qPCR results show N-AURKA binding to HREcontaining promoters of specific hypoxia genes, also occupied by HIF1B (Fig.6E-F). Other proteins that interact with N-AURKA on chromatin include hnRNPk, Aurora-B Kinase, Histone H3 and Histone H2B (Fig.6F). To map the protein interaction network of 
N-AURKA, we carried out LC-MS/MS analysis of AURKA-IP complex. The identified proteins were clustered based on the cellular compartment and biological function (Fig.6G). A large subset of proteins was nuclear and classified as DNA/RNA-binding. Notably, the two principal HIF transcription cofactors CBP and P300 were identified within the AURKA complex, along with RNA Polll and multiple proteins involved with the super elongation complex (Fig.6H-I).

\section{HIF1A/B is required to mediate N-AURKA-driven invasion.}

To test the role of HIF1A/B in mediating N-AURKA driven processes, we generated NLSAURKA and control cell lines with depletion of HIF1A/B (Fig.7A-B). The 3D invasion/migration analysis shows a significant reduction in invasion of NLSAURKA/siHIF1 cells as documented by the decrease in speed and distance (Fig.7C-F). The transactivation of hypoxia-signature genes was also significantly reduced upon depletion of HIF1A/B (Fig.7G). Interestingly, depletion of HIF1A/B led to a decrease in FOXM1 expression (Fig.7H). In comparison, depletion of FOXM1 did not change expression levels of HIF1A/B (Fig.7I-J), suggesting that the N-AURKA/HIF complex is upstream of FOXM1. Supporting this notion, mammosphere formation potential in NLSAURKA cells was not affected by FOXM1 depletion (Supp. Fig.2I).

\section{Inhibition of N-AURKA kinase activity decreases breast cancer metastasis.}

The orthotopic xenograft study was conducted using control and NLS-AURKA cells treated with AURKA-specific inhibitor, Alisertib/MLN8237 (Fig.8A-B). The tumor volume was not affected by Alisertib/MLN8237 treatment (Fig.8C), while metastases in the lungs and liver were significantly decreased (Fig.8D-F), suggesting that kinase activity might be required to enable metastatic colonization. The metastatic penetrance in the NLSAURKA group was not affected by the MLN8237 (Fig.8G) indicating that dissemination of NLS-AURKA cells is kinase-independent. In summary, these findings support the model of N-AURKA-driven activation of hypoxia-response genes via interaction with HIF1 promoting metastasis (Fig.8H). 


\section{Discussion}

AURKA has recently been found in the nucleus in multiple cancers $(4-6,33)$; however, the role of nuclear AURKA (N-AURKA) in metastasis is currently unknown. Here, we report that N-AURKA promotes metastasis. The AURKA subcellular distribution in BC-TMA shows accumulation in the nucleus correlating with more aggressive subtypes, invasive stage, and metastasis (Fig.1A-C, Suppl.Fig1E). The analysis of TCGA data indicates a strong correlation between levels of AURKA mRNA and poor outcomes (Suppl.Fig.1A-C). The NLS-AURKA induced hypoxia gene-signature correlates with decreased overall and relapse-free survival (Suppl.Fig.5J-K). In human breast cancer cell lines, the localization of AURKA in the nucleus closely correlates with the metastatic proficiency of the cells (Fig.1D-E, Suppl.Fig.1F-G).

The critical role of N-AURKA in metastasis was documented by the enhanced metastatic burden in orthotopic mouse models (Fig.4). The metastatic penetrance of NLS-AURKA cells is $100 \%$ in the lungs, lymph node, liver, and bone (Fig.4C) without the need for multiple rounds of selection $(34,35)$. NLS-AURKA upregulates genes that promote bone metastasis, including ADAMST1, FGF5, FST, CXCR4, IL-11, MMP1 (34). Note that tumor cells with cytoplasmic AURKA, found in non-transformed cells, have limited to no metastatic capacity (Fig.2A, Fig.4).

The increased metastatic capabilities are supported by changes in morphology, migration, and stemness. Cells with nuclear AURKA are round and small (Fig.2B-D), enabling fast movement throughout a constricted environment $(36,37)$, as in the invasion assay (Fig.2E-H). The upregulation of cytoskeleton (RHOJ, ARHGAP22, ARHGAP24, ELMO1, DEF6), adhesion (CADM2, SELL, ITGA6), matrix-degrading (ADAMTS5, ADAMTS1, MMP1, MMP14), and tight junction (CLDN4, CLDN11, CLDN12, CLDN23) proteins enables metastatic proficiency of N-AURKA cells (Fig.5). The decrease in extracellular matrix proteins (LAMB1, LAMC2) might explain the decline in cluster formation (Fig.2J-K). Interestingly, clustering disability did not affect the sensitivity to anoikis (Fig.2I) or metastatic proficiency (Fig.4), suggesting uncoupling of these processes. 
The analysis of stem cell markers showed an increase in CD24//CD44 ${ }^{+}$and CD24/CD104 ${ }^{+}$cells (Fig.2L-O) and a reduction in mean fluorescent intensity of CD24 (Suppl.Fig.2A-C). These findings agree with a recent study showing that N-AURKA promotes breast cancer stemness (6). The NLS-AURKA cells produced more and larger mammospheres, indicating an increase in stemness (Fig.2P-R). The depletion of FOXM1 was insufficient to change the stem cell markers or mammosphere formation (Suppl.Fig.2D-I). This activity of N-AURKA might be mediated by HIF1A/B, which in turn might upregulate FOXM1 (Fig.7H-J). These findings differ from previously published reports, using either an overexpression system (28) or NES-AURKA inducible system (6). Neither of those modeling approaches allows analysis of nuclear AURKA specific function directly.

The RNAseq analysis show changes in expression of hypoxia, transcription, and metastasis-related pathways (Fig.5, Suppl.Fig.5). It is well-established that hypoxia is an inducer of metastasis $(38,39)$. Our findings show that NLS-AURKA interacts with HIF1 and is a potent inducer of the hypoxia-response genes in vitro and in vivo (Fig.6, Suppl.Fig.6). Hypoxia signaling is primarily driven by hypoxia-inducible factors (HIFs). The activation/expression of HIF1A at diagnosis is predictive of early relapse and metastasis (40-43).

The NLS-AURKA-ChIP complex analysis and qPCR support the notion that AURKA is binding to HRE-containing promoters with HIF1A/B (Fig.6E-I). These changes are reported under normoxic conditions and could be further induced under hypoxia. A similar phenotype was observed in other breast cancer models (44). N-AURKA gene-signature changes were associated with metabolic reprogramming (HK1/2), angiogenesis (ADM, ANGPT1, EDN1, FECH), invasion (CXCR4, LOX, MMP1, MMP14, ITGA6, CSRP2), and proliferation (ENG, WT1, CCND1). Depletion of HIF1A/B in NLS-AURKA cells led to a reduction in migration/invasion and expression of the key hypoxia signature genes, suggesting that this metastasis-driving activity of AURKA is HIF1 dependent (Fig.7A-G). Note that not all genes connected to hypoxia were upregulated. Some canonical HIF1Ainduced genes PFKP, SNAI1, and NOS3 were downregulated, suggesting the involvement of additional factors affecting transcription (Fig.5I). 
The mass-spectrometry analysis of the AURKA-complex identified p300/CBP and RNAPII complex proteins, supporting the role of N-AURKA in transcription (Fig.6G-I). These findings are in agreement with the previous reports showing AURKA binding to the MYC promoter (6). In concordance with this report, we show that nuclear AURKA binds to chromatin complexes that contain hnRNPk (Fig.6F,H). The global ChIP-seq analysis of AURKA has not been reported; therefore, many of the potential targets are still unknown.

Previously it was shown that transcription-related activities of nuclear AURKA are kinaseindependent. In our study, inhibition of N-AURKA leads to a significant decrease in metastatic burden (Fig.8). Interestingly, the kinase activity was not required for dissemination but was critical for colonization of distant organs. Combining AURKA inhibitors with HIF-targeting compounds might prove to be even more beneficial in treating metastatic cancer $(6,25)$. A better understanding of the nuclear AURKA functions may enable discovery of new biomarkers for metastatic disease and therapeutic targets. 
Acknowledgements. We thank WVU HSC Office of Graduate Research and Education for outstanding administrative support, WVU Tissue Bank, Genetic Tumor Modeling Core, and Animal Models \& Imaging Facilities, supported by the WVUCl and NIH grants P20 RR016440, P30 RR032138/GM103488, and S10RR026378. Flow Cytometry Facility was supported by NIH grants P30GM103488, P30RR032138, and RCP1101809. Bioinformatics Core by NIH grants P20GM103434 and U54 GM-104942. This work was supported by a grant from NIH-NCI CA148671 to E.N.P.

Author Contributions. K.M.W and E.N.P conceived the project and wrote the manuscript. TMA statistical analysis was performed by E.N.P. Animal pathology and tumor analysis was done by M.S.S and K.M.W. Bioinformatics analysis was performed by D.C, G.H, J.G, and K.M.W. All remaining experiments and data analysis were performed by K.M.W, A.M, M.A.V, J.L, H.C, S.Y, N.V.M, S.W, M.L.P and E.N.P.

Conflicts of interest: The authors declare that there are no conflicts of interest. 


\section{$\underline{\text { References }}$}

1. Schumacher JM, Ashcroft N, Donovan PJ, Golden A. A highly conserved centrosomal kinase, AIR-1, is required for accurate cell cycle progression and segregation of developmental factors in Caenorhabditis elegans embryos. Development. 1998;125(22):4391-402.

2. Giet R, McLean D, Descamps S, Lee MJ, Raff JW, Prigent C, et al. Drosophila Aurora A kinase is required to localize D-TACC to centrosomes and to regulate astral microtubules. $J$ Cell Biol. 2002;156(3):437-51.

3. Wang LH, Xiang J, Yan M, Zhang Y, Zhao Y, Yue CF, et al. The mitotic kinase Aurora-A induces mammary cell migration and breast cancer metastasis by activating the Cofilin-F-actin pathway. Cancer Res. 2010;70(22):9118-28.

4. Baba Y, Nosho K, Shima K, Irahara N, Kure S, Toyoda S, et al. Aurora-A expression is independently associated with chromosomal instability in colorectal cancer. Neoplasia. 2009;11(5):418-25.

5. Xu HT, Ma L, Qi FJ, Liu Y, Yu JH, Dai SD, et al. Expression of serine threonine kinase 15 is associated with poor differentiation in lung squamous cell carcinoma and adenocarcinoma. Pathol Int. 2006;56(7):375-80.

6. Zheng F, Yue C, Li G, He B, Cheng W, Wang X, et al. Nuclear AURKA acquires kinaseindependent transactivating function to enhance breast cancer stem cell phenotype. Nat Commun. 2016;7:10180.

7. Tatsuka M, Sato S, Kanda A, Miki T, Kamata N, Kitajima S, et al. Oncogenic role of nuclear accumulated Aurora-A. Mol Carcinogen. 2009;48(9):810-20.

8. Mao JH, Wu D, Perez-Losada J, Jiang T, Li Q, Neve RM, et al. Crosstalk between Aurora-A and p53: frequent deletion or downregulation of Aurora-A in tumors from p53 null mice. Cancer Cell. 2007;11(2):161-73.

9. Yang $\mathrm{H}, \mathrm{He} \mathrm{L}, \mathrm{Kruk} \mathrm{P}, \mathrm{Nicosia} \mathrm{SV}$, Cheng JQ. Aurora-A induces cell survival and chemoresistance by activation of Akt through a p53-dependent manner in ovarian cancer cells. Int J Cancer. 2006;119(10):2304-12.

10. Briassouli P, Chan F, Savage K, Reis-Filho JS, Linardopoulos S. Aurora-A regulation of nuclear factor-kappaB signaling by phosphorylation of IkappaBalpha. Cancer Res. 2007;67(4):1689-95.

11. Xu J, Wu X, Zhou WH, Liu AW, Wu JB, Deng JY, et al. Aurora-A identifies early recurrence and poor prognosis and promises a potential therapeutic target in triple negative breast cancer. PLoS One. 2013;8(2):e56919.

12. D'Assoro AB, Liu T, Quatraro C, Amato A, Opyrchal M, Leontovich A, et al. The mitotic kinase Aurora--a promotes distant metastases by inducing epithelial-to-mesenchymal transition in ERalpha(+) breast cancer cells. Oncogene. 2014;33(5):599-610.

13. Nadler Y, Camp RL, Schwartz C, Rimm DL, Kluger HM, Kluger Y. Expression of Aurora A (but not Aurora $B$ ) is predictive of survival in breast cancer. Clin Cancer Res. 2008;14(14):4455-62. 
14. Jiang BH, Rue E, Wang GL, Roe R, Semenza GL. Dimerization, DNA binding, and transactivation properties of hypoxia-inducible factor 1. J Biol Chem. 1996;271(30):17771-8. 15. Semenza GL. The hypoxic tumor microenvironment: A driving force for breast cancer progression. Biochim Biophys Acta. 2016;1863(3):382-91.

16. De Bock K, Mazzone M, Carmeliet P. Antiangiogenic therapy, hypoxia, and metastasis: risky liaisons, or not? Nat Rev Clin Oncol. 2011;8(7):393-404.

17. Zhang H, Wong CC, Wei H, Gilkes DM, Korangath P, Chaturvedi P, et al. HIF-1dependent expression of angiopoietin-like 4 and L1CAM mediates vascular metastasis of hypoxic breast cancer cells to the lungs. Oncogene. 2012;31(14):1757-70.

18. Hayashi Y, Yokota A, Harada H, Huang G. Hypoxia/pseudohypoxia-mediated activation of hypoxia-inducible factor-1alpha in cancer. Cancer Sci. 2019;110(5):1510-7.

19. Pugacheva EN, Golemis EA. The focal adhesion scaffolding protein HEF1 regulates activation of the Aurora-A and Nek2 kinases at the centrosome. Nat Cell Biol. 2005;7(10):93746.

20. Pugacheva EN, Jablonski SA, Hartman TR, Henske EP, Golemis EA. HEF1-dependent Aurora A activation induces disassembly of the primary cilium. Cell. 2007;129(7):1351-63.

21. Gyorffy B, Lanczky A, Eklund AC, Denkert C, Budczies J, Li Q, et al. An online survival analysis tool to rapidly assess the effect of 22,277 genes on breast cancer prognosis using microarray data of 1,809 patients. Breast Cancer Res Treat. 2010;123(3):725-31.

22. Nagy A, Lanczky A, Menyhart O, Gyorffy B. Validation of miRNA prognostic power in hepatocellular carcinoma using expression data of independent datasets. Sci Rep. 2018;8(1):9227.

23. Jones BC, Kelley LC, Loskutov YV, Marinak KM, Kozyreva VK, Smolkin MB, et al. Dual Targeting of Mesenchymal and Amoeboid Motility Hinders Metastatic Behavior. Mol Cancer Res. 2017;15(6):670-82.

24. Ice RJ, McLaughlin SL, Livengood RH, Culp MV, Eddy ER, Ivanov AV, et al. NEDD9 depletion destabilizes Aurora A kinase and heightens the efficacy of Aurora A inhibitors: implications for treatment of metastatic solid tumors. Cancer Res. 2013;73(10):3168-80. 25. Kozyreva VK, Kiseleva AA, Ice RJ, Jones BC, Loskutov YV, Matalkah F, et al. Combination of Eribulin and Aurora A Inhibitor MLN8237 Prevents Metastatic Colonization and Induces Cytotoxic Autophagy in Breast Cancer. Mol Cancer Ther. 2016;15(8):1809-22.

26. Bierie B, Pierce SE, Kroeger C, Stover DG, Pattabiraman DR, Thiru P, et al. Integrinbeta4 identifies cancer stem cell-enriched populations of partially mesenchymal carcinoma cells. Proc Natl Acad Sci U S A. 2017;114(12):E2337-E46.

27. Al-Hajj M, Wicha MS, Benito-Hernandez A, Morrison SJ, Clarke MF. Prospective identification of tumorigenic breast cancer cells. Proc Natl Acad Sci U S A. 2003;100(7):39838.

28. Yang N, Wang C, Wang Z, Zona S, Lin SX, Wang X, et al. FOXM1 recruits nuclear Aurora kinase $A$ to participate in a positive feedback loop essential for the self-renewal of breast cancer stem cells. Oncogene. 2017;36(24):3428-40. 
29. Azab AK, Hu J, Quang P, Azab F, Pitsillides C, Awwad R, et al. Hypoxia promotes dissemination of multiple myeloma through acquisition of epithelial to mesenchymal transitionlike features. Blood. 2012;119(24):5782-94.

30. Melchionna R, Romani M, Ambrosino V, D'Arcangelo D, Cencioni C, Porcelli D, et al. Role of HIF-1alpha in proton-mediated CXCR4 down-regulation in endothelial cells. Cardiovasc Res. 2010;86(2):293-301.

31. Orlando IMC, Lafleur VN, Storti F, Spielmann P, Crowther L, Santambrogio S, et al. Distal and proximal hypoxia response elements cooperate to regulate organ-specific erythropoietin gene expression. Haematologica. 2020;105(12):2774-84.

32. Brooks DL, Schwab LP, Krutilina R, Parke DN, Sethuraman A, Hoogewijs D, et al. ITGA6 is directly regulated by hypoxia-inducible factors and enriches for cancer stem cell activity and invasion in metastatic breast cancer models. Mol Cancer. 2016;15:26.

33. Tanaka E, Hashimoto Y, Ito T, Okumura T, Kan T, Watanabe G, et al. The clinical significance of Aurora-A/STK15/BTAK expression in human esophageal squamous cell carcinoma. Clin Cancer Res. 2005;11(5):1827-34.

34. Kang Y, Siegel PM, Shu W, Drobnjak M, Kakonen SM, Cordon-Cardo C, et al. A multigenic program mediating breast cancer metastasis to bone. Cancer Cell. 2003;3(6):53749.

35. Andrzejewski S, Klimcakova E, Johnson RM, Tabaries S, Annis MG, McGuirk S, et al. PGC-1alpha Promotes Breast Cancer Metastasis and Confers Bioenergetic Flexibility against Metabolic Drugs. Cell Metab. 2017;26(5):778-87 e5.

36. Friedl $\mathrm{P}$, Wolf $\mathrm{K}$, Lammerding J. Nuclear mechanics during cell migration. Curr Opin Cell Biol. 2011;23(1):55-64.

37. Pankova K, Rosel D, Novotny M, Brabek J. The molecular mechanisms of transition between mesenchymal and amoeboid invasiveness in tumor cells. Cell Mol Life Sci. 2010;67(1):63-71.

38. Rankin EB, Giaccia AJ. Hypoxic control of metastasis. Science. 2016;352(6282):17580.

39. Chen A, Sceneay J, Godde N, Kinwel T, Ham S, Thompson EW, et al. Intermittent hypoxia induces a metastatic phenotype in breast cancer. Oncogene. 2018;37(31):4214-25. 40. Bos R, van der Groep P, Greijer AE, Shvarts A, Meijer S, Pinedo HM, et al. Levels of hypoxia-inducible factor-1alpha independently predict prognosis in patients with lymph node negative breast carcinoma. Cancer. 2003;97(6):1573-81 .

41. Gruber G, Greiner RH, Hlushchuk R, Aebersold DM, Altermatt HJ, Berclaz G, et al. Hypoxia-inducible factor 1 alpha in high-risk breast cancer: an independent prognostic parameter? Breast Cancer Res. 2004;6(3):R191-8.

42. Generali D, Berruti A, Brizzi MP, Campo L, Bonardi S, Wigfield S, et al. Hypoxiainducible factor-1alpha expression predicts a poor response to primary chemoendocrine therapy and disease-free survival in primary human breast cancer. Clin Cancer Res. 2006;12(15):4562-8. 
43. Wang W, He YF, Sun QK, Wang Y, Han XH, Peng DF, et al. Hypoxia-inducible factor 1alpha in breast cancer prognosis. Clin Chim Acta. 2014;428:32-7.

44. Dupuy F, Tabaries S, Andrzejewski S, Dong Z, Blagih J, Annis MG, et al. PDK1Dependent Metabolic Reprogramming Dictates Metastatic Potential in Breast Cancer. Cell Metab. 2015;22(4):577-89. 


\section{Figure Legends}

Figure 1. Nuclear AURKA positivity correlates with metastasis and more aggressive breast cancer subtypes. A. Representative images of tissue microarray IHC, $(n=206)$ stained with AURKA/DAB-brown, hematoxylin-nuclei/blue. Scale bar$300 \mu \mathrm{m}$. Insets- $\times 250$ enlarged areas. B-C. Quantification N-AURKA positive $(+)$ cells as in (A), 3 randomly-assigned fields, $n=100$ cells/field. (B) Pathological stages (Normal=32, $D C I S=24, I D C=72$, MIDC-LN= 32, ILC=24) and (C) receptor-based subtypes (Normal=32, $\left.\mathrm{TNBC}=39, \quad \mathrm{HER} 2^{+}=32, \quad \mathrm{ER}^{+} / \mathrm{PR}^{+}=30\right) . \quad$ D. WB analysis of nuclear/cytoplasmic fractionations, as indicated. E. Quantification of AURKA in cytoplasm/nucleus, percentof-total, normalized to controls. F. Schematic outline of cell line production. G-H. Immunofluorescence and WB analysis of AURKA-sublines produced in (F) stained with AURKA(green), RFP(red), DAPI-nuclei/blue; clones indicated as c1/c2/c3. Scale bar-

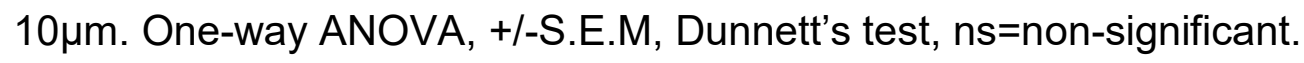

Figure 2. N-AURKA drives cancer migration/invasion but does not affect proliferation. A. Cell proliferation/viability assay, mixed-effect model analysis on cell growth. B. Representative bright-field images of cells, scale bar-10 $\mu$ m. C. Cell elongation index and D. Nuclei size. E. Individual cell movement tracking-plots toward chemoattractant. Graphs of F. Total distance, G. Cell-body directionality, H. Cell speed. I. Quantification of anoikis (live/dead cells). J. Representative bright-field images of clusters, scale bar-50 $\mu \mathrm{m}, \mathbf{K}$. Quantification of clusters as in (J); 3-6 randomly-assigned fields/per clone normalized to area, $\geq 40$ cells/clone. L-O. Representative flow cytometry dot-plots and quantification of CD24/CD44/CD104 positive cells. P. Representative images of mammospheres. Scale bar-50 $\mu \mathrm{m}$. Mammosphere quantification of $\mathbf{Q}$. Diameter, R. \# mammospheres/area. One-way ANOVA, +/-S.E.M, Dunnett's test, ns=non-significant.

Figure 3. N-AURKA induces hypoxia in xenograft models of breast cancer. A. Experimental design of xenograft study, $n=2$ clones/subline, $n \geq 5$ mice/group, $n=2$ experiments. B. Quantification of ultrasound-based tumor volume $\left(\mathrm{mm}^{3}\right)$ plotted over 
time. Mixed-effect model analysis. C. Representative images of gross tumor pathology, scale bar-5mm. D. Tumor H\&E images, inset-necrotic area, scale bar- $1 \mathrm{~mm}$. E. Quantification of necrosis/area in tumors. F. Representative tumor images of F-IHC staining with CD31, scale bar-100 $\mathrm{m}$ (top image), $50 \mu \mathrm{m}$ (inset). G. Quantification of CD31(+) staining area (\%) as in (F) normalized to total area, DAPI/nuclei(blue), CD31(white). H. Representative tumor images of F-IHC staining with anti-Pimonidazole (Hypoxyprobe-FITC/green), scale bar-1mm(top image), 100 $\mu$ m(inset). I. Quantification of Pimonidazole $(+)$ staining area $(\%)$ as in $(\mathrm{H})$ normalized to total area, DAPI/nuclei(blue). One-way ANOVA, +/-S.E.M, Dunnett's test, ns=non-significant.

Figure 4. N-AURKA expressing tumors are highly metastatic. A. Representative DAB-IHC images of Lymph Node (LN) metastases stained with anti-RFP-antibody. Scale

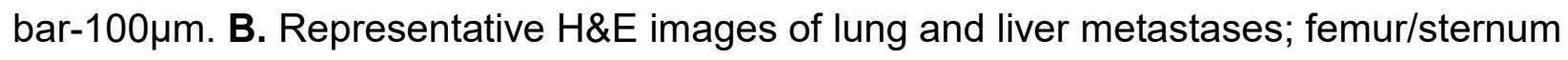
bone metastases stained with human-specific anti-mitochondria antibody. Metastases

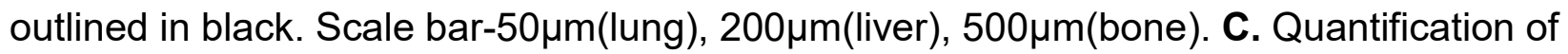
metastatic penetrance, as percent of mice which developed LN, lung, liver, and bone metastases. D. Quantification of number of metastases/area of lung, liver, or bone. E. Quantification of size of LN and lung metastases. One-way ANOVA, +/-S.E.M, Dunnett's test, ns=non-significant.

Figure 5. RNA-seq profile of N-AURKA cells. A. Heat-map of differentially expressed genes (DEGs, mean values) in cells. Gene expression $(n=3167)$ is normalized log2 counts/million. B. Principal Component Analysis of RNA-Seq libraries as in (A). C. Volcano-plot analysis of RNAseq data as in (A) NLS-AURKA vs. control, log2 fold changes of gene expression on the x-axis, FDR statistical significance (- $\log 10 p$-value) on the y-axis; upregulated (red), downregulated (black) genes in NLS, all genes (blue). Genes with at least $a>1.5$ fold change and FDR $<0.01$ are displayed. D. Visualization of Gene Ontology terms for NLS-AURKA vs. control; up/downregulated GOterms (FDR<0.1) are depicted as circles; the distance indicates the relationship between terms: closer distance means higher similarity. Color and size of circles indicate significance of differential expression of an individual GO term in log10 p-value. E. WB analysis of 
selected RNA-seq target proteins as in (A). F. Quantification of WB in (E), fold change over control. G. GSEA comparison NLS-AURKA vs. control for selected GOterm gene sets. H. Heat-map of HIF-dependent DEGs. I. Predicted upstream regulators: activated (yellow), inhibited (blue) using IPA activation z-score. One-way ANOVA, +/-S.E.M, Dunnett's test, ns=non-significant.

Figure 6. N-AURKA binds to HIF1A/B and promotes transactivation of hypoxiaresponse genes. A. WB analysis of HIFs in cells with indicated antibodies, DMSOvehicle or DMOG for $7 \mathrm{hr}$. B. Quantification of WB results as in (A), fold of change over DMSO-control. C-D. Representative images of Immunoprecipitation/WB analysis with indicated antibodies, WCL-whole cell lysate. E. Quantification of ChIP qPCR against selected promoter region, normalized to total input. F. WB analysis of ChIP (before decrosslinking). G. Mass spectrometry analysis of AURKA-IP complexes: Venn diagram displaying the numbers of proteins found in the NLS- or NES-AURKA complexes. The 850 proteins/yellow were further filtered, nuclear/blue. Pie-chart showing distribution of N-AURKA binding partners based on functional Panther Gene Ontology terms. Tables showing selected nuclear protein classifications for $\mathbf{H}$. RNA-binding and I. DNA-binding from PANTHER Gene Ontology. One-way ANOVA, +/-S.E.M, Dunnett's test, ns=nonsignificant.

Figure 7. HIF1A/B is required for N-AURKA-driven invasion. A. WB analysis of HIFs in cells as indicated, treated with siRNA: control-scr or anti-HIF1A/B. B. Quantification of WB results in $(A)$, fold of change over siScr. $C$. Individual cell movement tracking-plots toward chemoattractant. Cell lines as indicated. Graphs of D. Total distance, E. Cell-body directionality, F. Cell speed. G. qPCR analysis of select genes in control and NLS-AURKA cells with siScr and SiHIF1A/B, fold change over control-siScr. H. qPCR analysis of FOXM1 in control and NLS-AURKA cells treated with siScr and siHIF1A/B, fold change over control-siScr. I-J. qPCR analysis of FOXM1, HIF1A, and HIF1B in control and NLSAURKA cells treated with siScr and siFOXM1, fold change over control-siScr. HIF1B: (unpaired t-test: con-Scr vs NLS-AURKA-Scr). One-way ANOVA, +/-S.E.M. Tukey's test, ns=non-significant. 
Figure 8. Inhibition of N-AURKA kinase activity decreases breast cancer metastasis. A. Experimental design of xenograft study, $n=3$ mice/group B. Quantification of Fluorescent-IHC using phospho-AURKA-T288 antibody in tumors. $n=50$ mitoticcells/tumor. C. Quantification of final tumor volume $/ \mathrm{mm}^{3}$. D. Representative H\&E images of lung metastases and DAB-IHC images of liver metastases stained with anti-RFP-

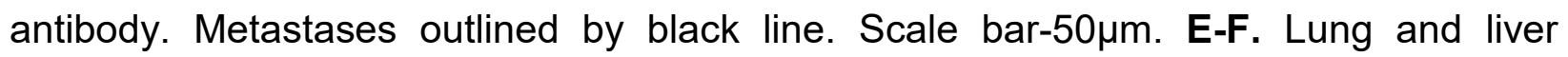
metastasis penetrance in mice treated with vehicle or MLN8237. G-H. Quantification of metastases: number and area of metastases normalized to total area. One-way ANOVA, +/-S.E.M. Tukey's test. I. Model of Nuclear-AURKA-HIF1 mediated gene expression. Normoxia: HIF1A is hydroxylated/ubiquitinated by $\mathrm{PHDs} / \mathrm{VHL}$ resulting in degradation. Hypoxia: low-oxygen stabilizes HIF1A leading to HIF1A/B dimerization/activation, transactivation of hypoxia-response genes. Normoxia+N-AURKA: HIF1A/B activity is increased leading to metastasis. MLN8237 inhibits AURKA activity decreasing metastasis. 


\section{Figures}

A

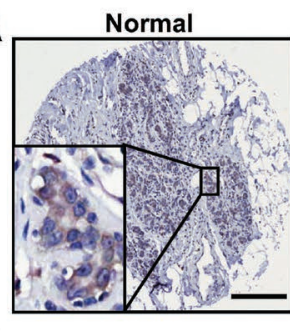

B

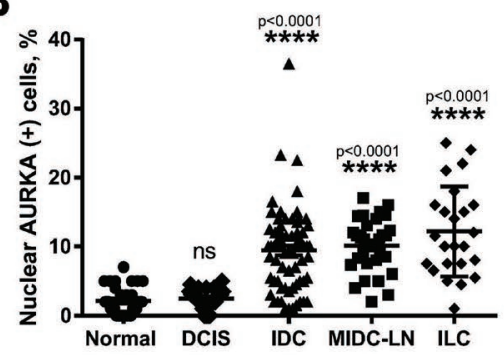

IDC

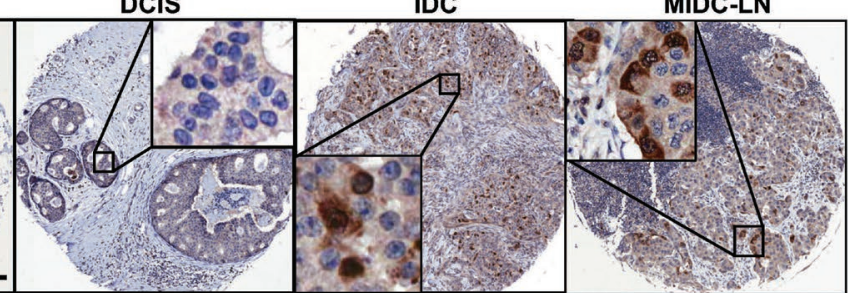

C

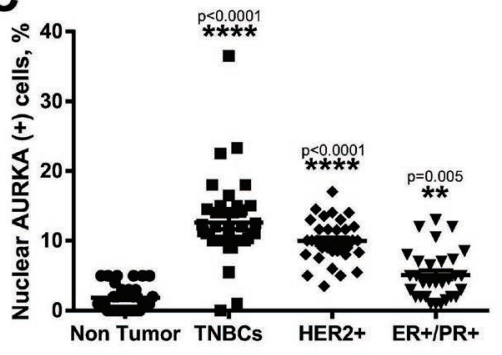

D
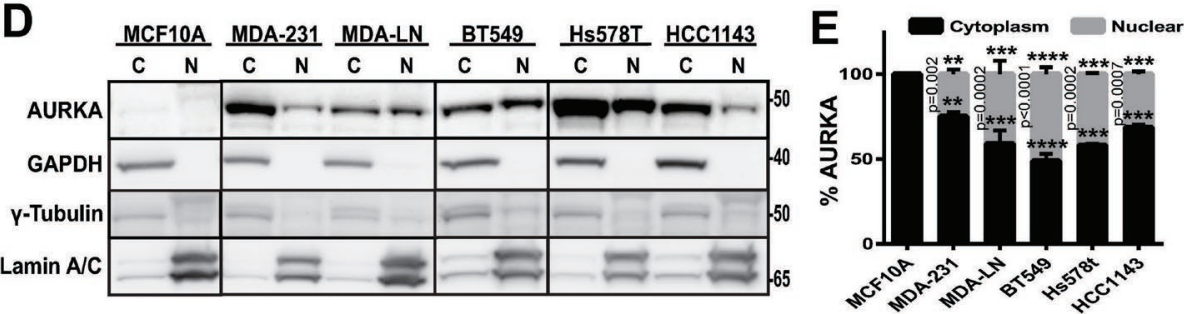

F Step 1: Creation of Vectors

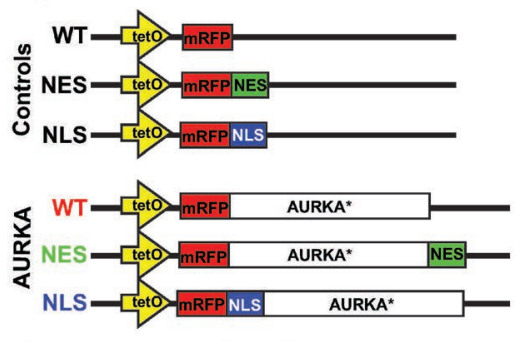

AURKA $^{*}=$ exogenous AURKA cDNA resistant to sgAURKA

Step 2: Expression of Exogenous AURKA Controls:
mRFP-WT- MRFP-NES- MRFP-NLS-

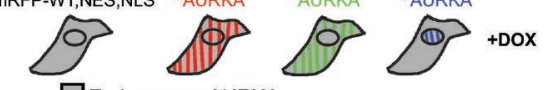

$\square$ Endogenous AURKA

四口面Both Endogenous and Exogenous AURKA* Step 3: Knock-out of Endogenous AURKA

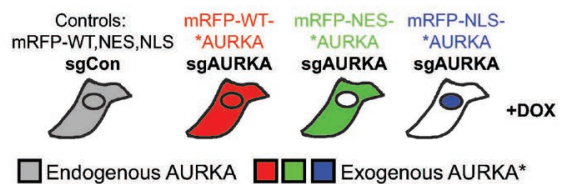

$\square$ Endogenous AURKA $\square \square \square$ Exogenous AURKA*

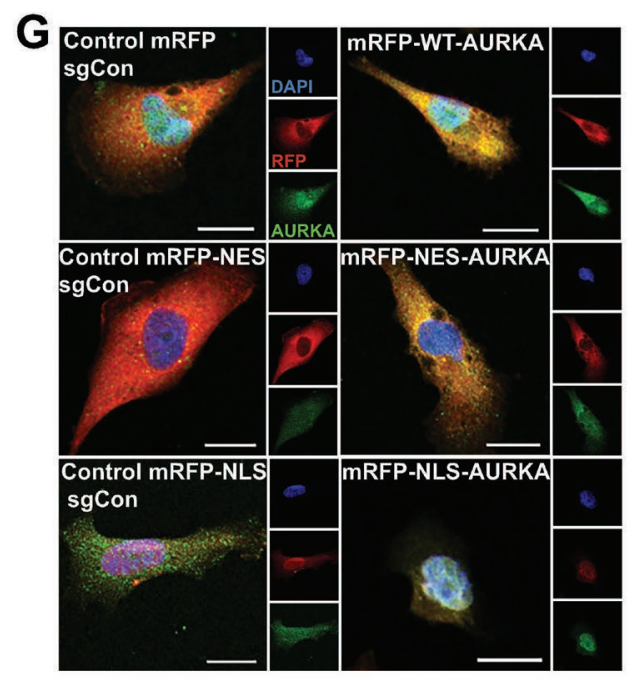

H

AURKA: - $\quad$ WT NES NLS CRISPR sg: Con AURKA AURKA AURKA GAPDH

Figure 1. Whately 

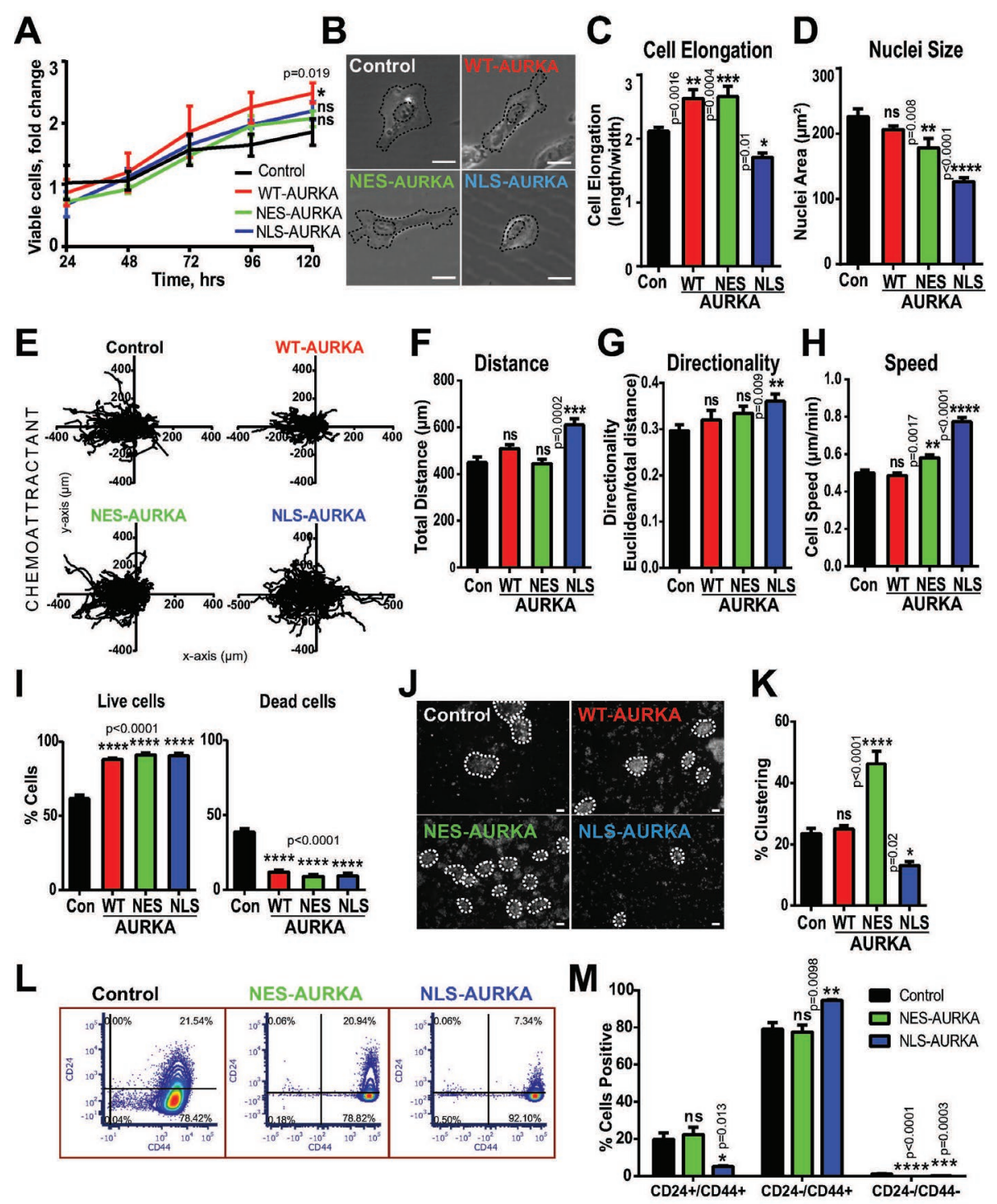

$\mathbf{N}$

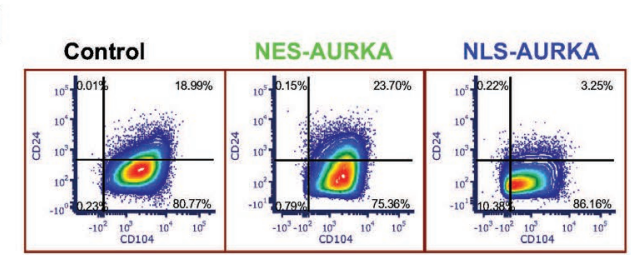

0
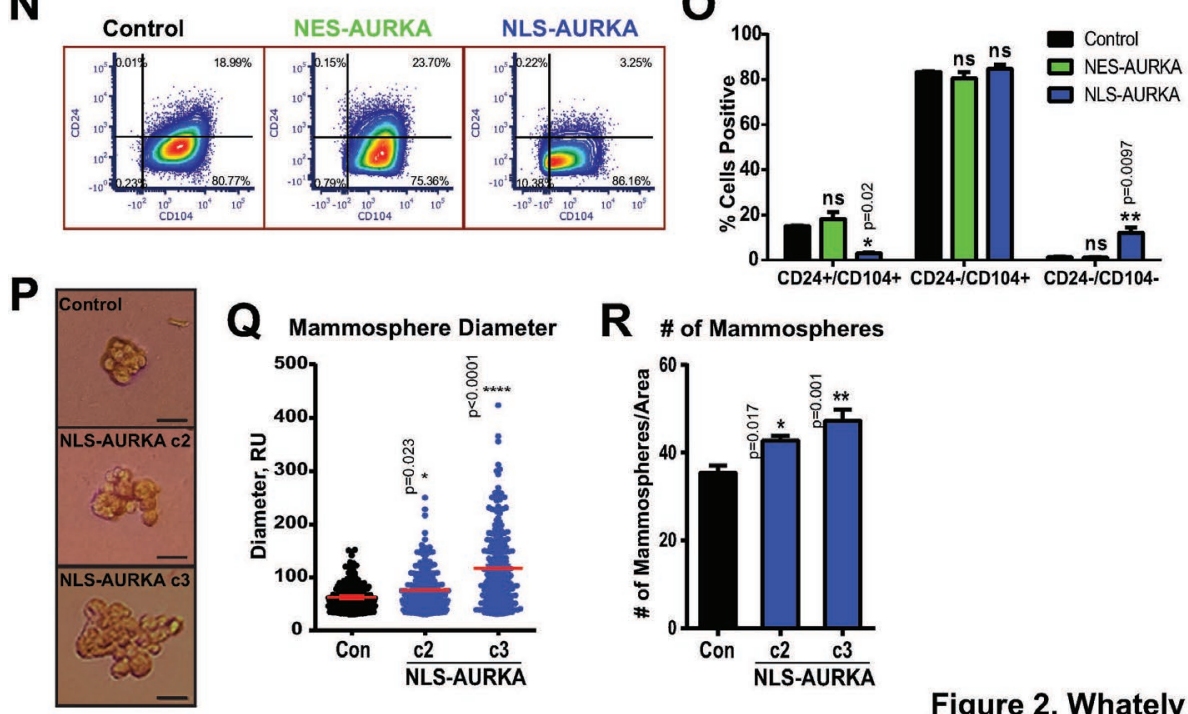

Q Mammosphere Diameter

$\mathbf{R}$ \# of Mammospheres
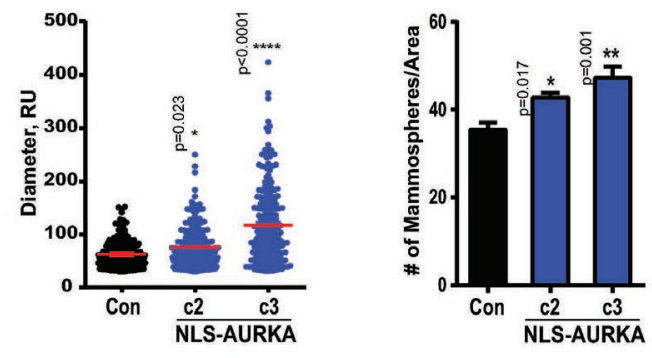

Figure 2. Whately 
A

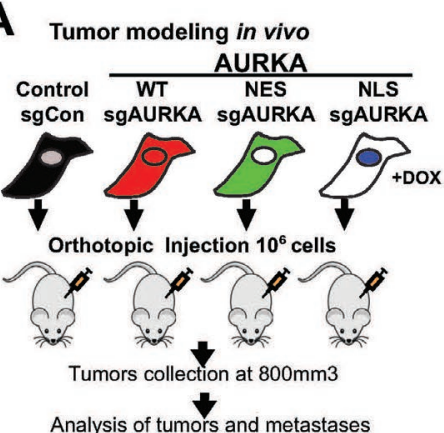

B

Analysis of tumors and metastases

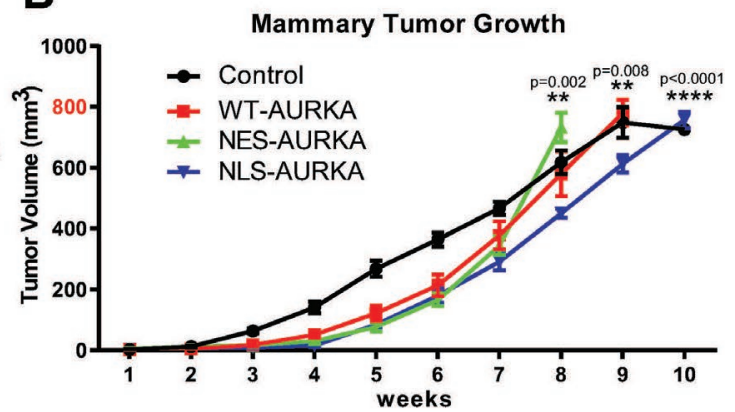

D

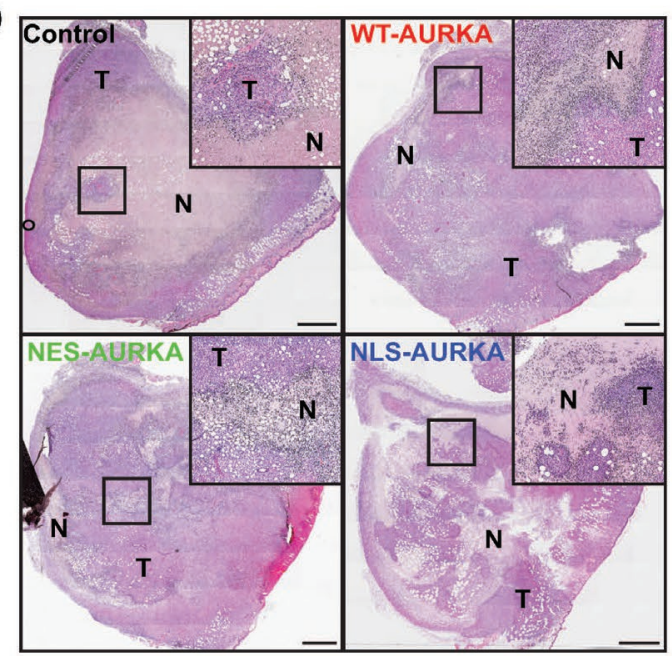

E

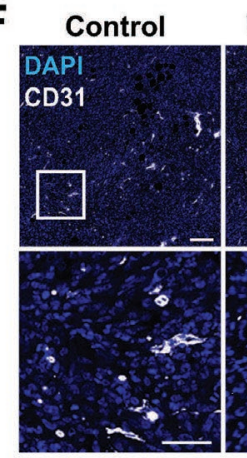

H Control

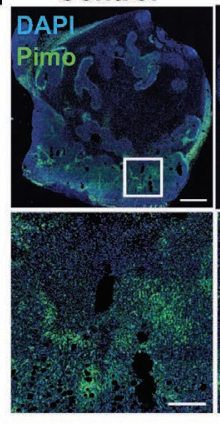

WT-AURKA

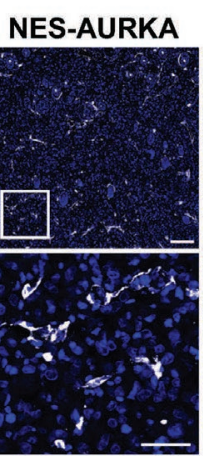

WT-AURKA
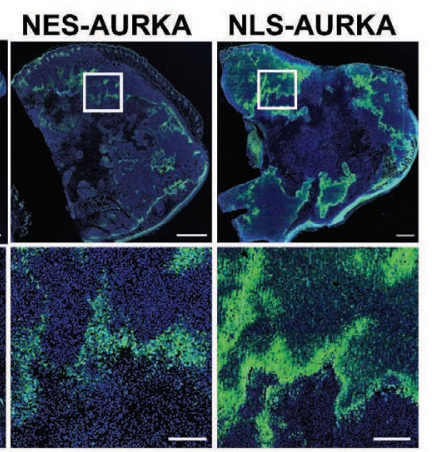

NLS-AURKA

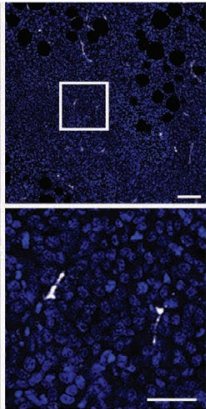

C Control

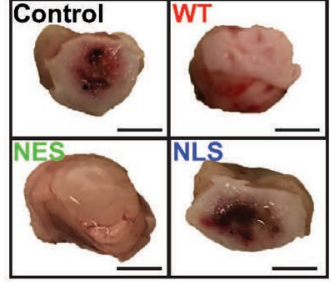

E

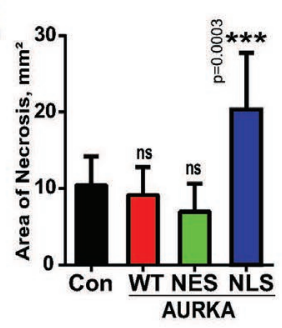

G
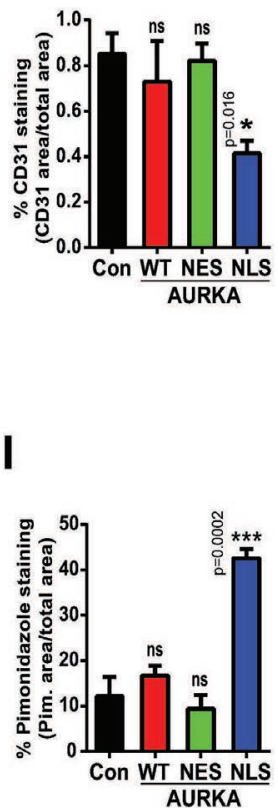

Figure 3. Whately 


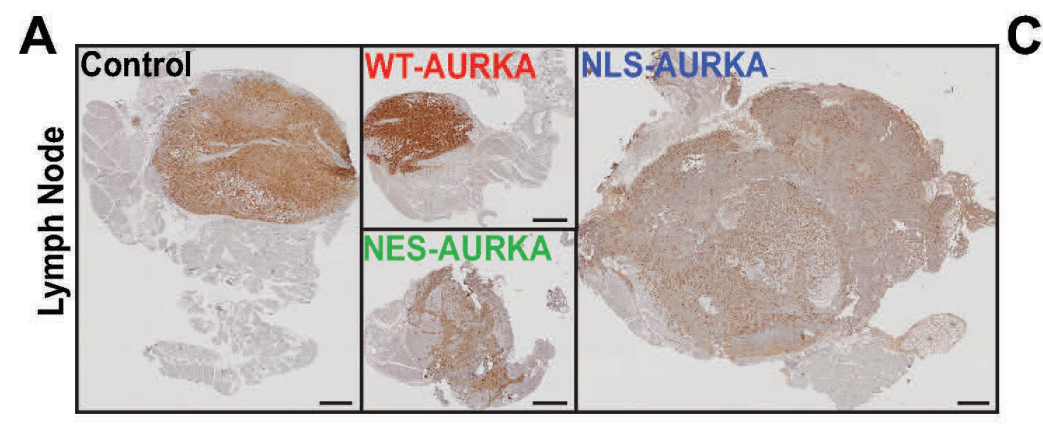

Metastasis Penetrance


Figure 4. Whately 


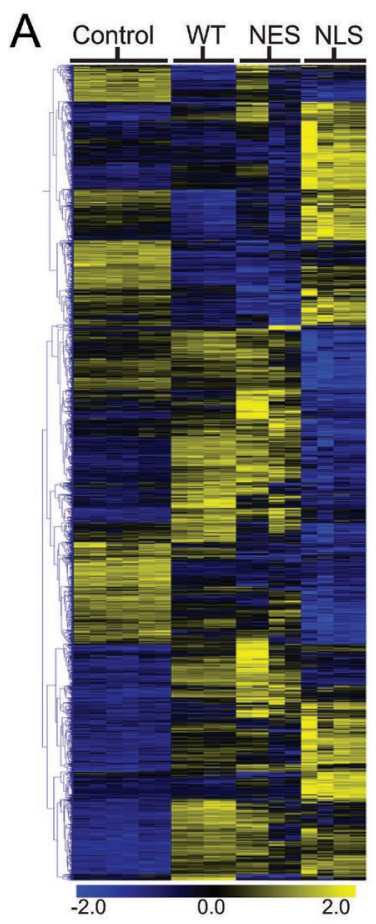

E

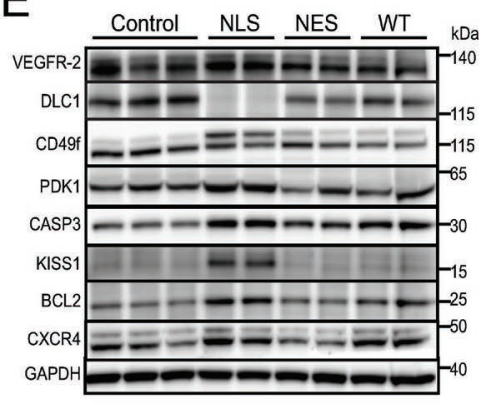

B

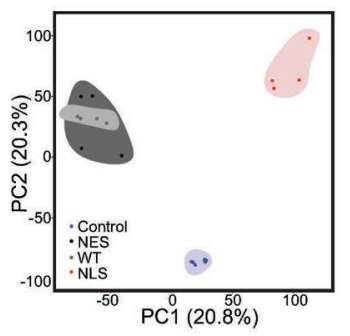

C

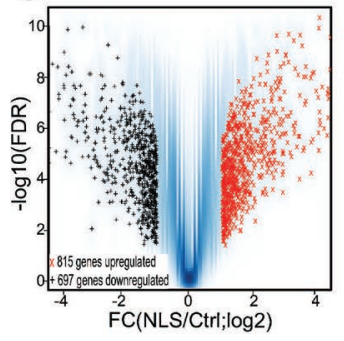

$\mathrm{F}$
D Upregulated genes
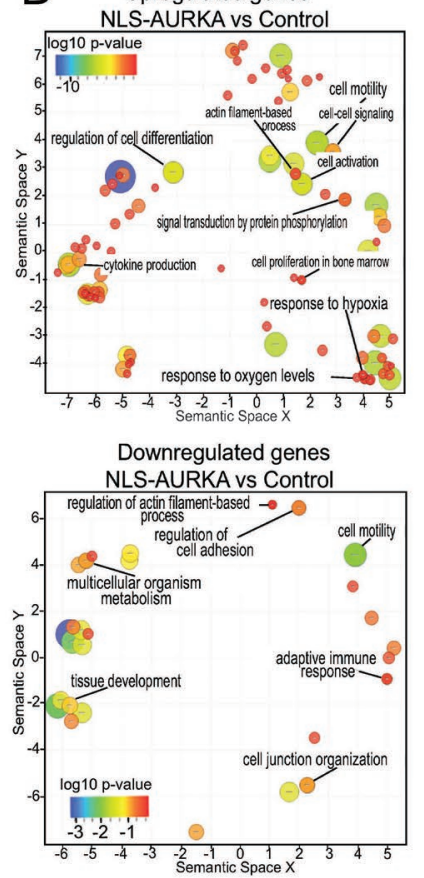
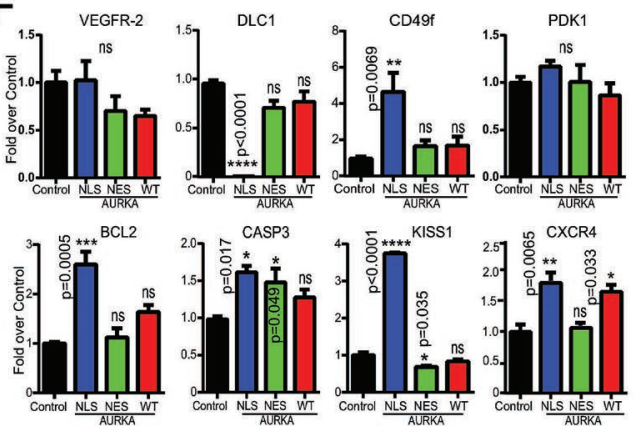

G GO EPTHELIALTO-
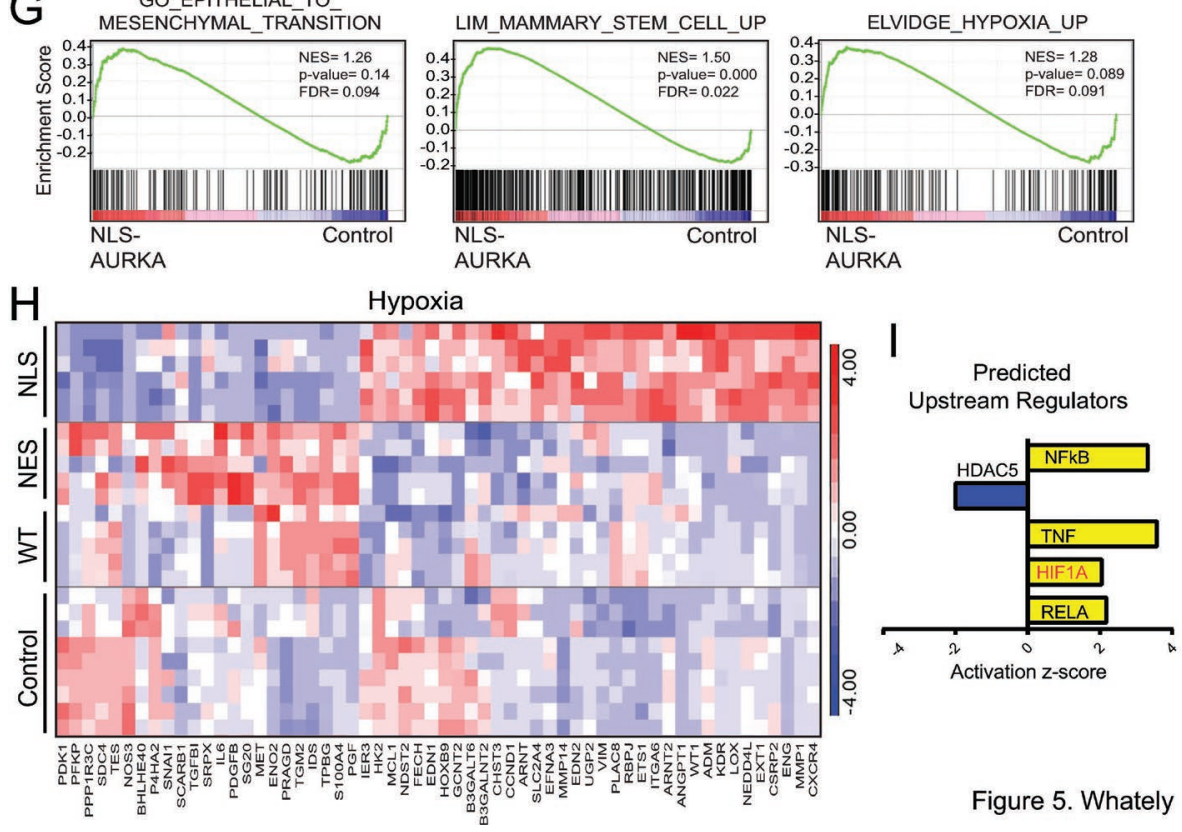

Figure 5. Whately 

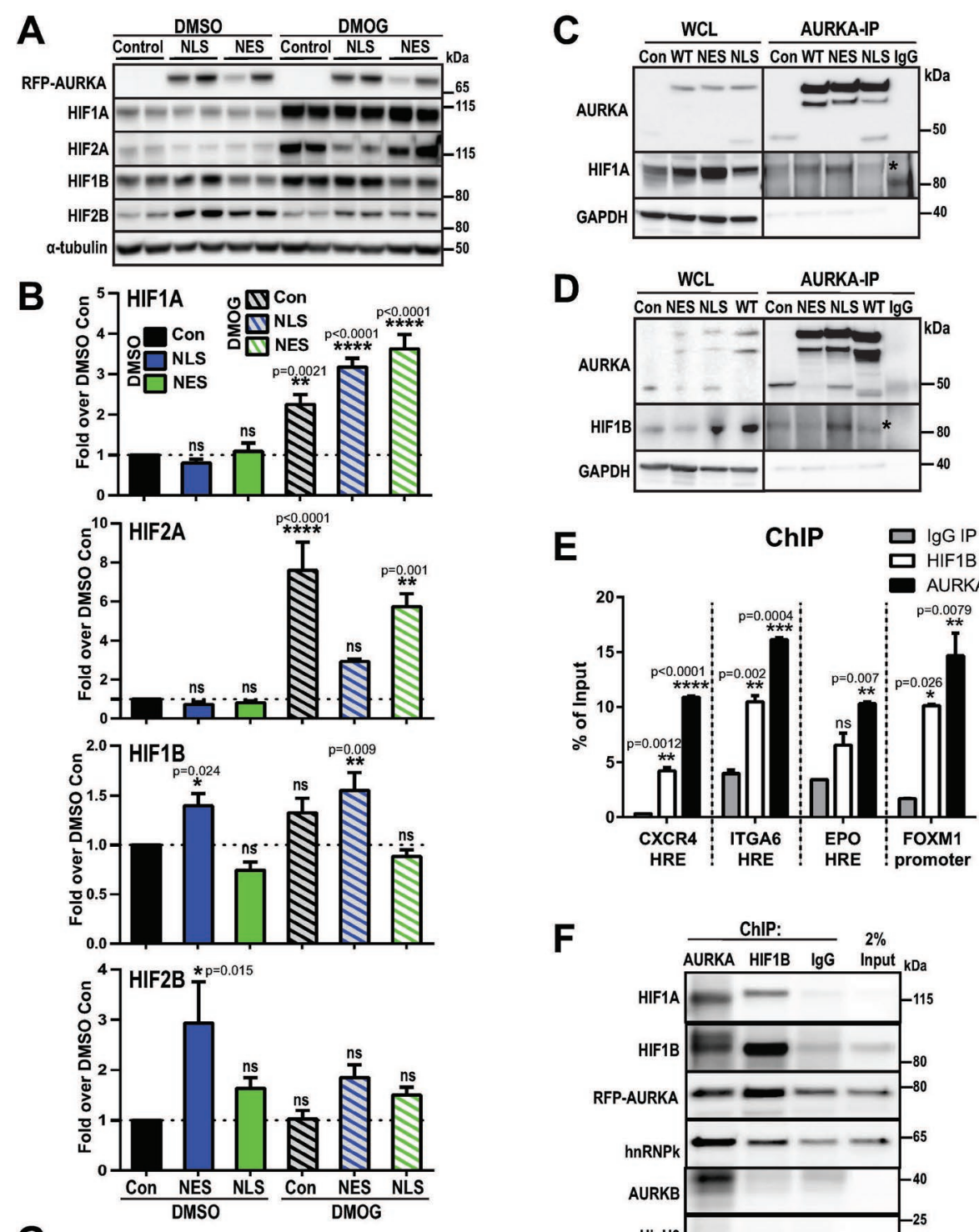

\section{G}
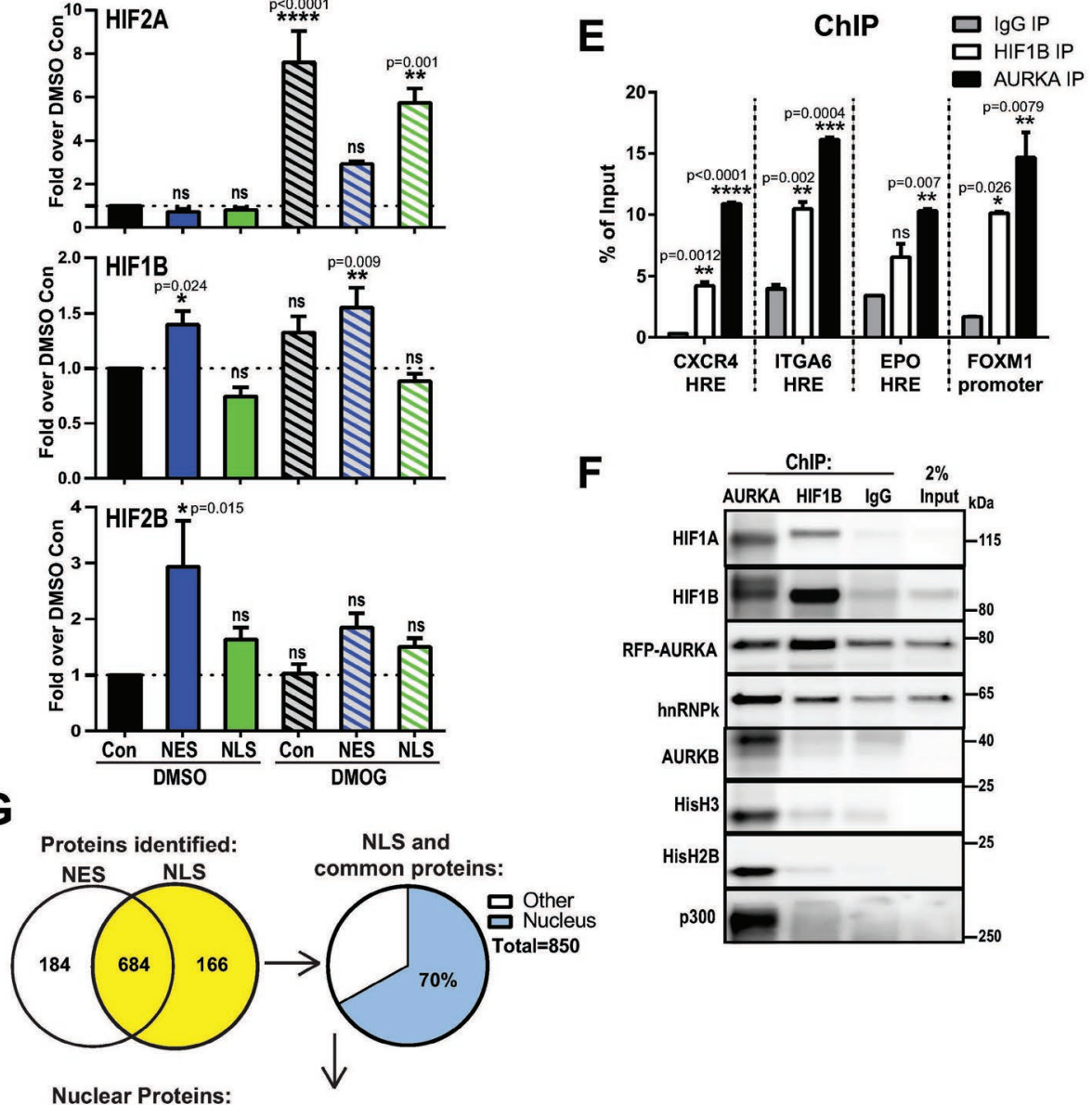

F
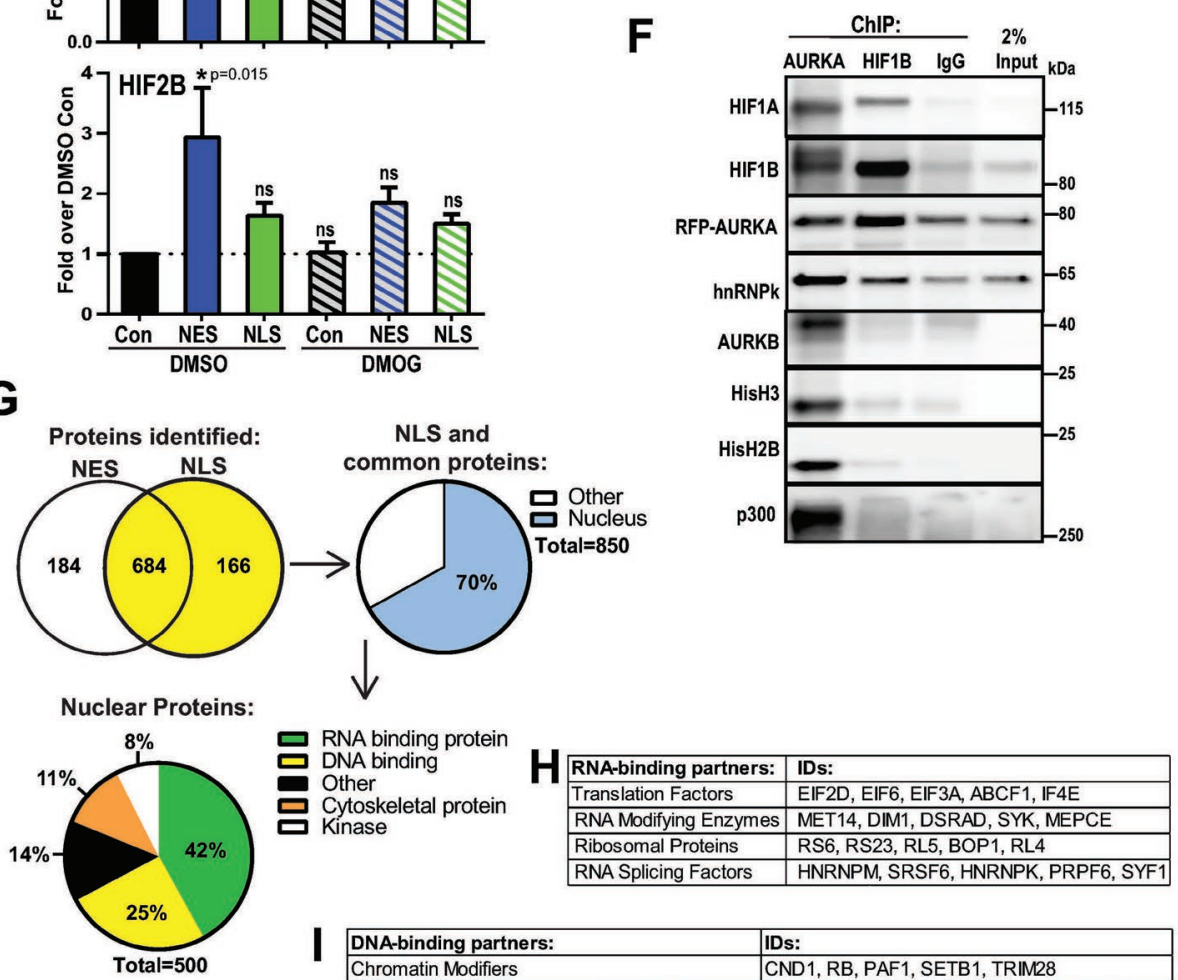

\begin{tabular}{|l|l|}
\hline DNA-binding partners: & IDs: \\
\hline Chromatin Modifiers & CND1, RB, PAF1, SETB1, TRIM28 \\
\hline Chromatin/Chromosome structure/maintenance & TOP2A, HP1B3, MCM5, RPA1, H31, H2A1 \\
\hline DNA directed RNA polymerase & RPB1, RPB2, RPABC1, RPC2, RPA1 \\
\hline Transcriptional Factors/Regulators & ATRX, CBP, EP300, TCEA1, MCAF1, CDK9 \\
\hline
\end{tabular}

Figure 6. Whately 


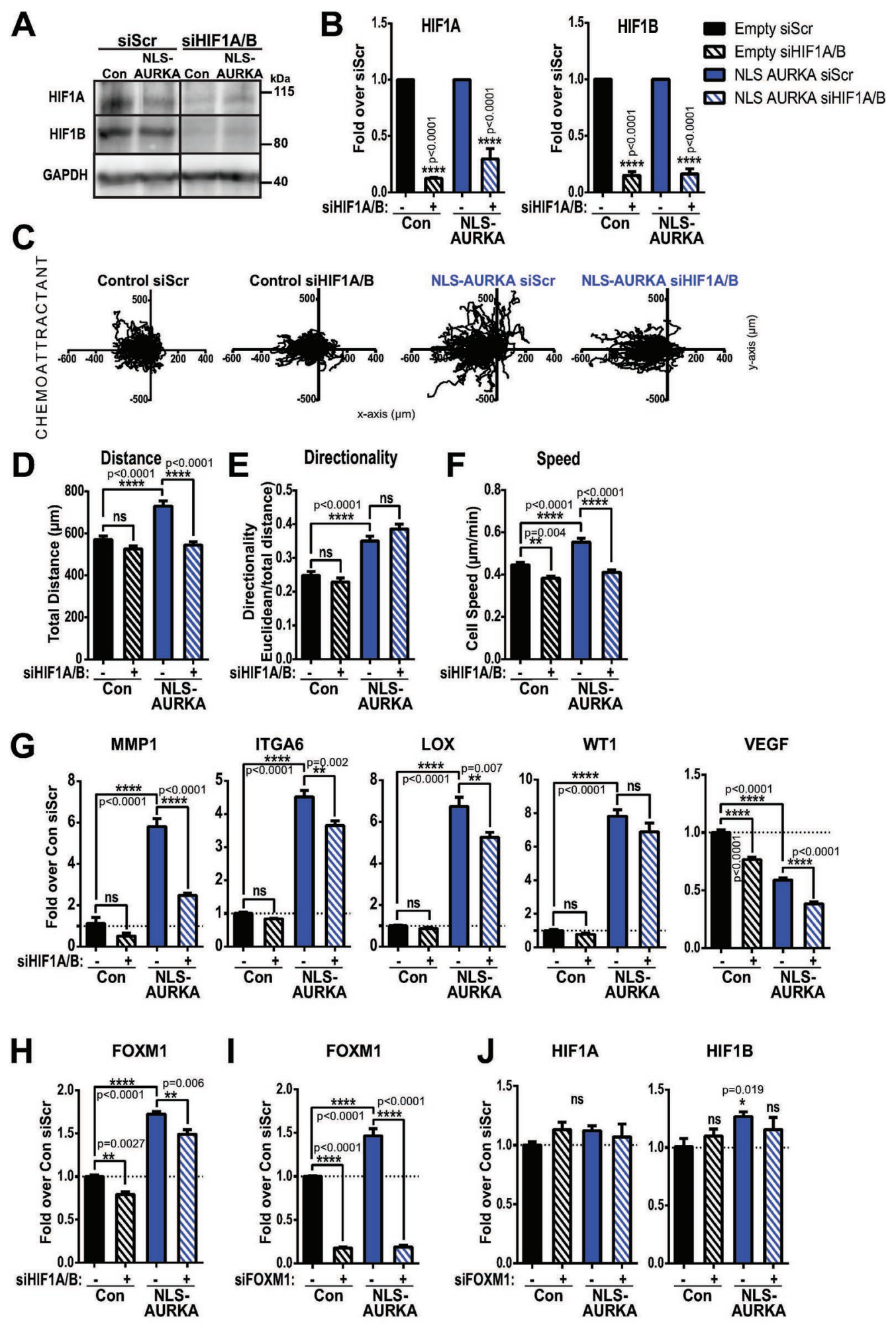

Figure 7. Whately 

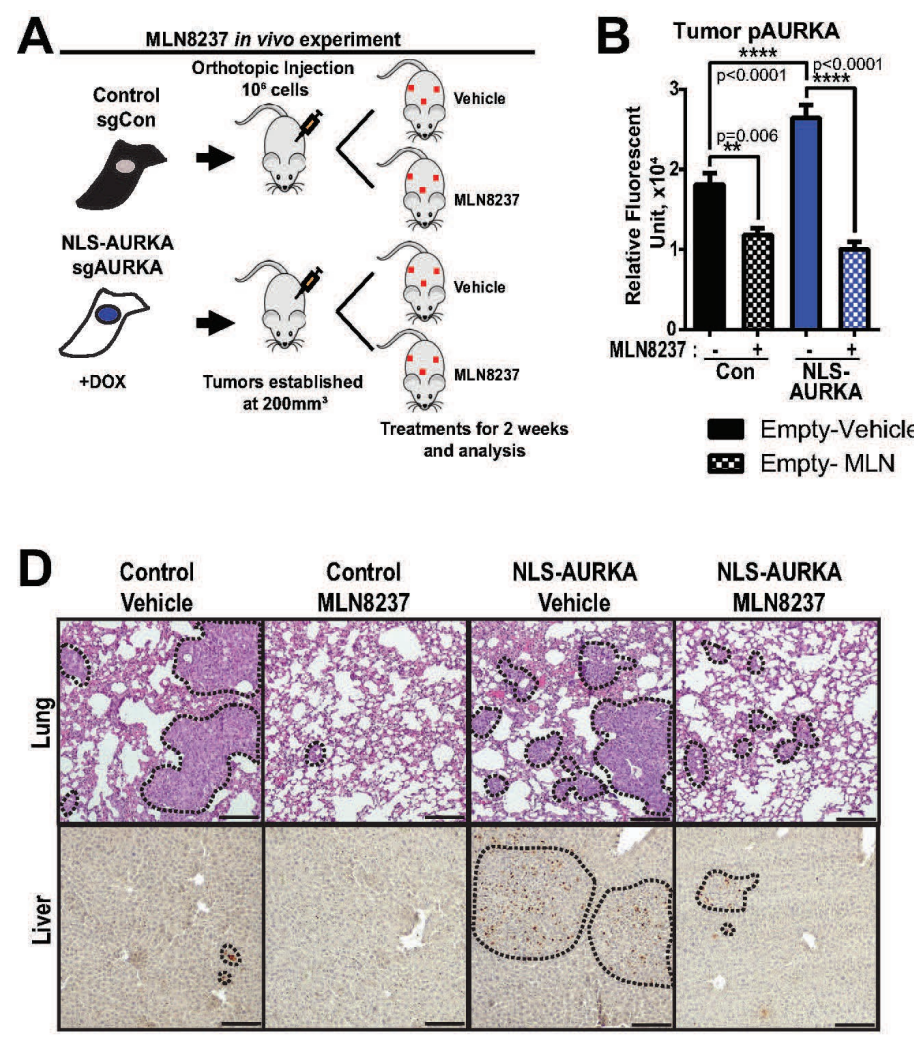

E
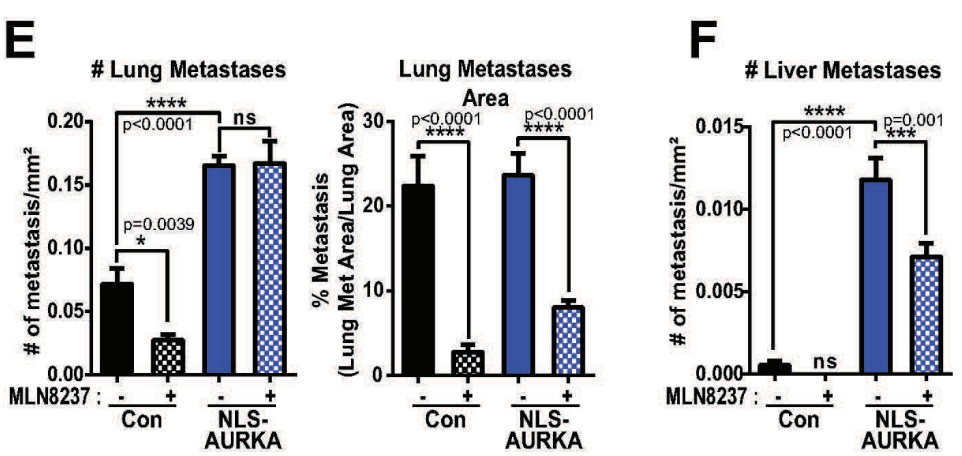

C Final Tumor Volume

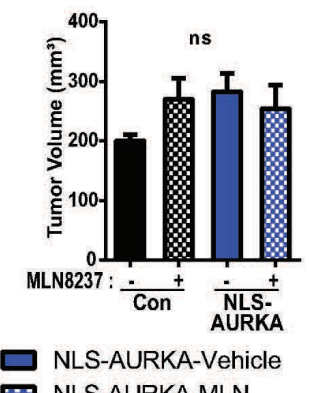

四 NLS-AURKA-MLN
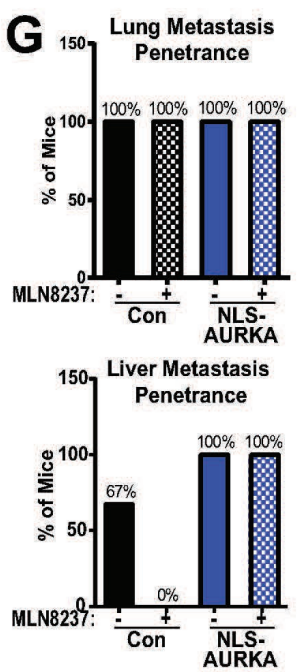

H

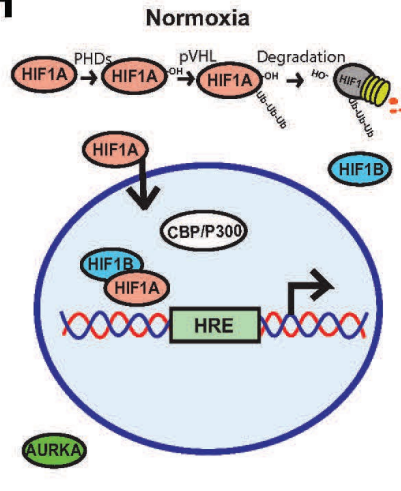

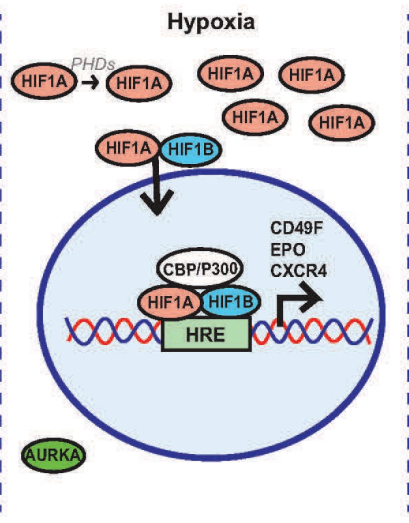

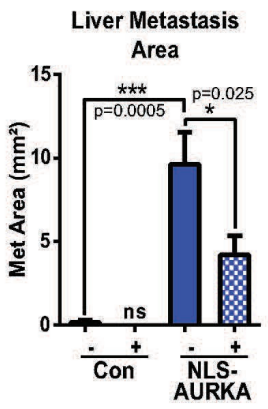




\section{Supplementary Materials and Methods}

Cell Culture, plasmids, and reagents. Cell medium, supplements were purchased from ATCC, FBS (fetal bovine serum, VWR), Doxycycline (Sigma). MLN8237 was purchased from Sellekchem and dissolved in 5\% DMSO, 30\% PEG-300, and 5\% Tween-80 in water. cDNA for human AURKA (Open Biosystems) was subcloned (Xhol/EcoRI) into pcDNA3.1-mRFP (Invitrogen) and pLUTz-mRPF (tet-inducible) vectors for cell culture experiments, generating pLUTz-mRFP-AURKA. To create pLUTz-mRFP-NLS-AURKA, pmRT2 plasmid was used as an intermediate to clone a NLS sequence (5'-CCTAAGAAGAAGCGTAAGGTC-3') to the N-term of AURKA by EcoRI and Pstl restriction sites. A NES sequence (5'-

TTACAATTACCTCCTTTAGAACGTTTAACTTTA-3') was added to the C-term of AURKA cDNA by PCR to produce pLUTZ-mRFP-NES-AURKA. The resultant plasmids pLUTZ-NLS/NES or no-Tag-mRFP-AURKA were expressed in MDA-MB-231 and BT549 cell lines. To allow for sgRNA targeting of endogenous, but not exogenous AURKA, site-directed mutagenesis was done on AURKA cDNA constructs to create 4 silent mutations (MUT1, MUT2) interfering with sgRNAs targeting AURKA (sgAURKA1, sgAURKA2) (Fig.1F outlines cell line production). Sequences for cloning primers, mutagenesis primers, and sgRNAs are in Supplementary Table S1. pLenti PGK-V5LUC/Neo (gift from Eric Campeau (1), RRID: Addgene_21471), lentiCRISPRv2 (gift from Feng Zhang (2), RRID: Addgene_52961), and pLUTZ-mRFP-AURKA were used to make lentiviral particles as previously described (3). Lastly, cells were transduced with LentiCRISPRv2-sgAURKA plasmids to knock-out endogenous AURKA. After each step cells were selected with either zeocin (Invivogen), puromycin (Mediatech Inc), or G418 (Cellgro). Clones were analyzed by DNA sequencing and western blot to confirm deletion of endogenous and expression of exogenous AURKA. siRNAs were introduced via nucleofection (Amaxa) according to manufacturer's recommendation and used in further assays 48 hours post nucleofection after confirmation of knockdown. siRNAs used are listed in Supplementary Table S1. For siRNA assays using siHIF1A and siHIF1B, they were combined for all assays, denoted as siHIF1A/B. 
Tumor Micro Array and Patient Data. Immunohistochemical (IHC) procedures were done according to the manufacturer's recommendations (US Biomax Inc.) in duplicates. Manual scoring of staining positivity, as well as location and cell types was completed by an independent pathologist from US Biomax, Inc. Each core was scanned by the Aperio Scanning System (Leica Biosystems). The total number of positive cells and the intensity of AURKA staining were computed by Aperio Image- Scope10.1 software based on the digital images taken from each core. The de-identified patient information for BR2082 is listed in Supplementary Table S3. Breast Cancer biopsies were collected through the WVU Cancer Institute (IRB protocol \# WVU011113) or Cooperative Human Tissue Network $(\mathrm{NCl})$ in accordance with WVU and $\mathrm{CHTN}$-approved IRB protocols. The de-identified patient information is listed in Supplementary Table S4.

Nuclear/Cytoplasmic Fractionation. $5 \times 10^{6}$ cells were lysed in PTY buffer (50 mM HEPES, $50 \mathrm{mM} \mathrm{NaCl}$, 5mM EDTA, $1 \%$ Triton X-100, 50mM NaF) with protease/phosphatase inhibitors (ThermoFisher) for $10 \mathrm{~min}$ at $4^{\circ} \mathrm{C}$ and centrifuged to pellet nuclei. The supernatant was collected as the cytoplasmic fraction. The remaining nuclei-containing pellet was washed, centrifuged, and re-suspended in PTY buffer. The nuclei were disrupted by sonication followed by centrifugation. The resultant supernatant was used as the nuclear fraction.

Fluorescent (F-IHC). The tissue sections were processed for fluorescent immunohistochemistry (F-IHC) as previously described (4). IHC images were obtained using Olympus VS120 Slide Scanner microscope with 20X U Plan S Apo/0.75 NA objective. The images inside each data set were collected with the same microscopy and image capture settings and the raw data were used for image quantification. Percent staining was quantified by using area of positive stain divided by total area, done in ImageJ software using thresholding. Integrated density was quantified using Image J software. Antibodies used are listed in Supplementary Table S2.

DAB-IHC. The tissue sections were processed for immunohistochemistry (IHC) as previously described (5). Briefly, following antigen retrieval and blocking steps, sections were incubated in primary antibody for $60 \mathrm{~min}$, followed by species appropriate 
biotinylated secondary antibodies (Biocare Medical), and then streptavidin peroxidase (ThermoFisher). Stain was developed with 3,3'-diaminobenzidine substrate (ThermoFisher) and sections were counterstained with hematoxylin (Biocare Medical). As a negative control, adjacent serial sections were incubated with species appropriate non-specific IgG (Jackson ImmunoResearch). IHC images were obtained using Olympus VS120 Slide Scanner microscope with 10X Plan S Apo/0.40 NA objective. Antibodies used are listed in Supplementary Table S2.

Anoikis assay. $2.5 \times 10^{5}$ cells were plated on Ultra-Low attachment plates (Corning) with growth medium for 48 hours. Ready-Probes Cell Viability Imaging Kit (Blue/Red, ThermoFisher) was used to detect anoikis. Labeled cells were imaged on a Leica-DMIL microscope with a Leica-HI/PLAN I 10x/0.22 objective. Quantification was based on Hoechst33342 (360/460nm, total) and Propidium iodide (535/617nm, dead) positivity using ImageJ. Two independent experiments with two biological and three technical replicates for each group with 100 cells/condition were counted in 8 random fields.

Flow cytometry analysis. Single-cell suspension of $1 \times 10^{6}$ cells in FACS staining buffer (PBS, $0.5 \%$ BSA, $0.1 \%$ sodium azide) was blocked with $1 \mu \mathrm{g}$ anti-human IgG (Sigma) for $15 \mathrm{~min}$ then stained with a combination of antibodies listed in Suppl.Table S2 for $1 \mathrm{hr}$. Cells were washed, fixed with $0.4 \%$ paraformaldehyde (EMS). A minimum of 50,000 events were recorded for each subline with 2 biological clones and 2 technical replicates. Cells were analyzed by LSR-Fortessa (BD Biosciences) and FCS-Express-6 (DeNovo) software. Cells were fist gated on FSC vs SSC and then on live cells (Live/Dead). After gating on single stained controls, negative control (MCF7), and nostain control was finished, each sample was collected. Samples were quantified for positive cells, negative cells, and median fluorescent intensity for CD44, CD24, and CD104.

Immunoprecipitation (IP) assay. $10^{6}$ cells were washed with Dulbecco PBS (Corning), lysed with M-PER lysis buffer (ThermoFisher) with protease inhibitor cocktail (ThermoFisher) and placed in $4^{\circ} \mathrm{C}$ for $10 \mathrm{~min}$. The lysate is centrifuged for $15 \mathrm{~min}$ at 
$15000 \mathrm{rpm}, 4^{\circ} \mathrm{C}$. The whole cell lysate $(\mathrm{WCL})$ supernatant is pre-cleared via incubation with Protein $\mathrm{A} / \mathrm{G}$ sepharose (GE Healthcare) rotating for 30 min at $4^{\circ} \mathrm{C}$. After preclearing, beads are separated by centrifugation, $600 \mathrm{rpm}$ for $5 \mathrm{~min}, 4^{\circ} \mathrm{C}$ and the supernatant $(300 \mu \mathrm{g}$ of protein) is used for IP of AURKA with $0.3 \mu \mathrm{g}$ of affinity purified rabbit polyclonal anti-AURKA antibody (AurA-N, Open Biosystems, custom made using 1-126aa N-terminal fragment of AURKA) (6), conjugated to 4B sepharose or rabbit nonspecific, affinity pure IgG/protein $A / G$ sepharose (negative control). Samples were incubated overnight rotating at $4^{\circ} \mathrm{C}$. Next, beads were washed three times with lysis buffer supplemented with protease inhibitors followed by addition of laemmli gel-loading dye, $10 \mathrm{~min}$ at $100 \mathrm{C}$ boiling and loading on $4-12 \%$ SDS-PAGE gel $(2 \mathrm{~h}, 120 \mathrm{v})$ and transfer onto PVDF membrane. IPs were done with 2 clones/subline and repeated 3 times. GAPDH was used as the loading control.

Mass Spectrometry. IP samples eluted from the beads were submitted to MS Bioworks (Ann Arbor, MI) for protein complex profiling which involved SDS-PAGE, in-gel digestion with trypsin, and LC-MS/MS. Protein identification data was received as an excel file and Scaffold (Proteome Software) file with contaminants and reverse hits removed. Proteins identified were normalized to IgG control, to determine significant partners. Protein bioinformatics was done using Gene Ontology Resource (http://geneontology.org/). Due to usage of WCL for IP some of the NLS-AURKA interacting proteins are cytoplasmic, and thus were excluded from further analysis.

Orthotopic xenograft model of breast cancer. Two days before cell injection, female mice were placed on Doxycycline (Bio-Serv) diet to enable AURKA expression in injected cells. The endpoint of study was when a tumor volume of $800 \mathrm{~mm}^{3}$ was reached. The study has been conducted with 5-10 mice/group and repeated at least twice. MLN8237 or vehicle administration began when primary tumors reached 150$200 \mathrm{~mm} 3.20 \mathrm{mg} / \mathrm{kg} /$ dose were administered via oral gavage once daily for 5 days/week for 2 weeks and endpoint was after treatment ended. 3 mice/group in MLN8237 experiment. The organs from 3-5 mice/condition were collected, fixed in formalin, and processed using hematoxylin/eosin staining or IHC. A WVU clinical pathologist, blinded 
to sample identity, analyzed the de-identified samples for metastatic burden. The number/size of metastases were normalized to organ area in multiple fields of view for each mouse.

RNA Sequencing and Bioinformatics. Total RNA was isolated from MDA-MB-231 cells expressing empty-RFP vector controls, WT-, NES- or NLS-AURKA (2 clones of each and 2 independent experiments) using an RNeasy Mini-kit (Qiagen). RNA quality analyzed using Agilent 2100 Bioanalyzer (Agilent Technologies, Inc.). RNA-Seq libraries were constructed from 500ng of total RNA using the KAPA mRNA Hyper Prep kitBiosciences with Illumina compatible adapters. The concentrations of the completed libraries were quantified with a qubit fluorometer using high sensitivity DNA reagent. Libraries were subsequently run on the bioanalyzer using a high sensitivity DNA chip to determine average fragment size. Completed libraries were then pooled in equimolar concentrations and sequenced on the HiSeq 2500 with PE50bp reads. RNA-Seq data analysis follows the procedures established in previous publications (7-9). Briefly, RNASeq short reads were aligned to the hg38 with subread (10). The summarization of read counts against RNA-Seq gene annotation was processed with the FeatureCounts function implemented in the Rsubread $R$ package (11). Differentially expressed genes were predicted by EdgeR (12) with FDR less than 0.01 and a FC more than 2. Gene ontology enrichment analysis was done with the online DAVID Bioinformatics Resource (13) and visualized with REVIGO (14). Hierarchical clustering was applied to generate heatmaps after z-normalization. The RNA-seq raw and processed files were deposited to GEO and can be accessed at GSE154494. Processed files of comparisons with fold change were analyzed through the use of IPA (15) (QIAGEN Inc., https://www.qiagenbioinformatics.com/products/ingenuitypathway-analysis)." For GSEA, comparison lists of Control/NLS and NES/NLS were used in analysis performed against gene sets (16-18) from the MSigDb database $(19,20)$. The analysis was done in the desktop GSEA software $(19,21)$ using 1000 phenotype permutations, and gene sets with a nominal $p$ value $<0.05$ and false discovery rate FDR $<0.25$ were considered significant. 
Quantitative RT-PCR. qRT-PCR was performed using PrimeTime Gene Expression Master-Mix (IDT \#1055770) or Taqman Gene Expression Master-Mix (Applied Biosciences \#4369016) and the Applied Biosystems-7500 Fast real-time PCR-system and software. 2 clones/subline and 2 replicates per qPCR. The relative expression of each gene was calculated using the comparative CT values and normalized to the housekeeping gene GAPDH or beta-actin.

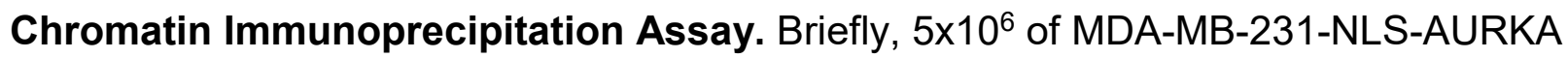
cells (two clones) were used for each IP. Cells were cross-linked with $1 \%$ formaldehyde, treated with micrococcal nuclease for chromatin digestion, and briefly sonicated (3x, 20 sec pulses). The $2 \mu \mathrm{g}$ of anti-AURKA (Bethyl), positive control anti-HIF1A antibodies (Cell Signaling \#5537S), or negative control (rabbit lgG) were used for immunoprecipitation overnight. After de-crosslinking and DNA purification, the ChIP DNA was used for quantitative-polymerase chain reaction (qPCR, IDT, PrimeTime assays) for HRE gene promoters. Primer sequences are listed in the Supplementary Table S6. At least 2 repeats of ChIP assay and qPCR analysis were conducted. 


\section{Supplementary References}

1. Campeau E, Ruhl VE, Rodier F, Smith CL, Rahmberg BL, Fuss JO, et al. A versatile viral system for expression and depletion of proteins in mammalian cells. PLoS One. 2009;4(8):e6529.

2. Sanjana NE, Shalem O, Zhang F. Improved vectors and genome-wide libraries for CRISPR screening. Nat Methods. 2014;11(8):783-4.

3. Pugacheva EN, Golemis EA. The focal adhesion scaffolding protein HEF1 regulates activation of the Aurora-A and Nek2 kinases at the centrosome. Nat Cell Biol. 2005;7(10):937-46.

4. Loskutov YV, Griffin CL, Marinak KM, Bobko A, Margaryan NV, Geldenhuys WJ, et al. LPA signaling is regulated through the primary cilium: a novel target in glioblastoma. Oncogene. 2018;37(11):1457-71.

5. Topczewska JM, Postovit LM, Margaryan NV, Sam A, Hess AR, Wheaton WW, et al. Embryonic and tumorigenic pathways converge via Nodal signaling: role in melanoma aggressiveness. Nat Med. 2006;12(8):925-32.

6. Ice RJ, McLaughlin SL, Livengood RH, Culp MV, Eddy ER, Ivanov AV, et al. NEDD9 depletion destabilizes Aurora A kinase and heightens the efficacy of Aurora A inhibitors: implications for treatment of metastatic solid tumors. Cancer Res. 2013;73(10):3168-80.

7. Monaghan KL, Zheng W, Hu G, Wan ECK. Monocytes and Monocyte-Derived Antigen-Presenting Cells Have Distinct Gene Signatures in Experimental Model of Multiple Sclerosis. Front Immunol. 2019;10:2779.

8. Ma Z, Xu J, Wu L, Wang J, Lin Q, Chowdhury FA, et al. Hes1 deficiency causes hematopoietic stem cell exhaustion. Stem Cells. 2020;38(6):756-68.

9. Wang Y, Hu G, Hill RC, Dzieciatkowska M, Hansen KC, Zhang XB, et al. Matrix reverses immortalization-mediated stem cell fate determination. Biomaterials. 2021;265:120387.

10. Liao Y, Smyth GK, Shi W. The Subread aligner: fast, accurate and scalable read mapping by seed-and-vote. Nucleic Acids Res. 2013;41(10):e108.

11. Liao Y, Smyth GK, Shi W. The R package Rsubread is easier, faster, cheaper and better for alignment and quantification of RNA sequencing reads. Nucleic Acids Res. 2019;47(8):e47.

12. McCarthy DJ, Chen Y, Smyth GK. Differential expression analysis of multifactor RNA-Seq experiments with respect to biological variation. Nucleic Acids Res. 2012;40(10):4288-97.

13. Jiao X, Sherman BT, Huang da W, Stephens R, Baseler MW, Lane HC, et al. DAVID-WS: a stateful web service to facilitate gene/protein list analysis. Bioinformatics. 2012;28(13):1805-6. 
14. Supek F, Bosnjak M, Skunca N, Smuc T. REVIGO summarizes and visualizes long lists of gene ontology terms. PLoS One. 2011;6(7):e21800.

15. Kramer A, Green J, Pollard J, Jr., Tugendreich S. Causal analysis approaches in Ingenuity Pathway Analysis. Bioinformatics. 2014;30(4):523-30.

16. Elvidge GP, Glenny L, Appelhoff RJ, Ratcliffe PJ, Ragoussis J, Gleadle JM.

Concordant regulation of gene expression by hypoxia and 2-oxoglutarate-dependent dioxygenase inhibition: the role of HIF-1alpha, HIF-2alpha, and other pathways. J Biol Chem. 2006;281(22):15215-26.

17. Ben-Porath I, Thomson MW, Carey VJ, Ge R, Bell GW, Regev A, et al. An embryonic stem cell-like gene expression signature in poorly differentiated aggressive human tumors. Nat Genet. 2008;40(5):499-507.

18. Lim E, Wu D, Pal B, Bouras T, Asselin-Labat ML, Vaillant F, et al. Transcriptome analyses of mouse and human mammary cell subpopulations reveal multiple conserved genes and pathways. Breast Cancer Res. 2010;12(2):R21.

19. Subramanian A, Tamayo P, Mootha VK, Mukherjee S, Ebert BL, Gillette MA, et al. Gene set enrichment analysis: a knowledge-based approach for interpreting genome-wide expression profiles. Proc Natl Acad Sci U S A. 2005;102(43):15545-50. 20. Liberzon A, Subramanian A, Pinchback R, Thorvaldsdottir H, Tamayo P, Mesirov JP. Molecular signatures database (MSigDB) 3.0. Bioinformatics. 2011;27(12):1739-40. 21. Mootha VK, Lindgren CM, Eriksson KF, Subramanian A, Sihag S, Lehar J, et al. PGC-1alpha-responsive genes involved in oxidative phosphorylation are coordinately downregulated in human diabetes. Nat Genet. 2003;34(3):267-73. 


\section{Supplementary Figures}
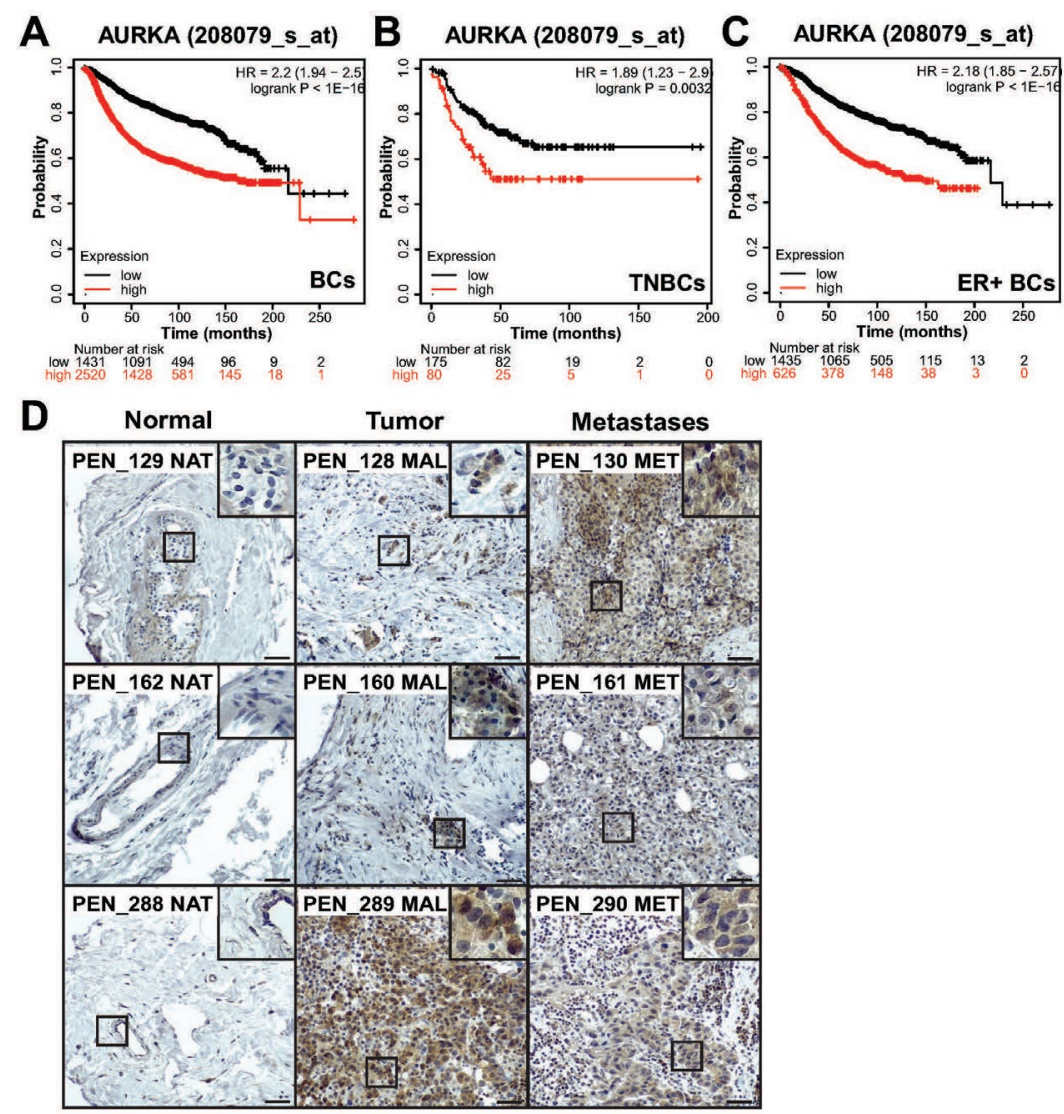

\begin{tabular}{|l|l|l|l|l|}
\hline & $\mathbf{N}=$ & $\mathbf{r}$ & $\mathbf{9 5 \%} \mathbf{C l}$ & $\mathbf{p}$-value \\
\hline $\begin{array}{c}\text { Lymph Node } \\
\text { Positive and/or } \\
\text { distant } \\
\begin{array}{c}\text { metastasis } \\
\text { positive/negative }\end{array}\end{array}$ & 9-negative & 0.8051 & $\begin{array}{c}0.5796 \text { to } \\
0.9161\end{array}$ & $<0.0001$ \\
\hline
\end{tabular}
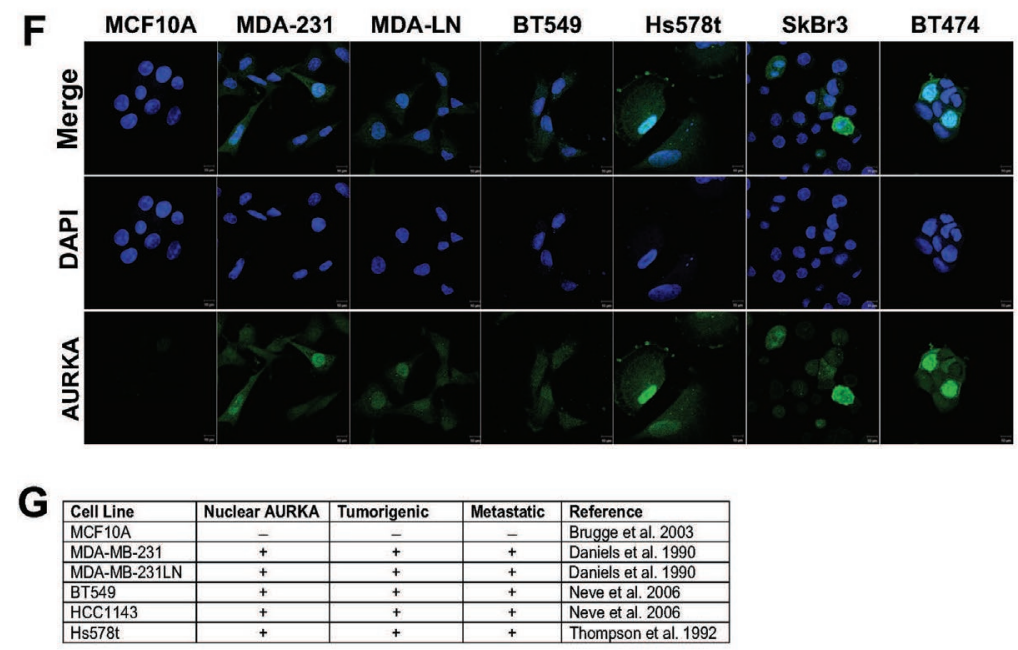

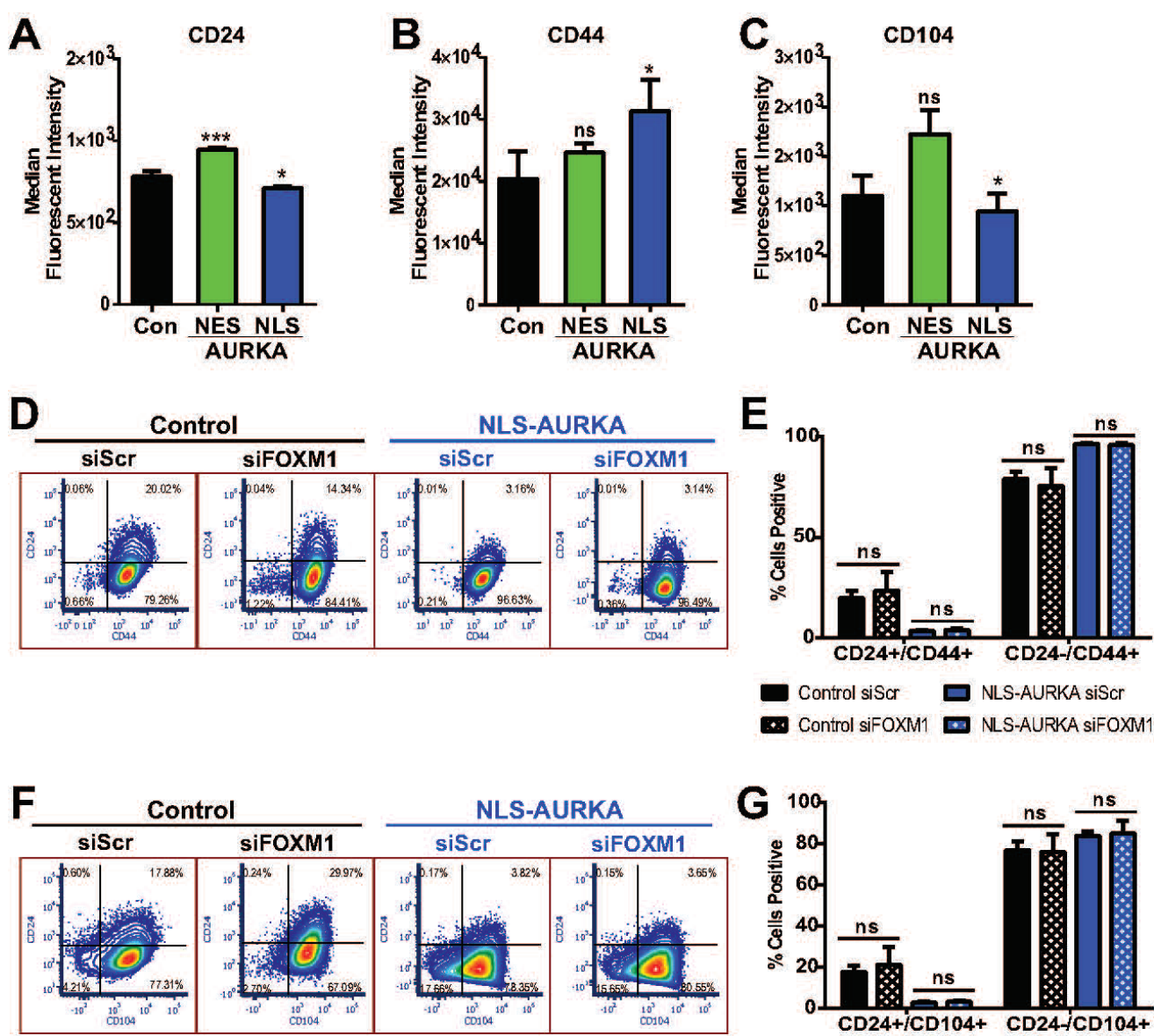

\section{H}
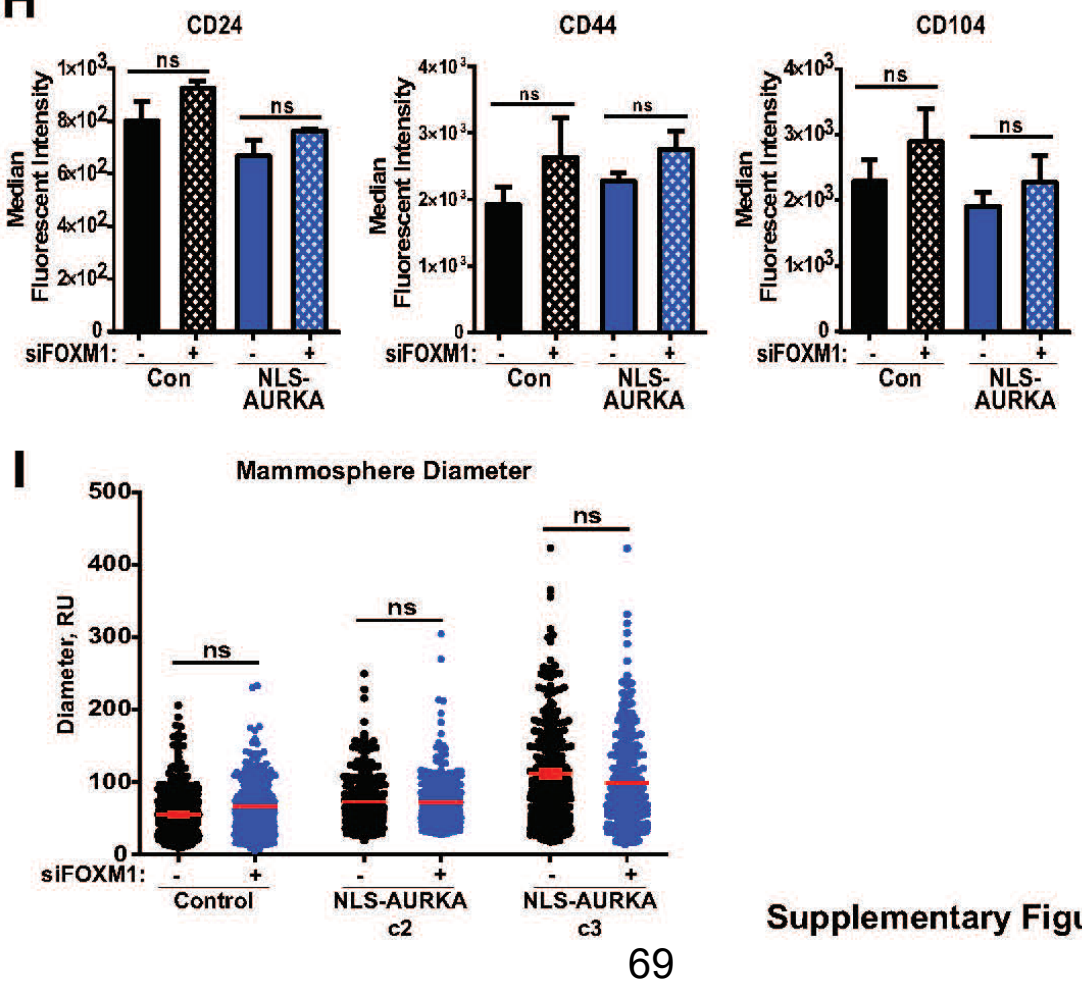

Supplementary Figure 2. Whately 69 
A

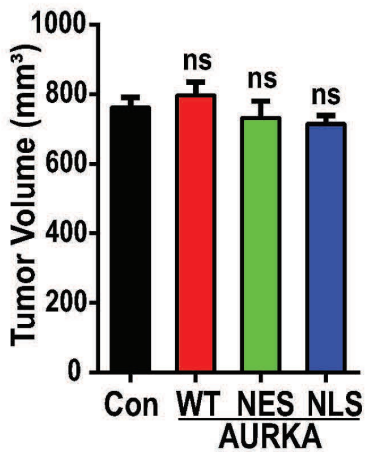

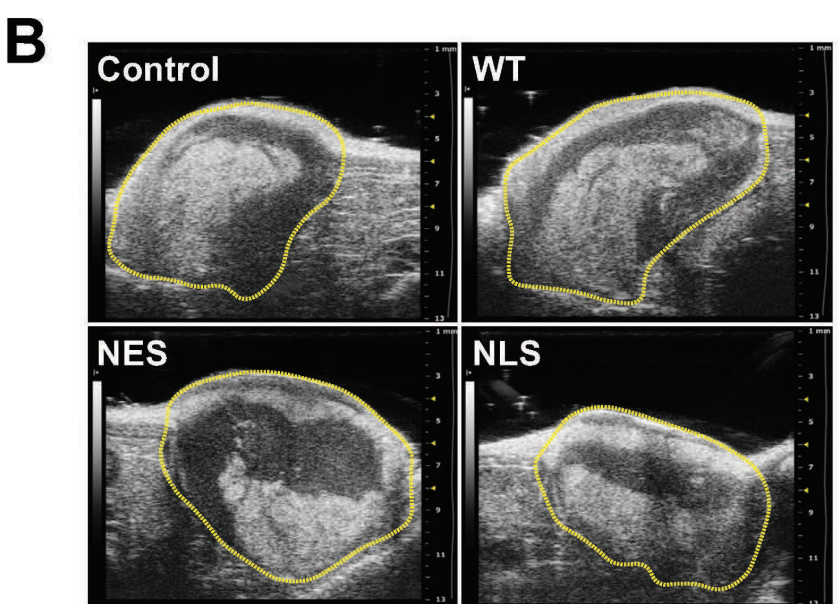

C

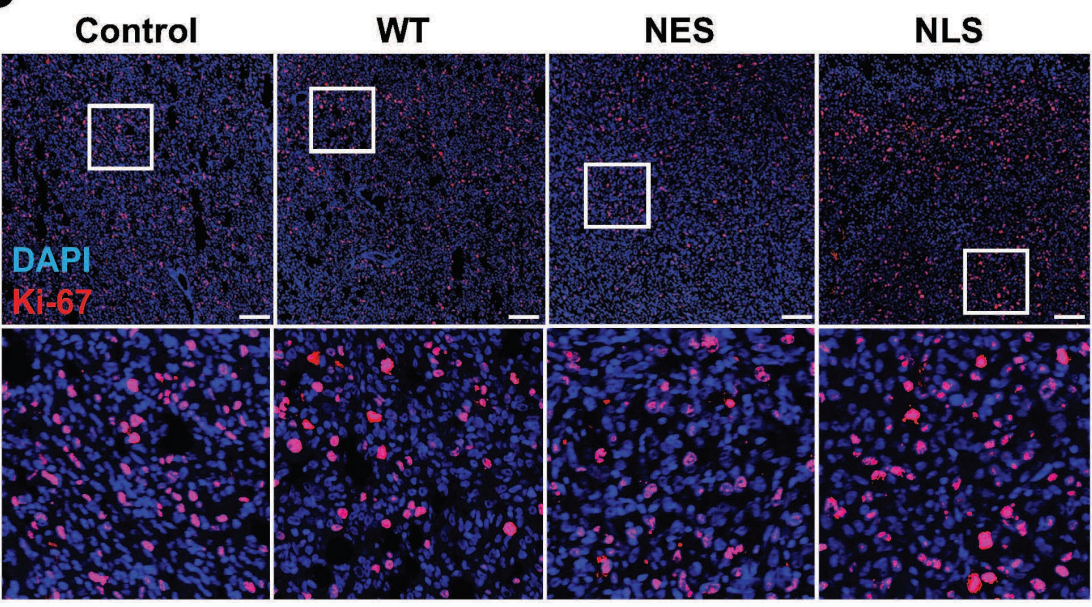

D

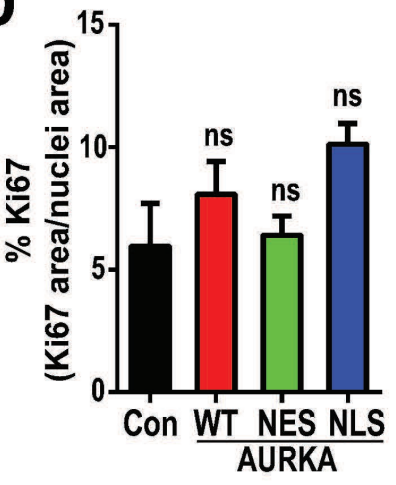

E

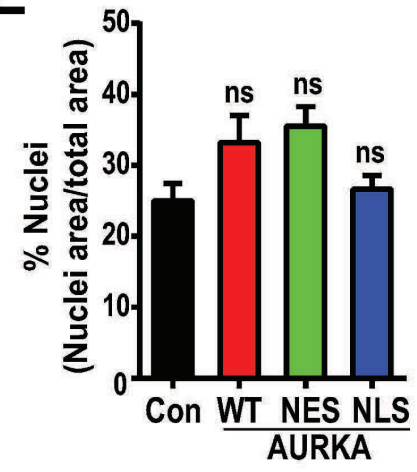



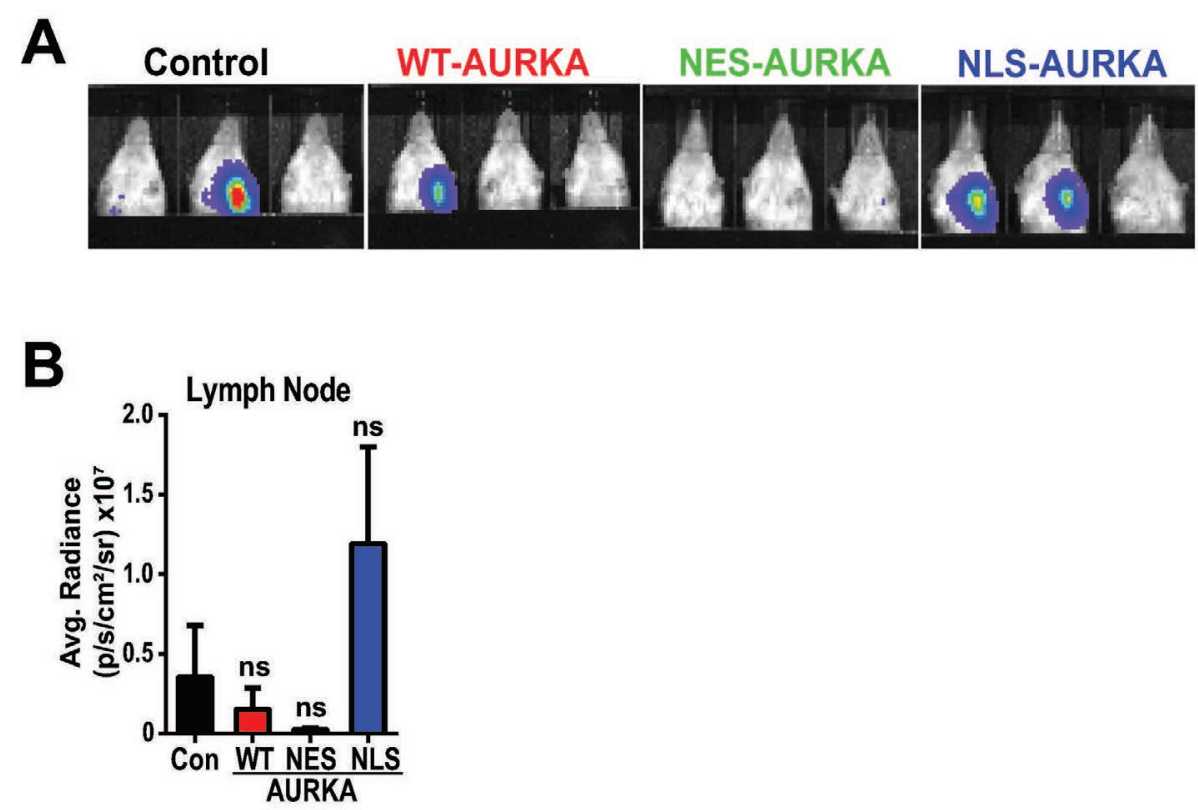

Supplementary Figure 4. Whately 

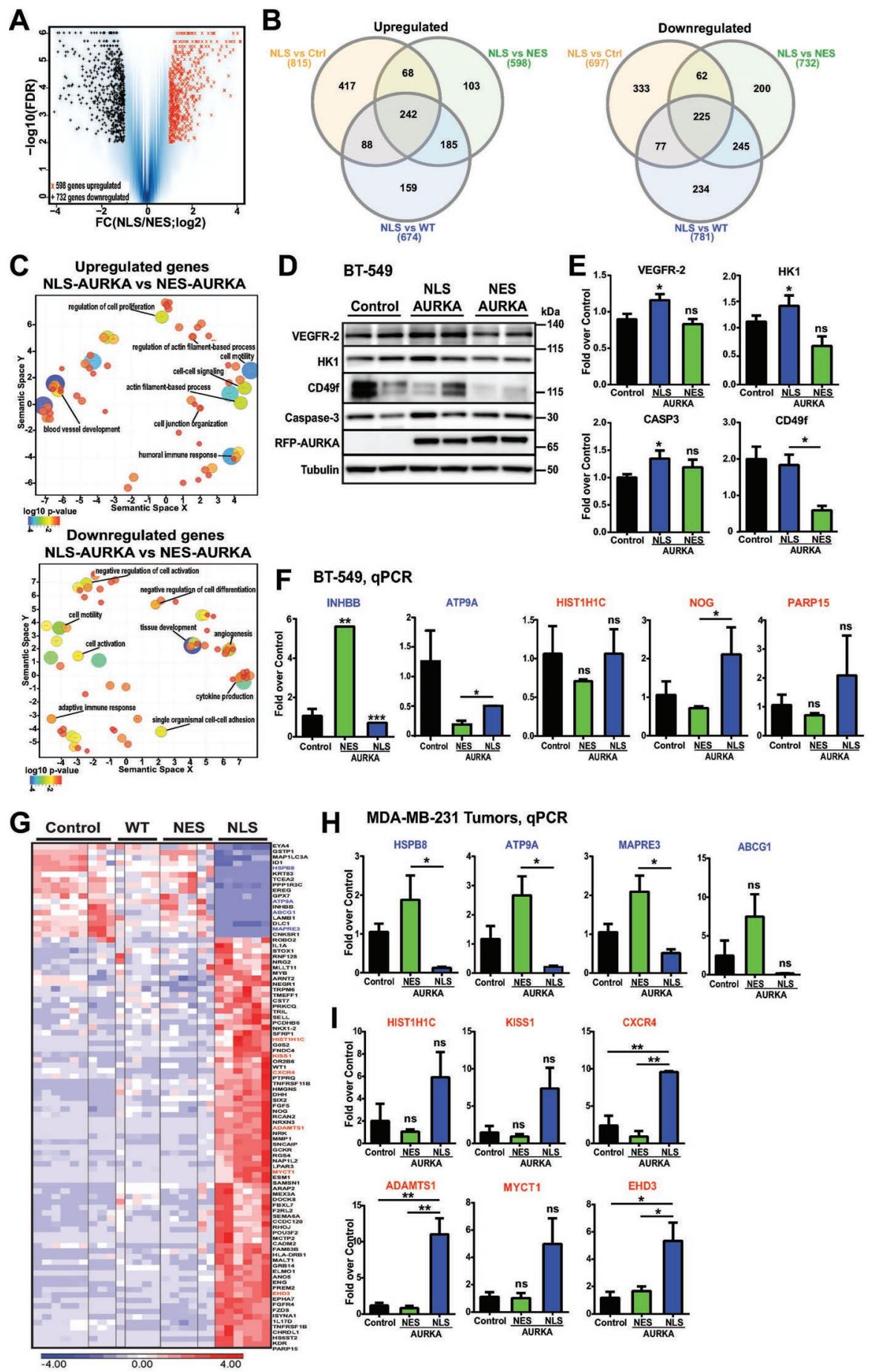

H MDA-MB-231 Tumors, qPCR
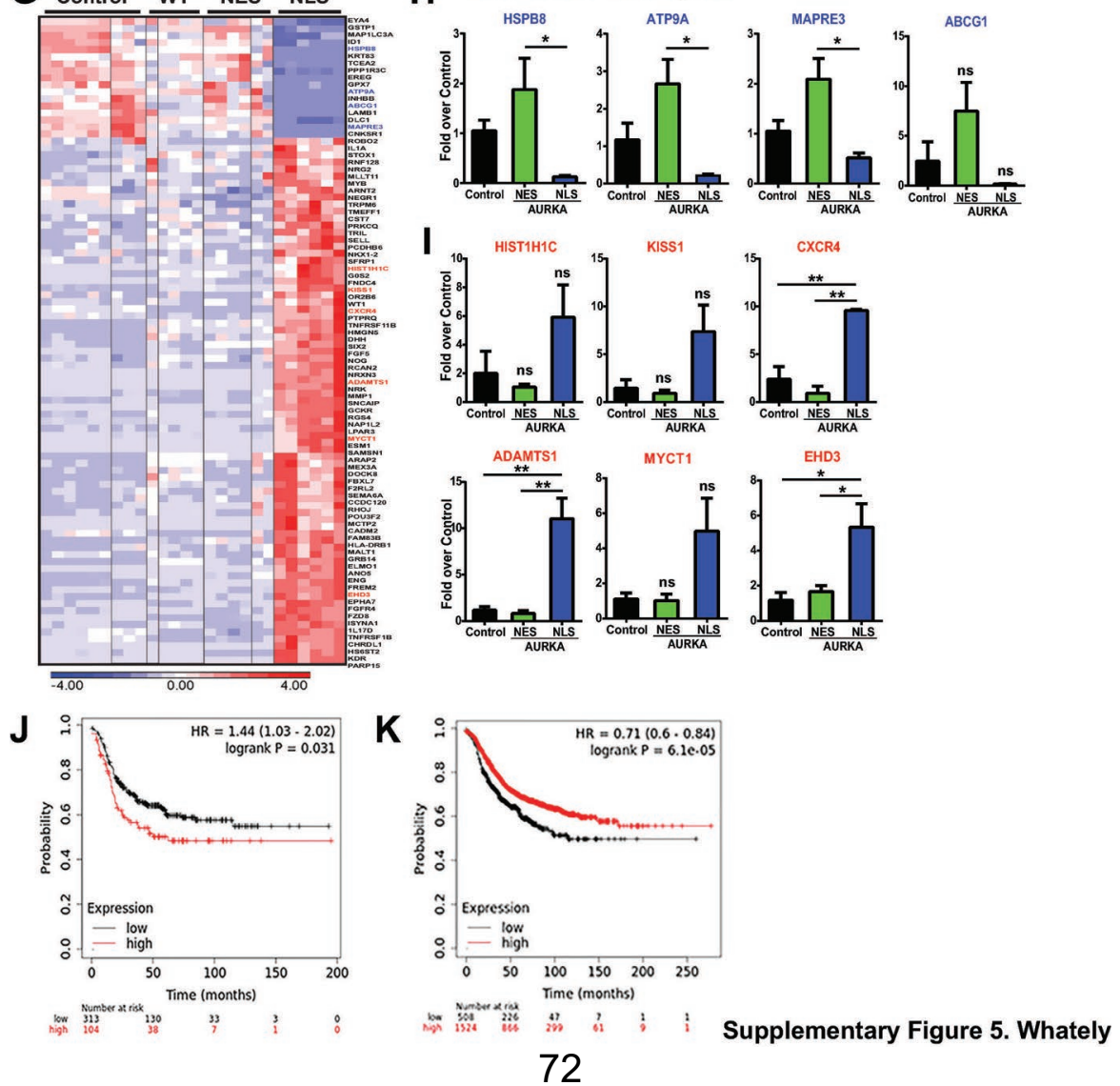

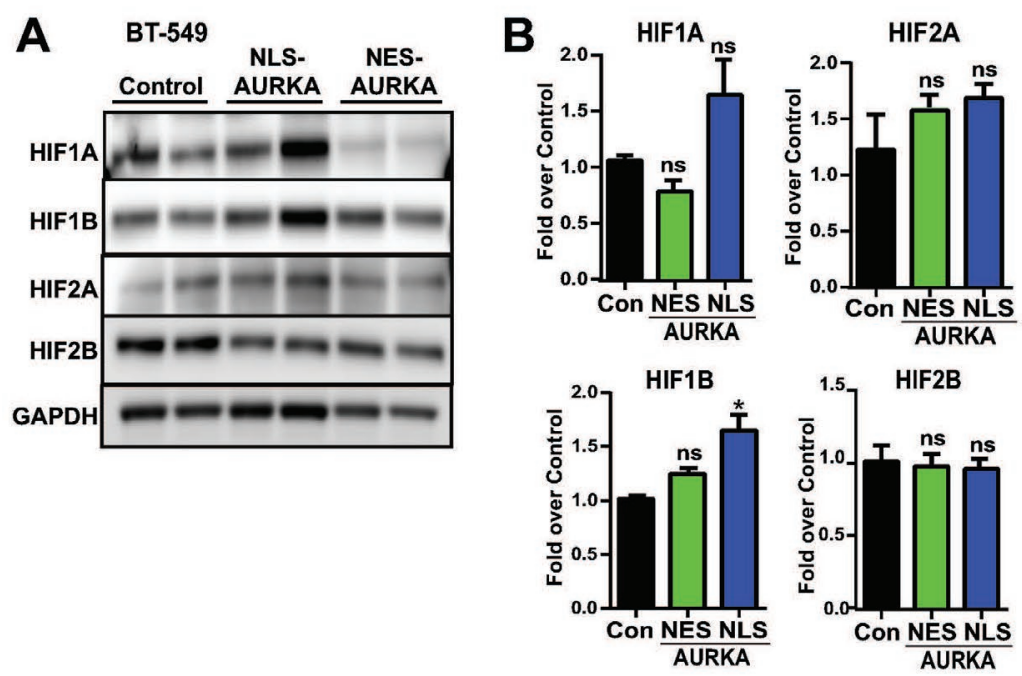

C MDA-MB-231-Tumors

D
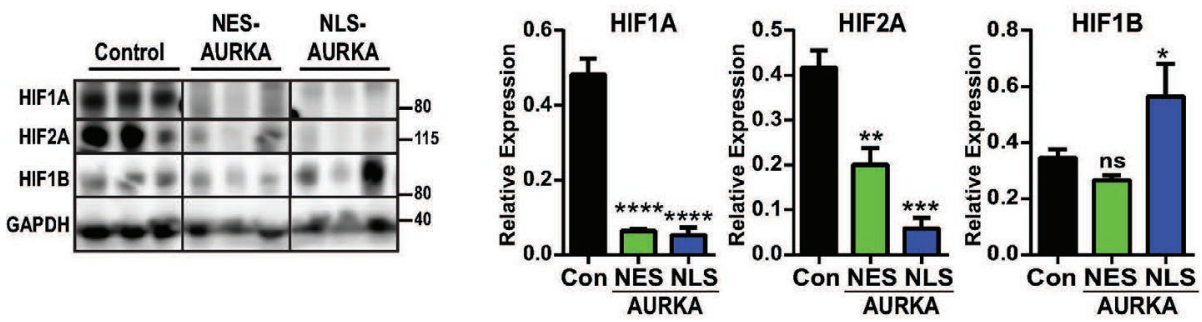

E

MDA-MB-231-Tumors

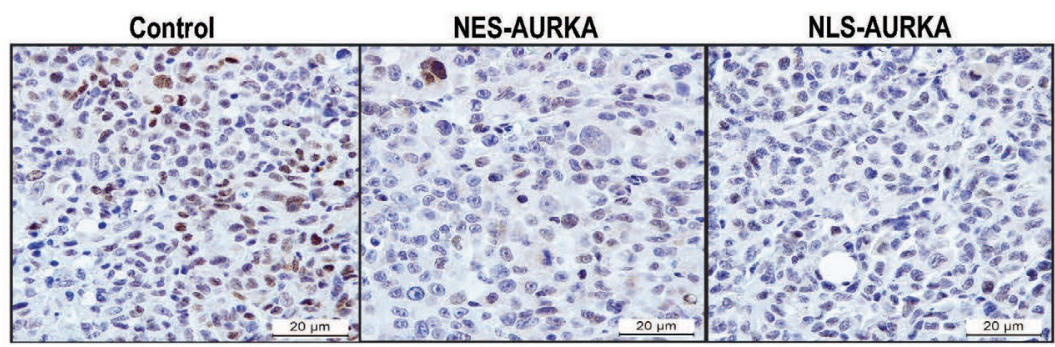




\section{Supplementary Figure Legends}

\section{Supplementary Figure 1. Nuclear AURKA is present in breast cancer metastatic cells.}

Kaplan-Meier patient survival plots were generated by the Kaplan-Meier Plotter (http://www.kmplot.com) to determine the effect of AURKA expression (microarray data Affy ID: 208079_s_at) on the progression free survival of A. 3,951 patients with breast cancer (BC), B. 255 patients with TNBC, C. 2,061 patients with ER+ BC. D. Representative IHC images of breast cancer patient biopsies (IRB protocol \# WVU011113) with AURKA antibody (brown, DAB), nucleus (blue) hematoxylin. Scale bar-20 $\mathrm{mm}$. The de-identified tumor biopsy information is shown in Suppl.Table S4. E. Breast cancer patient biopsies with metastases or no metastases at collection showing analysis of spearman's rank correlation between nuclear AURKA positivity and metastatic outcome. The de-identified tumor biopsy information is shown in Suppl.Table S4. F. Representative immunofluorescence images of BC cell lines and immortalized non-tumor control (MCF10A) as indicated. Blue-DAPI/nuclei, green-AURKA

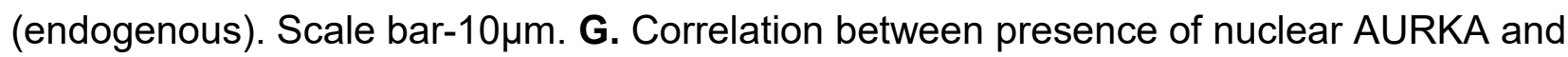
metastatic proficiency of indicated cell lines in mouse models based on published reports.

\section{Supplementary Figure 2. Depletion of FOXM1 does not change stem cell phenotype in} NLS-AURKA cells. Median fluorescent intensity of A. CD24, ${ }^{* * *} p=0.0001,{ }^{*} p=0.0161$ (Con vs NLS-AURKA), B. CD44, " $p=0.0492$, ns=non-significant, (Con vs NLS-AURKA), C. CD104 based on flow cytometry analysis. $n=2$ clones/subline, $n=2$ replicates, ${ }^{*} p=0.0166$ (NES-AURKA vs NLS-AURKA), one-way ANOVA, +/-S.E.M, Tukey's test. D. Representative dot plots of flow cytometry analysis of CD24 and CD44 in Control and NLS-AURKA cells with depletion of FOXM1 or scramble. E. Quantification of cells from (D) positive for CD24 and CD44 gated from live cells. $n=2$ clones/subline, $n=2$ replicates, $n s=n o n-s i g n i f i c a n t$, one-way ANOVA, +/-S.E.M, Tukey's test. F. Representative dot plots of flow cytometry analysis of CD24 and CD104 in Control and NLS-AURKA cells with depletion of FOXM1 or scramble. G. Quantification of cells from $(F)$ positive for $C D 24$ and CD104 gated from live cells. $n=2$ clones/subline, $n=2$ replicates, ns=non-significant, one-way ANOVA, +/-S.E.M, Tukey's test. H. Median fluorescent intensity of CD24, CD104, and CD44; ns=non-significant, based on flow cytometry analysis. n=2 clones/subline, $n=2$ replicates, one-way ANOVA, +/-S.E.M, Tukey's test. I. Mammosphere diameter analysis reported in relative units (RU) for Control and NLS-AURKA ( 2 clones) cells 
with depletion of FOXM1 or scramble. $n=2$ replicates, one-way ANOVA, +/-S.E.M, Tukey's test.

Supplementary Figure 3. Final tumor measurements. A. Final primary tumor volume $\left(\mathrm{mm}^{3}\right)$, ultrasound-based measurements, $n \geq 5$ mice in each group, 2 independent experiments, nsnon-significant, one-way ANOVA, +/-S.E.M, Dunnett's test. B. Representative ultrasound images of tumors at week 8 , tumors outlined in yellow. C. Representative Fluorescent-IHC images of staining with anti-Ki67 antibody, primary tumors, DAPI/nuclei (blue), Ki67 (red) scale

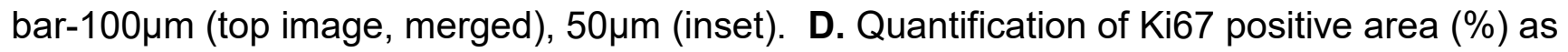
in (C) normalized to total nuclei area, $n \geq 5$ tumors/subline, 2 independent experiments, ns-nonsignificant, one-way ANOVA, +/-S.E.M, Dunnett's test. E. Quantification of Nuclei positive area (\%) as in (C) normalized to total tumor area, $n \geq 5$ tumors/subline, 2 independent experiments, ns=non-significant, one-way ANOVA, +/-S.E.M, Dunnett's test.

Supplementary Figure 4. Lymph node IVIS analysis. A. Representative bioluminescence images of mice with LN metastases at 8 weeks. B. Quantification of bioluminescence plotted as average radiance $\left(\mathrm{p} / \mathrm{s} / \mathrm{cm}^{2} / \mathrm{sr}\right), \mathrm{n} \geq 5$ mice/subline, ${ }^{*} \mathrm{p}<0.05$, ns=non-significant, one-way ANOVA, +/-S.E.M, Dunnett's test.

\section{Supplementary Figure 5. NLS-AURKA gene expression changes are reproduced in BT549 and MDA-MB-231 tumors. A. Volcano plot for NLS-AURKA vs NES-AURKA} comparison with the log2 fold changes in gene expression on the $\mathrm{x}$-axis and the FDR statistical significance (-log10 p-value) on the y-axis. Red: genes up-regulated in NLS; Black: genes down-regulated in NLS; Blue: all expressed genes. Annotated genes with at least a >1.5 fold change and FDR $<0.01$ are displayed. B. Venn Diagrams of DEGs as in Fig.5A in pair-wise comparisons of NLS-AURKA vs Control, NLS-AURKA vs NES-AURKA, and NLS-AURKA vs WT-AURKA. C. Visualization of Gene Ontology (GO) terms representing biological processes for NLS-AURKA vs NES-AURKA. Up- and down-regulated GOterms (FDR<0.5) are depicted as circles; the distance between those indicates the relationship between terms: closer distance means higher similarity. Color and size of circles indicates significance of differential expression of an individual GO term (red low and blue high, in log10 p-value). D. Western blot analysis of selected RNA-seq target proteins in BT-549-sublines (similarly produced as MDA- 
MB-231 sublines) with indicated antibodies, tubulin- loading control. E. Quantification of western blot as in (D) normalized to tubulin and referenced to Control (fold of change). VEGFR-2: " $p=0.029$, HK1: " $p=0.035$, CD49f: " $p=0.011$, CASP3: * $p=0.018$. F. qPCR array analysis of BT-549-AURKA sublines: empty vectors (Control), NLS-AURKA, NES-AURKA for selected genes from the RNA-seq DEGs (as in Fig.5A), which are down-regulated (blue) or upregulated (red) in NLS-AURKA cells. Fold change over Control, $n=2 /$ subline, INHBB: ${ }^{* *} p=0.002,{ }^{* * *} p=0.008$; one-way ANOVA, +/-S.E.M, Tukey's test. ATP9A: * $p=0.039$; NOG: ${ }^{*} p=0.039$, ns $=$ non-significant, unpaired t-test two-tail (NLS vs NES). G. Heat map of a subset of differentially (down-blue, up-red) expressed genes in MDA-MB-231-AURKA sublines which were used in the qPCR-based analysis of MDA-MB-231-AURKA sublines-derived tumors: $\mathbf{H}$. down-regulated and I. up-regulated genes in NLS-AURKA cells and tumors. The qPCR results normalized to house-keeping genes (actin and GAPDH) shown as fold change over Control, $n=3$ tumors in each group. DEGs: HSPB8: ${ }^{*} p=0.04$, ATP9A: * $p=0.021$, MAPRE3: ${ }^{*} p=0.019$, CXCR4: ${ }^{* *} p=0.0029$, ADAMTS1: ${ }^{* *} p=0.0043$, EHD3: ${ }^{*} p=0.029$, ns=non-significant, one-way ANOVA, +/-S.E.M. Tukey's test. J. Kaplan-Meier patient survival plots for BC (basal subtype) of up-regulated hypoxia genes (from Fig.5H). K. Kaplan-Meier patient survival plots for BC of down-regulated hypoxia genes (from Fig. $5 \mathrm{H}$ ).

\section{Supplementary Figure 6. HIF expression in BT549 and MDA-MB-231 tumors. A. Western} blot analysis of HIFs expression with antibodies as indicated in BT-549-AURKA sublines: empty vectors (Con), NES-AURKA (NES), NLS-AURKA (NLS), loading control- GAPDH. B. Quantification of WB as in (A), $n=2$ clones/sublines, ${ }^{*} p=0.035$, ns=non-significant, one-way ANOVA, +/-S.E.M, Tukey's test. C. WB analysis of HIFs expression in mammary tumors produced by MDA-MB-231 sublines as indicated using anti-HIF antibodies and GAPDH used as loading control. D. Quantification of WB as in (C), $n=3$ tumors for each group, ${ }^{* *} p=0.0078$, ${ }^{* * *} p=0.0006,{ }^{* * * *} p=0.0001, n s=$ non-significant, one-way ANOVA, +/-S.E.M, Dunnett's test. E. Representative images of IHC analysis of mammary tumors with HIF1A antibodies; $n=3$ tumors per each subline as indicated. HIF1A (DAB/brown), nuclei (blue), scale bar-20 $\mu$ m. 


\section{Supplementary Tables}

Supplementary Table S1. sgRNAs, primers, and siRNAs used in this study:

\begin{tabular}{|l|l|l|}
\hline Name & Forward & Reverse \\
\hline AURKA-NES Insert & $\begin{array}{l}\text { CTAGCAAACAGTCTTTACAATT } \\
\text { ACCTCCTTTAGACGTTAACT } \\
\text { TTATAGC }\end{array}$ & $\begin{array}{l}\text { TCGAGCTATAAAGTTAAACGT } \\
\text { TCTAAGGAGGTAATTGTAA } \\
\text { GACTGTTTG }\end{array}$ \\
\hline sgAURKA_1 & $\begin{array}{l}\text { caccgGCTTGTCTCCAGTCACAA } \\
\text { GC }\end{array}$ & $\begin{array}{l}\text { aaacGCTTGTGACTGGAGACA } \\
\text { AGCC }\end{array}$ \\
\hline sgAURKA_2 & $\begin{array}{l}\text { caccgTTACCAGGTGCCGATGG } \\
\text { CAG }\end{array}$ & $\begin{array}{l}\text { aaacCTGCCATCGGCACCTGG } \\
\text { TAAC }\end{array}$ \\
\hline AURKA MUT1.1 & $\begin{array}{l}\text { GCTTGTCTCCAGCCATAAGCC } \\
\text { GGTTCAG }\end{array}$ & $\begin{array}{l}\text { CTGAACCGGCTTATGGCTGG } \\
\text { AGACAAGC }\end{array}$ \\
\hline AURKA MUT1.2 & $\begin{array}{l}\text { GCACAAAAGCTCGTATCCAGC } \\
\text { CATAAGC }\end{array}$ & $\begin{array}{l}\text { GCTTATGGCTGGATACGAGC } \\
\text { TTTTGTGC }\end{array}$ \\
\hline AURKA MUT2.1 & $\begin{array}{l}\text { CAAGCAGCCCCTACCCTCGGC } \\
\text { ACCTG }\end{array}$ & $\begin{array}{l}\text { CAGGTGCCGAGGGTAGGGG } \\
\text { CTGCTTG }\end{array}$ \\
\hline AURKA MUT2.2 & $\begin{array}{l}\text { ACCCTCGGCACCGGAGAATAA } \\
\text { TCCTGAGG }\end{array}$ & $\begin{array}{l}\text { CCTCAGGATTATTCTCCGGT } \\
\text { GCCGAGGGT }\end{array}$ \\
\hline \begin{tabular}{|l|l|l|} 
siRNAs used in this study: \\
siRNA
\end{tabular} & Source & Catalog \# \\
\hline $\begin{array}{l}\text { SMARTpool: } \\
\text { TARGETplus HIF1A }\end{array}$ & ON- & Lharmacon \\
\hline $\begin{array}{l}\text { SMARTpool: } \\
\text { TARGETplus ARNT }\end{array}$ & ON-004018-00-0010 \\
\hline $\begin{array}{l}\text { SMARTpool: } \\
\text { TARGETplus FOXM1 }\end{array}$ & Dharmacon & L-007207-00-0010 \\
\hline Negative Control siRNA & Lioneer & SN-1005 \\
\hline
\end{tabular}


Supplementary Table S2. Antibodies used in this study:

\begin{tabular}{|c|c|c|c|c|c|}
\hline Target & Company and Cat\# & $\begin{array}{l}\text { Western } \\
\text { Blot }\end{array}$ & IHC & IF & $\begin{array}{l}\text { Flow } \\
\text { Cytometry }\end{array}$ \\
\hline Aurora Kinase A & $\begin{array}{l}\text { BD Biosciences } \\
\# 610939\end{array}$ & $1: 500$ & & $1: 100$ & \\
\hline Aurora Kinase A & Bethyl IHC-00062 & & $\begin{array}{l}\text { F-IHC } \\
1: 100, \\
\text { DAB } \\
1: 135\end{array}$ & & \\
\hline Aurora Kinase A & Cell Signaling \#91590 & $1: 1000$ & & & \\
\hline $\begin{array}{l}\text { Phospho-Aurora Kinase A } \\
\text { (T288) }\end{array}$ & Bethyl \#IHC-00067 & & $\begin{array}{l}\text { F-IHC } \\
1: 100\end{array}$ & & \\
\hline RFP & $\begin{array}{l}\text { Rockland \#600-401- } \\
379\end{array}$ & $1: 2000$ & $\begin{array}{l}\text { DAB } \\
1: 200\end{array}$ & $1: 500$ & \\
\hline HIF1A & Bethyl \#A700-001 & $1: 1000$ & $\begin{array}{l}\mathrm{DAB} \\
1: 50\end{array}$ & & \\
\hline HIF1B & Cell Signaling \#3537 & $1: 1000$ & & & \\
\hline HIF2A & Novus \#NB100-122 & $1: 1000$ & $\begin{array}{l}\text { DAB } \\
1: 1000\end{array}$ & & \\
\hline HIF2B & Proteintech \#12810-1 & $1: 500$ & & & \\
\hline GAPDH & Santa Cruz \#47724 & $1: 1000$ & & & \\
\hline Gamma-tubulin & Santa Cruz \#7396 & $1: 1000$ & & & \\
\hline Lamin $A / C$ & Bethyl \#A303-430 & $1: 1000$ & & & \\
\hline Alpha/beta-Tubulin & Cell Signaling \#2148 & $1: 1000$ & & & \\
\hline Tubulin-alpha & Sigma \#T9026 & $1: 1000$ & & & \\
\hline Human Mitochondria & Millipore \#MAB1273 & & $\begin{array}{l}\mathrm{DAB} \\
1: 150 \\
\end{array}$ & & \\
\hline CD31 & $\begin{array}{l}\text { Cell Signaling } \\
\# 3528 S\end{array}$ & & $\begin{array}{l}\text { F-IHC } \\
1: 100\end{array}$ & & \\
\hline $\begin{array}{l}\text { Pimonidazole-FITC (clone } \\
\text { 4.3.11.3) }\end{array}$ & $\begin{array}{l}\text { Hypoxyprobe } \\
\text { \#HP FITC MAb-1 }\end{array}$ & & $\begin{array}{l}\text { F-IHC } \\
1: 50\end{array}$ & & \\
\hline Ki67-555 & $\begin{array}{l}\text { BD Biosciences } \\
\# 558617\end{array}$ & & $\begin{array}{l}\text { F-IHC } \\
1: 100\end{array}$ & & \\
\hline VEGFR-2 & Santa Cruz \#6251 & $1: 1000$ & & & \\
\hline PDK1 & Cell Signaling \#3062 & $1: 2000$ & & & \\
\hline Caspase-3 & Santa Cruz \#56053 & $1: 1000$ & & & \\
\hline KISS1 & Proteintech \#18375-1 & $1: 500$ & & & \\
\hline DLC1 & $\begin{array}{l}\text { BD Biosciences } \\
\# 612-020\end{array}$ & $1: 500$ & & & \\
\hline BCL2 & Millipore \#A1784 & $1: 1000$ & & & \\
\hline
\end{tabular}




\begin{tabular}{|c|c|c|c|c|c|}
\hline CD49f & Bethyl \#A303-682A & $1: 1000$ & & & \\
\hline HK1 & Cell Signaling \#2024 & $1: 2000$ & & & \\
\hline HnRNPk & Santa Cruz \#28380 & $1: 1000$ & & & \\
\hline Aurora Kinase B & $\begin{array}{l}\text { Cell Signaling } \\
\# 3094 S\end{array}$ & $1: 1000$ & & & \\
\hline Histone $\mathrm{H} 2 \mathrm{~B}$ & Santa Cruz \#515808 & $1: 1000$ & & & \\
\hline Histone H3 & Cell Signaling \#14269 & $1: 1000$ & & & \\
\hline $\begin{array}{l}\text { Peroxidase AffiniPure } \\
\text { Donkey Anti-Rabbit IgG } \\
(\mathrm{H}+\mathrm{L})\end{array}$ & \begin{tabular}{|l} 
Jackson \\
ImmunoResearch \\
Labs \#711-035-152 \\
\end{tabular} & 1:10000 & & & \\
\hline $\begin{array}{l}\text { Peroxidase AffiniPure } \\
\text { Donkey Anti-Mouse lgG } \\
(\mathrm{H}+\mathrm{L})\end{array}$ & $\begin{array}{l}\text { Jackson } \\
\text { ImmunoResearch } \\
\text { Labs \#715-035-150 }\end{array}$ & $1: 10000$ & & & \\
\hline Live/Dead Near-IR & $\begin{array}{l}\text { Thermo Scientific } \\
\text { \#L10119 }\end{array}$ & & & & $\begin{array}{l}1 \mu \mathrm{l} / 1 \times 10^{6} \\
\text { cells }\end{array}$ \\
\hline EpCam-VioBue & $\begin{array}{l}\text { Miltenyi \#130-097- } \\
324\end{array}$ & & & & $1: 50$ \\
\hline CD44-FITC & $\begin{array}{l}\text { Miltenyi \#130-115- } \\
867\end{array}$ & & & & $1: 50$ \\
\hline CD24-APC & $\begin{array}{l}\text { Miltenyi \#130-112- } \\
657\end{array}$ & & & & $1: 66$ \\
\hline CD104-PE-Vio770 & \begin{tabular}{|l} 
Miltenyi \#130-101- \\
441
\end{tabular} & & & & 1:50 \\
\hline Anti-Rabbit-488 & $\begin{array}{l}\text { Jackson } \\
\text { ImmunoResearch } \\
\text { Labs \#711-545-152 }\end{array}$ & & $\begin{array}{l}\text { F-IHC } \\
1: 200\end{array}$ & $1: 1000$ & \\
\hline Anti-Mouse-488 & $\begin{array}{l}\text { Jackson } \\
\text { ImmunoResearch } \\
\text { Labs \# 715-545-150 }\end{array}$ & & $\begin{array}{l}\text { F-IHC } \\
1: 200\end{array}$ & $1: 1000$ & \\
\hline Anti-Rabbit-555 & Invitrogen \#A31572 & & $\begin{array}{l}\text { F-IHC } \\
1: 200\end{array}$ & 1:1000 & \\
\hline Anti-Mouse-555 & Invitrogen \#A31570 & & $\begin{array}{l}\text { F-IHC } \\
1: 200\end{array}$ & $1: 1000$ & \\
\hline Anti-Mouse-647 & $\begin{array}{l}\text { Jackson } \\
\text { ImmunoResearch } \\
\text { Labs \#715-605-150 }\end{array}$ & & $\begin{array}{l}\text { F-IHC } \\
1: 200\end{array}$ & $1: 1000$ & \\
\hline Anti-Human IgG & Sigma \#14506 & & & & 1ug \\
\hline
\end{tabular}


Supplementary Table S3. Tumor Micro Array.

\begin{tabular}{|c|c|c|c|c|c|c|}
\hline Position & Age & Sex & Organ & Pathology diagnosis & Grade & Type \\
\hline A1 & 40 & $\mathrm{~F}$ & $\begin{array}{l}\text { Lymph } \\
\text { node }\end{array}$ & $\begin{array}{l}\text { Metastatic invasive ductal } \\
\text { carcinoma }\end{array}$ & 2 & metastasis \\
\hline A2 & 55 & $\mathrm{~F}$ & $\begin{array}{l}\text { Lymph } \\
\text { node }\end{array}$ & $\begin{array}{l}\text { Metastatic invasive ductal } \\
\text { carcinoma }\end{array}$ & 1 & metastasis \\
\hline A3 & 56 & $\mathrm{~F}$ & $\begin{array}{l}\text { Lymph } \\
\text { node }\end{array}$ & $\begin{array}{l}\text { Metastatic invasive ductal } \\
\text { carcinoma }\end{array}$ & 2 & metastasis \\
\hline A5 & 57 & $\mathrm{~F}$ & $\begin{array}{l}\text { Lymph } \\
\text { node }\end{array}$ & $\begin{array}{l}\text { Metastatic invasive ductal } \\
\text { carcinoma }\end{array}$ & 2 & metastasis \\
\hline A6 & 56 & $\mathrm{~F}$ & $\begin{array}{l}\text { Lymph } \\
\text { node }\end{array}$ & $\begin{array}{l}\text { Metastatic invasive ductal } \\
\text { carcinoma }\end{array}$ & 2 & metastasis \\
\hline A7 & 42 & $\mathrm{~F}$ & $\begin{array}{l}\text { Lymph } \\
\text { node }\end{array}$ & $\begin{array}{l}\text { Metastatic invasive ductal } \\
\text { carcinoma }\end{array}$ & 2 & metastasis \\
\hline A8 & 49 & $\mathrm{~F}$ & $\begin{array}{l}\text { Lymph } \\
\text { node }\end{array}$ & $\begin{array}{l}\text { Metastatic invasive ductal } \\
\text { carcinoma }\end{array}$ & 2 & metastasis \\
\hline A9 & 66 & $\mathrm{~F}$ & $\begin{array}{l}\text { Lymph } \\
\text { node }\end{array}$ & $\begin{array}{l}\text { Metastatic invasive ductal } \\
\text { carcinoma }\end{array}$ & 2 & metastasis \\
\hline A10 & 38 & $\mathrm{~F}$ & $\begin{array}{l}\text { Lymph } \\
\text { node }\end{array}$ & $\begin{array}{l}\text { Metastatic invasive ductal } \\
\text { carcinoma }\end{array}$ & 1 & metastasis \\
\hline A11 & 51 & $\mathrm{~F}$ & $\begin{array}{l}\text { Lymph } \\
\text { node }\end{array}$ & $\begin{array}{l}\text { Metastatic invasive ductal } \\
\text { carcinoma }\end{array}$ & 2 & metastasis \\
\hline $\mathrm{A} 12$ & 39 & $\mathrm{~F}$ & $\begin{array}{l}\text { Lymph } \\
\text { node }\end{array}$ & $\begin{array}{l}\text { Metastatic invasive ductal } \\
\text { carcinoma }\end{array}$ & 2 & metastasis \\
\hline A13 & 53 & $\mathrm{~F}$ & $\begin{array}{l}\text { Lymph } \\
\text { node }\end{array}$ & $\begin{array}{l}\text { Metastatic invasive ductal } \\
\text { carcinoma }\end{array}$ & 2 & metastasis \\
\hline A15 & 44 & $\mathrm{~F}$ & $\begin{array}{l}\text { Lymph } \\
\text { node }\end{array}$ & $\begin{array}{l}\text { Metastatic invasive ductal } \\
\text { carcinoma }\end{array}$ & 2 & metastasis \\
\hline A16 & 55 & $F$ & $\begin{array}{l}\text { Lymph } \\
\text { node }\end{array}$ & $\begin{array}{l}\text { Metastatic invasive ductal } \\
\text { carcinoma }\end{array}$ & 2 & metastasis \\
\hline B1 & 47 & $\mathrm{~F}$ & $\begin{array}{l}\text { Lymph } \\
\text { node }\end{array}$ & $\begin{array}{l}\text { Metastatic invasive ductal } \\
\text { carcinoma }\end{array}$ & 2 & metastasis \\
\hline B2 & 39 & $\mathrm{~F}$ & $\begin{array}{l}\text { Lymph } \\
\text { node }\end{array}$ & $\begin{array}{l}\text { Metastatic invasive ductal } \\
\text { carcinoma }\end{array}$ & 1 & metastasis \\
\hline B3 & 52 & $\mathrm{~F}$ & $\begin{array}{l}\text { Lymph } \\
\text { node }\end{array}$ & $\begin{array}{l}\text { Metastatic invasive ductal } \\
\text { carcinoma of No. } 81\end{array}$ & 2 & metastasis \\
\hline B4 & 60 & $\mathrm{~F}$ & $\begin{array}{l}\text { Lymph } \\
\text { node }\end{array}$ & $\begin{array}{l}\text { Metastatic invasive ductal } \\
\text { carcinoma }\end{array}$ & 2 & metastasis \\
\hline B5 & 52 & $\mathrm{~F}$ & $\begin{array}{l}\text { Lymph } \\
\text { node }\end{array}$ & $\begin{array}{l}\text { Metastatic invasive ductal } \\
\text { carcinoma }\end{array}$ & 2 & metastasis \\
\hline B6 & 28 & $\mathrm{~F}$ & $\begin{array}{l}\text { Lymph } \\
\text { node }\end{array}$ & $\begin{array}{l}\text { Metastatic invasive ductal } \\
\text { carcinoma }\end{array}$ & 3 & metastasis \\
\hline B7 & 58 & $\mathrm{~F}$ & $\begin{array}{l}\text { Lymph } \\
\text { node }\end{array}$ & $\begin{array}{l}\text { Metastatic invasive ductal } \\
\text { carcinoma }\end{array}$ & 2 & metastasis \\
\hline B8 & 42 & $\mathrm{~F}$ & $\begin{array}{l}\text { Lymph } \\
\text { node }\end{array}$ & $\begin{array}{l}\text { Metastatic invasive ductal } \\
\text { carcinoma }\end{array}$ & 2 & metastasis \\
\hline B9 & 42 & $\mathrm{~F}$ & $\begin{array}{l}\text { Lymph } \\
\text { node }\end{array}$ & $\begin{array}{l}\text { Metastatic invasive ductal } \\
\text { carcinoma }\end{array}$ & 2 & metastasis \\
\hline
\end{tabular}




\begin{tabular}{|c|c|c|c|c|c|c|}
\hline B10 & 48 & $\mathrm{~F}$ & $\begin{array}{l}\text { Lymph } \\
\text { node }\end{array}$ & $\begin{array}{l}\text { Metastatic invasive ductal } \\
\text { carcinoma }\end{array}$ & 2 & metastasis \\
\hline B11 & 80 & $\mathrm{~F}$ & $\begin{array}{l}\text { Lymph } \\
\text { node }\end{array}$ & $\begin{array}{l}\text { Metastatic invasive ductal } \\
\text { carcinoma }\end{array}$ & 2 & metastasis \\
\hline B12 & 59 & $F$ & $\begin{array}{l}\text { Lymph } \\
\text { node }\end{array}$ & $\begin{array}{l}\text { Metastatic invasive ductal } \\
\text { carcinoma }\end{array}$ & 2 & metastasis \\
\hline B13 & 60 & $\mathrm{~F}$ & $\begin{array}{l}\text { Lymph } \\
\text { node }\end{array}$ & $\begin{array}{l}\text { Metastatic invasive ductal } \\
\text { carcinoma }\end{array}$ & 2 & metastasis \\
\hline B14 & 28 & $F$ & $\begin{array}{l}\text { Lymph } \\
\text { node }\end{array}$ & $\begin{array}{l}\text { Metastatic invasive ductal } \\
\text { carcinoma of No. } 79\end{array}$ & 2 & metastasis \\
\hline B15 & 55 & $\mathrm{~F}$ & $\begin{array}{l}\text { Lymph } \\
\text { node }\end{array}$ & $\begin{array}{l}\text { Metastatic invasive ductal } \\
\text { carcinoma }\end{array}$ & 2 & metastasis \\
\hline B16 & 62 & $F$ & $\begin{array}{l}\text { Lymph } \\
\text { node }\end{array}$ & $\begin{array}{l}\text { Metastatic invasive ductal } \\
\text { carcinoma }\end{array}$ & 2 & metastasis \\
\hline $\mathrm{C} 1$ & 30 & $\mathrm{~F}$ & Breast & Invasive ductal carcinoma & 1 & malignant \\
\hline $\mathrm{C} 2$ & 44 & $\mathrm{~F}$ & Breast & Invasive ductal carcinoma & 1 & malignant \\
\hline $\mathrm{C} 3$ & 37 & $\mathrm{~F}$ & Breast & Invasive ductal carcinoma & 1 & malignant \\
\hline $\mathrm{C} 4$ & 61 & $\mathrm{~F}$ & Breast & Invasive ductal carcinoma & 2 & malignant \\
\hline $\mathrm{C5}$ & 50 & $\mathrm{~F}$ & Breast & Invasive ductal carcinoma & 2 & malignant \\
\hline $\mathrm{C} 6$ & 39 & $\mathrm{~F}$ & Breast & Invasive ductal carcinoma & 2 & malignant \\
\hline $\mathrm{C7}$ & 42 & $\mathrm{~F}$ & Breast & Invasive ductal carcinoma & 1 & malignant \\
\hline $\mathrm{C} 8$ & 41 & $\mathrm{~F}$ & Breast & Invasive ductal carcinoma & 2 & malignant \\
\hline $\mathrm{C9}$ & 65 & $\mathrm{~F}$ & Breast & Invasive ductal carcinoma & 2 & malignant \\
\hline C10 & 63 & $\mathrm{~F}$ & Breast & Invasive ductal carcinoma & 2 & malignant \\
\hline C11 & 71 & $\mathrm{~F}$ & Breast & Invasive ductal carcinoma & 2 & malignant \\
\hline C12 & 43 & $\mathrm{~F}$ & Breast & Invasive ductal carcinoma & 2 & malignant \\
\hline C13 & 54 & $\mathrm{~F}$ & Breast & Invasive ductal carcinoma & 2 & malignant \\
\hline C14 & 38 & $\mathrm{~F}$ & Breast & Invasive ductal carcinoma & 2 & malignant \\
\hline C15 & 47 & $\mathrm{~F}$ & Breast & Invasive ductal carcinoma & 2 & malignant \\
\hline C16 & 44 & $\mathrm{~F}$ & Breast & Invasive ductal carcinoma & 2 & malignant \\
\hline D1 & 53 & $\mathrm{~F}$ & Breast & Invasive ductal carcinoma & 2 & malignant \\
\hline D2 & 42 & $\mathrm{~F}$ & Breast & Invasive ductal carcinoma & 2 & malignant \\
\hline D3 & 59 & $\mathrm{~F}$ & Breast & Invasive ductal carcinoma & 2 & malignant \\
\hline D4 & 38 & $\mathrm{~F}$ & Breast & Invasive ductal carcinoma & 2 & malignant \\
\hline D5 & 43 & $\mathrm{~F}$ & Breast & Invasive ductal carcinoma & 2 & malignant \\
\hline D6 & 48 & $\mathrm{~F}$ & Breast & Invasive ductal carcinoma & 2 & malignant \\
\hline D7 & 41 & $\mathrm{~F}$ & Breast & Invasive ductal carcinoma & 2 & malignant \\
\hline D8 & 38 & $\mathrm{~F}$ & Breast & Invasive ductal carcinoma & 2 & malignant \\
\hline D9 & 45 & $\mathrm{~F}$ & Breast & Invasive ductal carcinoma & 2 & malignant \\
\hline D11 & 41 & $\mathrm{~F}$ & Breast & Invasive ductal carcinoma & 2 & malignant \\
\hline D12 & 32 & $\mathrm{~F}$ & Breast & Invasive ductal carcinoma & 2 & malignant \\
\hline D13 & 62 & $\mathrm{~F}$ & Breast & Invasive ductal carcinoma & 2 & malignant \\
\hline D14 & 50 & $\mathrm{~F}$ & Breast & Invasive ductal carcinoma & 2 & malignant \\
\hline D15 & 68 & $\mathrm{~F}$ & Breast & Invasive ductal carcinoma & 2 & malignant \\
\hline
\end{tabular}




\begin{tabular}{|c|c|c|c|c|c|c|}
\hline D16 & 44 & $\mathrm{~F}$ & Breast & Invasive ductal carcinoma & 2 & malignant \\
\hline E1 & 45 & $\mathrm{~F}$ & Breast & Invasive ductal carcinoma & 2 & malignant \\
\hline E2 & 29 & $\mathrm{~F}$ & Breast & Invasive ductal carcinoma & 2 & malignant \\
\hline E3 & 67 & $\mathrm{~F}$ & Breast & Invasive ductal carcinoma & 1 & malignant \\
\hline E4 & 50 & $\mathrm{~F}$ & Breast & Invasive ductal carcinoma & 1 & malignant \\
\hline E5 & 54 & $\mathrm{~F}$ & Breast & Invasive ductal carcinoma & 2 & malignant \\
\hline E6 & 35 & $\mathrm{~F}$ & Breast & Invasive ductal carcinoma & 2 & malignant \\
\hline E8 & 29 & $\mathrm{~F}$ & Breast & Invasive ductal carcinoma & 2 & malignant \\
\hline E9 & 55 & $\mathrm{~F}$ & Breast & Invasive ductal carcinoma & 2 & malignant \\
\hline E10 & 50 & $\mathrm{~F}$ & Breast & Invasive ductal carcinoma & 2 & malignant \\
\hline E11 & 43 & $\mathrm{~F}$ & Breast & Invasive ductal carcinoma & 2 & malignant \\
\hline E12 & 43 & $\mathrm{~F}$ & Breast & Invasive ductal carcinoma & 2 & malignant \\
\hline E13 & 45 & $\mathrm{~F}$ & Breast & Invasive ductal carcinoma & 2 & malignant \\
\hline E14 & 50 & $\mathrm{~F}$ & Breast & Invasive ductal carcinoma & 2 & malignant \\
\hline E15 & 28 & $\mathrm{~F}$ & Breast & Invasive ductal carcinoma & 2 & malignant \\
\hline E16 & 55 & $\mathrm{~F}$ & Breast & Invasive ductal carcinoma & 2 & malignant \\
\hline $\mathrm{F} 1$ & 52 & $\mathrm{~F}$ & Breast & Invasive ductal carcinoma & 2 & malignant \\
\hline F2 & 38 & $\mathrm{~F}$ & Breast & Invasive ductal carcinoma & 2 & malignant \\
\hline F3 & 49 & $\mathrm{~F}$ & Breast & Invasive ductal carcinoma & 2 & malignant \\
\hline F4 & 46 & $\mathrm{~F}$ & Breast & Invasive ductal carcinoma & 2 & malignant \\
\hline F5 & 62 & $\mathrm{~F}$ & Breast & Invasive ductal carcinoma & 2 & malignant \\
\hline F6 & 42 & $\mathrm{~F}$ & Breast & Invasive ductal carcinoma & 2 & malignant \\
\hline F7 & 53 & $\mathrm{~F}$ & Breast & Invasive ductal carcinoma & 2 & malignant \\
\hline F8 & 45 & $\mathrm{~F}$ & Breast & Invasive ductal carcinoma & 2 & malignant \\
\hline F9 & 32 & $\mathrm{~F}$ & Breast & Invasive ductal carcinoma & 2 & malignant \\
\hline F10 & 29 & $\mathrm{~F}$ & Breast & Invasive ductal carcinoma & 2 & malignant \\
\hline F11 & 65 & $\mathrm{~F}$ & Breast & Invasive ductal carcinoma & 2 & malignant \\
\hline F12 & 64 & $\mathrm{~F}$ & Breast & Invasive ductal carcinoma & 2 & malignant \\
\hline F13 & 63 & $\mathrm{~F}$ & Breast & Invasive ductal carcinoma & 2 & malignant \\
\hline F14 & 51 & $\mathrm{~F}$ & Breast & Invasive ductal carcinoma & 3 & malignant \\
\hline F15 & 56 & $\mathrm{~F}$ & Breast & Invasive ductal carcinoma & 2 & malignant \\
\hline F16 & 62 & $\mathrm{~F}$ & Breast & Invasive ductal carcinoma & 2 & malignant \\
\hline G2 & 32 & $\mathrm{~F}$ & Breast & Invasive ductal carcinoma & 2 & malignant \\
\hline G3 & 55 & $\mathrm{~F}$ & Breast & Invasive ductal carcinoma & 2 & malignant \\
\hline G4 & 53 & $\mathrm{~F}$ & Breast & Invasive ductal carcinoma & 2 & malignant \\
\hline G5 & 50 & $\mathrm{~F}$ & Breast & Invasive lobular carcinoma & - & malignant \\
\hline G7 & 47 & $\mathrm{~F}$ & Breast & Invasive lobular carcinoma & - & malignant \\
\hline G8 & 51 & $\mathrm{~F}$ & Breast & Invasive lobular carcinoma & - & malignant \\
\hline G9 & 69 & $\mathrm{~F}$ & Breast & Invasive lobular carcinoma & - & malignant \\
\hline G10 & 70 & $\mathrm{~F}$ & Breast & Invasive lobular carcinoma & - & malignant \\
\hline G11 & 59 & $\mathrm{~F}$ & Breast & Invasive lobular carcinoma & - & malignant \\
\hline G12 & 35 & $\mathrm{~F}$ & Breast & Invasive lobular carcinoma & - & malignant \\
\hline
\end{tabular}




\begin{tabular}{|c|c|c|c|c|c|c|}
\hline G13 & 38 & $\mathrm{~F}$ & Breast & Invasive lobular carcinoma & - & malignant \\
\hline G14 & 42 & $\mathrm{~F}$ & Breast & Invasive lobular carcinoma & - & malignant \\
\hline G15 & 52 & $\mathrm{~F}$ & Breast & Invasive lobular carcinoma & - & malignant \\
\hline G16 & 41 & $\mathrm{~F}$ & Breast & Invasive lobular carcinoma & - & malignant \\
\hline $\mathrm{H} 1$ & 47 & $\mathrm{~F}$ & Breast & Invasive lobular carcinoma & - & malignant \\
\hline $\mathrm{H} 2$ & 50 & $\mathrm{~F}$ & Breast & Invasive lobular carcinoma & - & malignant \\
\hline $\mathrm{H3}$ & 66 & $\mathrm{~F}$ & Breast & Invasive lobular carcinoma (sparse) & - & malignant \\
\hline $\mathrm{H} 4$ & 46 & $\mathrm{~F}$ & Breast & Invasive lobular carcinoma & - & malignant \\
\hline $\mathrm{H} 5$ & 48 & $\mathrm{~F}$ & Breast & Invasive lobular carcinoma & - & malignant \\
\hline $\mathrm{H} 6$ & 38 & $\mathrm{~F}$ & Breast & Invasive lobular carcinoma & - & malignant \\
\hline $\mathrm{H} 7$ & 45 & $\mathrm{~F}$ & Breast & Invasive lobular carcinoma (sparse) & - & malignant \\
\hline $\mathrm{H} 8$ & 52 & $\mathrm{~F}$ & Breast & Invasive lobular carcinoma & - & malignant \\
\hline $\mathrm{H9}$ & 45 & $\mathrm{~F}$ & Breast & Invasive lobular carcinoma & - & malignant \\
\hline $\mathrm{H} 10$ & 52 & $\mathrm{~F}$ & Breast & Invasive lobular carcinoma (sparse) & - & malignant \\
\hline $\mathrm{H} 11$ & 41 & $\mathrm{~F}$ & Breast & Squamous cell carcinoma & $1--2$ & malignant \\
\hline $\mathrm{H} 12$ & 37 & $\mathrm{~F}$ & Breast & Squamous cell carcinoma & 2 & malignant \\
\hline $\mathrm{H} 13$ & 48 & $\mathrm{~F}$ & Breast & Squamous cell carcinoma & 2 & malignant \\
\hline $\mathrm{H} 14$ & 47 & $\mathrm{~F}$ & Breast & Squamous cell carcinoma & 2 & malignant \\
\hline $\mathrm{H} 15$ & 49 & $\mathrm{~F}$ & Breast & Intraductal carcinoma & - & malignant \\
\hline 11 & 38 & $\mathrm{~F}$ & Breast & Intraductal carcinoma & - & malignant \\
\hline 12 & 42 & $\mathrm{~F}$ & Breast & Intraductal carcinoma & - & malignant \\
\hline 13 & 27 & $\mathrm{~F}$ & Breast & Intraductal carcinoma & - & malignant \\
\hline 15 & 41 & $\mathrm{~F}$ & Breast & $\begin{array}{l}\text { Intraductal carcinoma (hyperplasia } \\
\text { of breast duct) }\end{array}$ & - & malignant \\
\hline 16 & 43 & $\mathrm{~F}$ & Breast & Intraductal carcinoma & - & malignant \\
\hline 17 & 32 & $\mathrm{~F}$ & Breast & Intraductal carcinoma & - & malignant \\
\hline 18 & 58 & $\mathrm{~F}$ & Breast & Intraductal carcinoma & - & malignant \\
\hline 19 & 67 & $\mathrm{~F}$ & Breast & Intraductal carcinoma & - & malignant \\
\hline 111 & 49 & $\mathrm{~F}$ & Breast & $\begin{array}{l}\text { Intraductal carcinoma with early } \\
\text { infiltration }\end{array}$ & - & malignant \\
\hline 112 & 32 & $\mathrm{~F}$ & Breast & Intraductal carcinoma & - & malignant \\
\hline 113 & 81 & $\mathrm{~F}$ & Breast & Intraductal carcinoma & - & malignant \\
\hline 114 & 39 & $\mathrm{~F}$ & Breast & Intraductal carcinoma & - & malignant \\
\hline 115 & 43 & $\mathrm{~F}$ & Breast & Intraductal carcinoma & - & malignant \\
\hline J1 & 46 & $\mathrm{~F}$ & Breast & Intraductal carcinoma & - & malignant \\
\hline $\mathrm{J} 2$ & 60 & $\mathrm{~F}$ & Breast & Intraductal carcinoma & - & malignant \\
\hline J3 & 64 & $\mathrm{~F}$ & Breast & Intraductal carcinoma & - & malignant \\
\hline J4 & 40 & $\mathrm{~F}$ & Breast & Intraductal carcinoma & - & malignant \\
\hline J5 & 48 & $\mathrm{~F}$ & Breast & Lobular carcinoma in situ & - & In Situ \\
\hline J6 & 54 & $\mathrm{~F}$ & Breast & Lobular carcinoma in situ & - & In Situ \\
\hline J7 & 49 & $\mathrm{~F}$ & Breast & Lobular carcinoma in situ & - & In Situ \\
\hline
\end{tabular}




\begin{tabular}{|c|c|c|c|c|c|c|}
\hline J8 & 62 & $F$ & Breast & $\begin{array}{l}\text { Lobular carcinoma in situ (fibrous } \\
\text { tissue) }\end{array}$ & - & In Situ \\
\hline J9 & 44 & $\mathrm{~F}$ & Breast & Fibroadenoma & - & benign \\
\hline $\mathrm{J} 10$ & 27 & $\mathrm{~F}$ & Breast & Fibroadenoma & - & benign \\
\hline J11 & 23 & $F$ & Breast & Fibroadenoma & - & benign \\
\hline $\mathrm{J} 12$ & 23 & $\mathrm{~F}$ & Breast & Fibroadenoma & - & benign \\
\hline J13 & 19 & $\mathrm{~F}$ & Breast & Fibroadenoma & - & benign \\
\hline $\mathrm{J} 14$ & 23 & $\mathrm{~F}$ & Breast & Fibroadenoma & - & benign \\
\hline J15 & 42 & $\mathrm{~F}$ & Breast & Fibroadenoma & - & benign \\
\hline J16 & 25 & $\mathrm{~F}$ & Breast & Fibroadenoma & - & benign \\
\hline $\mathrm{K} 1$ & 48 & $F$ & Breast & Mild hyperplasia of breast duct & - & hyperplasia \\
\hline $\mathrm{K} 2$ & 43 & $\mathrm{~F}$ & Breast & Adenosis with hyperplasia of duct & - & hyperplasia \\
\hline $\mathrm{K} 3$ & 41 & $\mathrm{~F}$ & Breast & Adenosis with hyperplasia of duct & - & hyperplasia \\
\hline $\mathrm{K} 4$ & 34 & $\mathrm{~F}$ & Breast & Mild hyperplasia of breast duct & - & hyperplasia \\
\hline K5 & 40 & $\mathrm{~F}$ & Breast & $\begin{array}{l}\text { Atypical hyperplasia in duct (grade } \\
\text { II) }\end{array}$ & - & hyperplasia \\
\hline $\mathrm{K} 6$ & 76 & $\mathrm{~F}$ & Breast & Hyperplasia (fibrofatty tissue) & - & hyperplasia \\
\hline K8 & 37 & $\mathrm{~F}$ & Breast & $\begin{array}{l}\text { Adenosis with mild hyperplasia of } \\
\text { duct }\end{array}$ & - & hyperplasia \\
\hline K9 & 45 & $\mathrm{~F}$ & Breast & $\begin{array}{l}\text { Adenosis with mild hyperplasia of } \\
\text { duct }\end{array}$ & - & hyperplasia \\
\hline K12 & 45 & $\mathrm{~F}$ & Breast & $\begin{array}{l}\text { Atypical hyperplasia of duct (grade } \\
\text { II-III) }\end{array}$ & - & hyperplasia \\
\hline K13 & 40 & $\mathrm{~F}$ & Breast & Cyclomastopathy & - & hyperplasia \\
\hline K14 & 22 & $\mathrm{~F}$ & Breast & Cyclomastopathy & - & hyperplasia \\
\hline K15 & 28 & $\mathrm{~F}$ & Breast & Cyclomastopathy (sparse) & - & hyperplasia \\
\hline L1 & 61 & $\mathrm{~F}$ & Breast & Plasma cell mastitis & - & inflammation \\
\hline L2 & 28 & $\mathrm{~F}$ & Breast & Plasma cell mastitis & - & inflammation \\
\hline L3 & 55 & $\mathrm{~F}$ & Breast & Plasma cell mastitis & - & inflammation \\
\hline L4 & 26 & $\mathrm{~F}$ & Breast & Plasma cell mastitis & - & inflammation \\
\hline L5 & 78 & $\mathrm{~F}$ & Breast & Plasma cell mastitis & - & inflammation \\
\hline L6 & 46 & $\mathrm{~F}$ & Breast & Plasma cell mastitis & - & inflammation \\
\hline L7 & 28 & $\mathrm{~F}$ & Breast & Chronic inflammation & - & inflammation \\
\hline L8 & 10 & $\mathrm{~F}$ & Breast & Acute mastitis & - & inflammation \\
\hline L9 & 45 & $\mathrm{~F}$ & Breast & Mild chronic inflammation & - & inflammation \\
\hline L10 & 57 & $\mathrm{~F}$ & Breast & Mild chronic inflammation & - & inflammation \\
\hline $\mathrm{L} 11$ & 33 & $\mathrm{~F}$ & Breast & Mild chronic inflammation & - & inflammation \\
\hline L12 & 39 & $\mathrm{~F}$ & Breast & $\begin{array}{l}\text { Chronic inflammation of fibrous } \\
\text { tissue }\end{array}$ & - & inflammation \\
\hline L13 & 67 & $\mathrm{~F}$ & Breast & Granulomatous mastitis & - & inflammation \\
\hline L14 & 40 & $\mathrm{~F}$ & Breast & Chronic inflammation & - & inflammation \\
\hline
\end{tabular}




\begin{tabular}{|c|c|c|c|c|c|c|}
\hline L16 & 44 & $\mathrm{~F}$ & Breast & $\begin{array}{l}\text { Plasma cell mastitis with ductal } \\
\text { ectasia }\end{array}$ & - & inflammation \\
\hline M2 & 31 & $F$ & Breast & $\begin{array}{l}\text { Cancer adjacent normal breast } \\
\text { tissue (cyclomastopathy) }\end{array}$ & - & NAT \\
\hline M3 & 45 & $\mathrm{~F}$ & Breast & $\begin{array}{l}\text { Cancer adjacent normal breast } \\
\text { tissue }\end{array}$ & - & NAT \\
\hline M4 & 53 & $F$ & Breast & $\begin{array}{l}\text { Cancer adjacent normal breast } \\
\text { tissue }\end{array}$ & - & NAT \\
\hline M6 & 35 & $\mathrm{~F}$ & Breast & $\begin{array}{l}\text { Cancer adjacent normal breast } \\
\text { tissue }\end{array}$ & - & NAT \\
\hline M10 & 46 & $\mathrm{~F}$ & Breast & $\begin{array}{l}\text { Cancer adjacent normal breast } \\
\text { tissue }\end{array}$ & - & NAT \\
\hline M11 & 15 & $\mathrm{~F}$ & Breast & Normal breast tissue & - & normal \\
\hline M13 & 21 & $\mathrm{~F}$ & Breast & Normal breast tissue & - & normal \\
\hline M14 & 35 & $\mathrm{~F}$ & Breast & $\begin{array}{l}\text { Normal breast tissue (with mild } \\
\text { ductal ectasia) }\end{array}$ & - & normal \\
\hline M15 & 19 & $\mathrm{~F}$ & Breast & $\begin{array}{l}\text { Normal breast tissue (fibrous } \\
\text { tissue) }\end{array}$ & - & normal \\
\hline
\end{tabular}


Supplementary Table S5. qPCR assays:

Custom 96-well qPCR plates from Thermo scientific:

\begin{tabular}{|c|c|}
\hline $\begin{array}{l}\text { Gene } \\
\text { name }\end{array}$ & Assay catalog \# \\
\hline FGF5 & Hs03676587_s1 \\
\hline ACTB & Hs99999903_m1 \\
\hline MCTP2 & Hs01071657_m1 \\
\hline FBXL7 & Hs00202348_m1 \\
\hline RHOJ & Hs01112007_m1 \\
\hline $\begin{array}{l}\text { HLA- } \\
\text { DRB1 }\end{array}$ & Hs04192464_mH \\
\hline NRXN3 & Hs01028186_m1 \\
\hline SAMSN1 & Hs01090844_m1 \\
\hline HMGN5 & Hs04999451_m1 \\
\hline ESM1 & Hs00199831_m1 \\
\hline PARP15 & Hs00403748_m1 \\
\hline ELMO1 & Hs00404992_m1 \\
\hline GCKR & Hs00386984_m1 \\
\hline ANO5 & Hs01381106_m1 \\
\hline FREM2 & Hs01388268_m1 \\
\hline NRK & Hs00872692_m1 \\
\hline HS6ST2 & Hs02925656_m1 \\
\hline $\begin{array}{l}\text { ADAMTS } \\
1\end{array}$ & Hs00199608_m1 \\
\hline ARAP2 & Hs00367362_m1 \\
\hline NAP1L2 & Hs01114608_s1 \\
\hline ENG & Hs00923996_m1 \\
\hline KISS1 & Hs00158486_m1 \\
\hline MYCT1 & Hs00228305_m1 \\
\hline EPHA7 & Hs01033006_m1 \\
\hline CADM2 & Hs01549516_m1 \\
\hline ROBO2 & Hs00326067_m1 \\
\hline LPAR3 & Hs00173857_m1 \\
\hline $\begin{array}{l}\text { TNFRSF } \\
11 \mathrm{~B}\end{array}$ & Hs00900358_m1 \\
\hline EHD3 & Hs00997783_mH \\
\hline IL1A & Hs00174092_m1 \\
\hline SNCAIP & Hs00917423_m1 \\
\hline F2RL2 & Hs00187982_m1 \\
\hline CHRDL1 & Hs01035484_m1 \\
\hline DOCK8 & Hs00298892_m1 \\
\hline POU3F2 & Hs00271595_s1 \\
\hline
\end{tabular}




\begin{tabular}{|l|l|} 
MMP1 & Hs00899658_m1 \\
\hline WT1 & Hs01103751_m1 \\
\hline SELL & Hs01046459_m1 \\
\hline RGS4 & Hs01111690_g1 \\
\hline DHH & Hs00368306_m1 \\
\hline FNDC4 & Hs01100278_g1 \\
\hline CCDC12 & Hs01092013_m1 \\
0 & \\
\hline HIST1H1 & Hs00271185_s1 \\
\hline PRKCQ & Hs00234709_m1 \\
\hline FGFR4 & Hs01106908_m1 \\
\hline FZD8 & Hs00259040_s1 \\
\hline SEMA6A & Hs00221174_m1 \\
\hline OR2B6 & Hs01649949_s1 \\
\hline KDR & Hs00911700_m1 \\
\hline ISYNA1 & Hs01126940_gH \\
\hline NRG2 & Hs00993399_m1 \\
\hline TRIL & Hs04188203_s1 \\
\hline IL17D & Hs00370528_m1 \\
\hline SFRP1 & Hs00610060_m1 \\
\hline G0S2 & Hs00274783_s1 \\
\hline SIX2 & Hs00232731_m1 \\
\hline GRB14 & Hs00182949_m1 \\
\hline NOG & Hs00271352_s1 \\
\hline PCDHB6 & Hs00251789_s1 \\
\hline STOX1 & Hs03645108_m1 \\
\hline RNF128 & Hs00226053_m1 \\
\hline RCAN2 & Hs00195165_m1 \\
\hline MLLT11 & Hs05017984_s1 \\
\hline TMEFF1 & Hs00902905_m1 \\
\hline CXCR4 & Hs00607978_s1 \\
\hline CST7 & Hs00175361_m1 \\
\hline INHBB & Hs00173582_m1 \\
\hline EREG & Hs00914313_m1 \\
\hline EYA4 & Hs01012399_m1 \\
\hline ATP9A & Hs00391058_m1 \\
\hline DLC1 & Hs00183436_m1 \\
\hline GPX7 & Hs00210410_m1 \\
\hline HSPB8 & Hs00205056_m1 \\
\hline CNKSR1 & Hs00906471_m1 \\
\hline KRT83 & Hs05049821_s1 \\
\hline ABCG1 & Hs00245154_m1 \\
\hline
\end{tabular}




\begin{tabular}{|l|l|} 
NKX1-2 & Hs01392360_m1 \\
\hline GSTP1 & Hs00943350_g1 \\
\hline MAP1LC & Hs01076567_g1 \\
\hline ID1 & Hs03676575_s1 \\
\hline TCEA2 & Hs00920170_m1 \\
\hline LAMB1 & Hs01055960_m1 \\
\hline $\begin{array}{l}\text { PPP1R3 } \\
\text { C }\end{array}$ & Hs01921501_s1 \\
\hline MAPRE3 & Hs00202414_m1 \\
\hline FAM83B & Hs00289694_m1 \\
\hline ACTA2 & Hs00426835_g1 \\
\hline TRPM6 & Hs01019356_m1 \\
\hline B2M & Hs99999907_m1 \\
\hline SLC2A4 & Hs00168966_m1 \\
\hline MEX3A & Hs00863536_m1 \\
\hline MYB & Hs00920556_m1 \\
\hline PTPRQ & Hs01386285_m1 \\
\hline MALT1 & Hs01120060_m1 \\
\hline NEGR1 & Hs02387573_m1 \\
\hline $\begin{array}{l}\text { TNFRSF } \\
\text { 1B }\end{array}$ & Hs00961750_m1 \\
\hline
\end{tabular}

PrimeTime assays from IDT Technologies:

\begin{tabular}{|l|l|}
\hline $\begin{array}{l}\text { Gene } \\
\text { name }\end{array}$ & Assay catalog \# \\
\hline NOS3 & Hs.PT.58.21447620 \\
\hline S100A4 & Hs.PT.58.39700608 \\
\hline ITGA6 & Hs.PT.58.453862 \\
\hline PDGFB & Hs.PT.58.45327803 \\
\hline MMP1 & Hs.PT.58.38692586 \\
\hline ADM & Hs.PT.56a.25211580.g \\
\hline WT1 & Hs.PT.58.22568369 \\
\hline HIF1A & Hs.PT.58.534274 \\
\hline ARNT2 & Hs.PT.58.783416 \\
\hline EPAS1 & Hs.PT.58.2273374 \\
\hline SLC2A4 & Hs.PT.58.2557238 \\
\hline KDR & Hs.PT.58.3285240 \\
\hline CXCR4 & Hs.PT.58.22298491 \\
\hline ANGPT1 & Hs.PT.56a.761468 \\
\hline ARNT & Hs.PT.56a.807676.g \\
\hline ACTB & Hs.PT.39a.22214847 \\
\hline
\end{tabular}




\begin{tabular}{|l|l|l|l|}
\hline Name & Forward & Reverse & Probe \\
\hline GAPDH & $\begin{array}{l}\text { CTTTGGTATCGTGGAAG } \\
\text { GACTC }\end{array}$ & $\begin{array}{l}\text { GTAGAGGCAGGGATGA } \\
\text { TGTTC }\end{array}$ & $\begin{array}{l}\text { /56-FAM/CGG GAA ACT } \\
\text { /ZEN/GTG GCG TGA TGG } \\
\text { /3IABkFQ/ }\end{array}$ \\
\hline
\end{tabular}


Supplementary Table S6. ChIP qPCR primers:

\begin{tabular}{|l|l|l|l|}
\hline Name & Forward & Reverse & Probe \\
\hline $\begin{array}{l}\text { CXC } \\
\text { HRE }\end{array}$ & $\begin{array}{l}\text { GGGCCGAGAAACTG } \\
\text { GGT }\end{array}$ & $\begin{array}{l}\text { GGGATCGTGTGTAG } \\
\text { AGTGCAG }\end{array}$ & $\begin{array}{l}\text { /56- } \\
\text { FAM/AAATGGTCC/ZEN/CGAGGAGAG } \\
\text { GGATTG/3IABkFQ/ }\end{array}$ \\
\hline $\begin{array}{l}\text { ITGA } \\
\text { HRE }\end{array}$ & $\begin{array}{l}\text { AGTAAAGTCTCCCTC } \\
\text { GCTCTGT }\end{array}$ & $\begin{array}{l}\text { TCTCCAGCTGCCCG } \\
\text { GTA }\end{array}$ & $\begin{array}{l}\text { /56- } \\
\text { FAM/ACTCGGCAA/ZEN/CCACAATTCT } \\
\text { GTCCA/3IABkF/ }\end{array}$ \\
\hline $\begin{array}{l}\text { EPO } \\
\text { HRE }\end{array}$ & $\begin{array}{l}\text { GGCTCTGTCCCACT } \\
\text { CCTGTAGGCAGAGCT }\end{array}$ & $\begin{array}{l}\text { /56- } \\
\text { FAM/TGTGTGAGA/ZEN/CAGCACGTAG } \\
\text { GGC/3IABkFQ/ }\end{array}$ \\
\hline $\begin{array}{l}\text { FOX } \\
\text { M1 } \\
\text { prom } \\
\text { ter }\end{array}$ & ACCGGAGCTTTCAG & $\begin{array}{l}\text { GATTGGCGACGTTC } \\
\text { CGT }\end{array}$ & $\begin{array}{l}\text { /56-FAM/TCCGCTGTT/ZEN/TGA } \\
\text { AATTGGCGCC/3IABkFQ/ }\end{array}$ \\
\hline
\end{tabular}




\section{CHAPTER 3: General Discussion}

As mentioned in Chapter 1, AURKA has many functions in cancer progression and is a prognostic factor for worse survival in patients. Recently, the separation of AURKA's cytoplasmic and nuclear functions has come of interest. Most research focuses on deciphering AURKA's functions regardless of localization and under the assumption that it is cytoplasmic; however, identifying AURKA in the nucleus brought to light the significant differences in roles cytoplasmic vs. nuclear pools of AURKA play in cancer. Similar to the well-known tumor-suppressor - p53, which was initially identified as an oncogene, AURKA's oncogenic potential seems to be primarily driven by its nuclear pool. At the same time, cytoplasmic AURKA has limited oncogenic potential or even functions as a suppressor. The long-term goal of this study is to understand nuclear AURKA's function in tumorigenesis with a specific focus on metastasis. This chapter will discuss the main findings, differences in nuclear AURKA models, and future directions for studying nuclear AURKA.

In Chapter 2, this study tests the impact of nuclear AURKA on metastasis. We report, for the first time, that nuclear AURKA promotes metastasis. This conclusion is supported by the observation that the number of nuclear AURKA positive cells significantly increases during cancer progression from primary breast tumor to distant metastases; and there is a strong correlation between nuclear AURKA accumulation with more aggressive subtypes and metastases (Chapter 2, Fig.1A-C and Suppl.Fig1E). The next step would be to correlate nuclear AURKA presence with BC survival in patients. We 
predict that nuclear AURKA will be indicative of worse overall survival for breast cancer patients.

The model we created to test the cytoplasmic and nuclear AURKA function completely separates AURKA into those compartments. This was done by using an NES(nuclear exclusion signal) and NLS- (nuclear localization signal) tagged exogenous AURKA combined with a knockout of the endogenous AURKA to produce cells with a single compartment-restricted AURKA (Chapter 2, Fig.1F-H). These cells were used in in vitro assays for proliferation, invasion, and stemness. The resulting NLS-AURKA cells show increased invasion and stemness capabilities without changes in proliferation. Both invasion and stemness capabilities are involved in the metastatic cascade. It was previously reported that AURKA promotes invasion and migration as reviewed in Chapter 1; however, these effects were attributed to cytoplasmic AURKA. No other studies have been published on nuclear AURKA-driven function in regulating invasion and migration, except our research in Chapter 2. Based on RNA-seq findings, NLS-AURKA cells show upregulation of key cytoskeleton (RHOJ, ARHGAP22, ARHGAP24, ELMO1, DEF6), adhesion (CADM2, SELL, ITGA6), matrix-degrading (ADAMTS5, ADAMTS1, MMP1, MMP14), and tight junction (CLDN4, CLDN11, CLDN12, CLDN23) proteins, which may explain the increase in invasion (Chapter 2, Fig.5). Also, due to the morphology differences in NLS-AURKA cells (smaller nuclei and more round), this is indicative of an amoeboid morphology (1) (Chapter 2, Fig.2B-D). The amoeboid morphology and smaller size support the ability of cells to move throughout a constricted environment (2). Due to the morphology changes and differences in expression of genes involved with migration, this would warrant further study of these pathways in NLS-AURKA cells. 
In breast cancer, it has been reported that AURKA overexpression leads to increased stemness, noted by increased CD24-/CD44+ cell population and the ability to form mammospheres $(3,4)$. In these models, using fractionation of the AURKA overexpressed cells, AURKA is present in both the cytoplasm and nucleus, compared to normal (3). Also, when AURKA is excluded from the cytoplasm, the stem cell potential decreases, suggesting that nuclear AURKA is responsible for the increased stemness (3). Our model agrees with these conclusions that nuclear AURKA increases stemness. The NLS-AURKA increases the number of CD24-/CD44+ cells and their ability to form mammospheres, compared to control and NES-AURKA cells (Chapter 2, Fig.2L-R). A previous report by Yang et al. showed that the FOXM1/AURKA complex contributes to regulating the self-renewal of breast cancer stem cells (4). In our model, the depletion of FOXM1 was insufficient to change the expression of the stem cell markers or mammosphere formation (Chapter 2, Suppl.Fig.2D-I). Based on our findings, this activity of nuclear AURKA is mediated, at least partly, by activation of HIF1A/B, which in turn may upregulate FOXM1 (Chapter 2, Fig.7H-J). These findings differ from previously published reports, using either an overexpression system (4) or NES-AURKA inducible system (3). Neither of those modeling approaches allows gauging nuclear AURKA specific function directly. The overexpression system shows increased AURKA protein levels in both cytoplasmic and nuclear compartments $(3,4)$. This is not a clean system as functions of cytoplasmic AURKA will be increased.

The role of nuclear AURKA in metastasis is further supported by the increased metastatic dissemination/colonization at multiple distant organs in an orthotopic breast cancer mouse model, upon experimentally targeting AURKA to the nucleus (NLS- 
AURKA) (Chapter 2, Fig.4). The metastatic penetrance of NLS-AURKA cells is $100 \%$ in the lungs, lymph node, liver, and bone. Earlier studies showed that metastatic seeding in the bone and liver required multiple rounds of injection to select metastatic cells $(5,6)$. In our model, the bone and liver metastases were achieved without prior enrichment of cells, suggesting that disseminating cells were selected for the presence of nuclear AURKA. Furthermore, nuclear AURKA cells show upregulation of genes that promote bone metastasis, including ADAMST1, FGF5, FST, CXCR4, IL-11, MMP1 (5). The metastatic gene signature and increased metastatic penetrance in multiple organs suggest that nuclear AURKA is a key driver of an aggressive, metastatic phenotype. Note that tumor cells with cytoplasmic AURKA, which is found in all normal, non-transformed cells, have limited to no metastatic capacity without impacting cell growth/proliferation (Chapter 2, Fig.2A and Fig.4).

By integrating global gene expression and computational analyses, we found that nuclear localization of AURKA leads to significant changes in expression of over 3,000 genes involved in the regulation of hypoxia, transcription, metastasis, and other cancerrelated pathways (Chapter 2, Fig.5 and Suppl.Fig.5). It is well-established that hypoxia is an inducer of invasion, stemness, and metastasis $(7,8)$, but the role of nuclear AURKA in the activation of hypoxia signaling is currently unknown. Our findings show that nuclear AURKA is a potent inducer of the hypoxia-response gene signature in vitro and in vivo (Chapter 2, Fig.6 and Suppl.Fig.6). Hypoxia signaling is primarily driven by hypoxiainducible factors (HIFs), which include oxygen-sensitive HIF-A subunits (HIF1A, HIF2A/EPAS1) and oxygen-independent HIF-B subunits (HIF1B/ARNT, HIF2B/ARNT2). The activation/expression of HIF-1A at diagnosis is predictive of early relapse and 
metastasis and correlates with poor clinical outcomes in human breast cancer (9-11) and distant metastasis-free survival (12).

An enrichment of hypoxia response genes (Chapter 2, Fig.5H) was observed in nuclear AURKA expressing cells and tumors without an increase in HIF1A or HIF2A (Chapter 2, Fig.6A-B and Suppl.Fig.6C-E), suggesting HIF1/2A transcriptional activity was elevated instead, potentially via recruitment/retention on the DNA. The AURKA-ChIP complex analysis and qPCR support the notion that AURKA is binding to HRE-containing promoters similarly to HIF1B and interacts with previously documented partners like hnRNPk (Chapter 2, Fig.6E-I). These changes are reported under normoxic conditions in metastatic cells and could be further induced under hypoxia. This similar phenotype was observed in other breast cancer models (13). Nuclear AURKA gene expression changes show metabolic reprogramming (HK1/2), angiogenesis (ADM, ANGPT1, EDN1, FECH), invasion (CXCR4, LOX, MMP1, MMP14, ITGA6, CSRP2), and proliferation (ENG, WT1, CCND1) being the most upregulated. The nuclear AURKA-driven hypoxia gene signature mainly contains genes driven by HIF1A (HK2, END1, VIM, CSRP2) or HIF1/2A (CCND1, MMP14, ITGA6, ANGPT1, ADM, LOX, CXCR4). Interestingly, in DMOG-treated NLSAURKA cells, only HIF1A was upregulated. Note that not all genes previously connected to hypoxia were upregulated. Some canonical HIF1A-induced genes such as PDK1, PFKP, SNAI1, and NOS3 were downregulated compared to empty-vector control, suggesting the involvement of additional cofactors affecting transcription besides just the HRE-driven mechanism (Chapter 2, Fig.5I). This has been demonstrated for several other transcription factors, including Sp1(14), AP1-GATA2-NF1(15), Erg1-C/EBPa(16), Sp1HNF4(17), ETS1(18), STAT3(19), and $\operatorname{Myc}(20)$. The ability of other transcriptional 
activators to enhance hypoxia gene transcription in cooperation with HIF1A or independently of HIF1A suggests the complexity of expression of HIF target genes. Depletion of HIF1A/B in nuclear AURKA cells led to a reduction in migration/invasion and expression of the key hypoxia signature genes, suggesting that this metastasis-driving activity of AURKA is HIF1 dependent (Chapter 2, Fig.7A-G).

HIF-dependent transactivation requires other cofactors, including CBP/P300, general transcription factors in assembling the pre-initiation complex (PIC), the RNAPII complex, and chromatin remodelers (21). Evidence shows that HIF target genes are in a paused state of transcription in normoxia conditions, which already contains the RNAPII complex with other transcription cofactors, and is preferred to HIF1a binding (22). With the reports of several other transcription factors enhancing hypoxia-responsive genes, we hypothesize that nuclear AURKA acts as a transcriptional activator and may reduce the pausing of RNAPII complex and cofactor machinery in a normoxia setting. The LCMS/MS analysis of the AURKA-complex shows p300/CBP and RNAPII complex proteins (RPB1, RPB2, RPABC1), thus supporting the role of nuclear AURKA in the regulation of transcription (Chapter 2, Fig.6G-I). Interestingly, LC-MS/MS analysis also revealed other members of the super elongation complex (SEC) (23) interacting with AURKA, including CDK9, MEPCE, TRIM28, PPM1G, and HEXI1. These findings support that AURKA being in the nucleus is interacting with RNAPII complex and the SEC. These findings are in agreement with the previous reports showing AURKA binding to the MYC promoter via interaction with hnRNPk increasing MYC transcription (3). In concordance with this report, we show that nuclear AURKA binds to chromatin complexes that contain hnRNPk (Chapter 2, Fig.6F,H). The global ChIP-seq analysis of AURKA has not been reported; 
therefore, this is a future direction to determine potential transcriptional targets of nuclear AURKA.

Previously it was shown that transactivation capabilities of nuclear AURKA do not require kinase activity. Our previous reports and the current study show that inhibiting AURKA, including nuclear kinase activity, leads to a significant decrease in metastatic burden (Chapter 2, Fig.8). Interestingly, the kinase activity was not required for dissemination but was critical for colonization of distant organs, suggesting a differential effect of kinase activity on different steps in the metastatic cascade. Combining AURKA inhibitors with HIF-targeting compounds might prove to be even more beneficial in preventing and treating metastatic cancer. Previous studies have shown the importance of AURKA inhibitors in decreasing tumors and metastasis $(3,24)$. Our data clearly shows the importance of nuclear AURKA in metastasis, but further research is needed to determine its role in regulating global transcription changes. A better understanding of the function of nuclear AURKA may implicate the discovery of new biomarkers for metastatic disease and potential therapeutic targets.

\section{Future Directions}

Due to the profound gene expression changes inflicted by nuclear AURKA, there are many opportunities for future research to determine the molecular mechanisms of these effects. The previous work $(3,4,25)$ and our work (Chapter 2) discovering transactivation capabilities of AURKA open a new chapter in AURKA biology related to the regulation of transcription (Figure 1). The global ChIP-seq analysis of NLS-AURKA cells compared to NES-AURKA and controls would identify specific promoter regions and genes where AURKA is bound. The mapping of AURKA-driven genes will lay a foundation 
for deciphering novel metastasis-driving genes that AURKA regulates directly or indirectly. The results will also assist in defining new AURKA binding partners involved in transcription control and/or chromatin modification. The knockdown experiments of these transcription factors, similar to siHIF experiments done in Chapter 2, will allow us to verify their role on AURKA-driven metastatic cascade.

The kinase activity of nuclear AURKA is another area of interest that is still not fully understood. Using AURKA inhibitors, it was shown that nuclear AURKA transcriptionally activates Myc and FOXM1 in a kinase-independent manner $(3,4)$. However, xenograft experiments with AURKA inhibitors show kinase function is essential for tumor progression. Using a breast cancer xenograft model in the flank, treatment with AURKA inhibitor led to decreased tumor growth $(3,4)$. From our orthotopic xenograft in Chapter 2, the kinase activity of NLS-AURKA is vital for metastatic colonization, showing significantly decreased metastases with AURKA inhibitor (MLN8237) treatment. This suggests that kinase activity of nuclear AURKA may be necessary for specific steps of tumor progression and metastasis via its effects on the downstream effector proteins, but may not be needed for its transcriptional functions. Future experiments to determine if kinase activity is required include treating cells with MLN8237 and doing qPCR, RNAseq, ChIP-seq, and immunoprecipitation combined with Mass Spec analysis of protein phosphorylation changes. These techniques will allow us to see global changes that may occur when we inhibit kinase function, both transcriptionally and protein-protein interactions. Experiments with MLN8237 can also be done with in vitro 3D invasion assays to look at earlier metastasis stages. It remains undetermined if the nuclear AURKA-HIF1 axis of transcriptional changes depends on kinase activity or if the HIF- 
dependent function is AURKA phosphorylation-dependent. Studies with MLN8237 in our model will need to be conducted to answer these questions.

Another area of further research would be the possible effects of nuclear AURKA on chromatin dynamics. In our study, in NLS-AURKA cells, we observed the DNA compaction to be different than NES-AURKA and control cells, and we also quantified nuclei size to be smaller in NLS-AURKA cells. This could suggest some chromatin remodeling. Supplementing these observations with high-resolution 3D microscopy of the DNA would be an interesting future direction (26). The other data to support the possible effects of AURKA on chromatin comes from our ChIP-WB and the Mass Spectrometry data. The western blot analysis of the ChIP complex precipitated with anti-AURKA antibodies detected multiple proteins, including Histone H3 and Histone H2B (Chapter 2, Fig.6F), suggesting that nuclear AURKA is either directly or indirectly bound to these histone subunits. The Mass Spectrometry analysis of the AURKA immunoprecipitated complex from NLS-AURKA cells identified the following chromatin modifiers RB, PAF1, SETB1, TRIM28, RBBP7, and more, suggesting a potential role of AURKA in the regulation of chromatin dynamics.

Another major interest is the mechanism controlling subcellular localization of AURKA. The only research done on nuclear AURKA localization is identifying the protein region in AURKA that localizes it into the nucleus (amino acids 333-383) (3). There is no identifiable NLS sequence present, but when this region of AURKA protein is deleted, its nuclear localization is lost. These findings suggest that a protein interaction in this region might drive localization. Even though we have done a Mass Spectrometry assessment of AURKA immunoprecipitated complex, this was done with whole-cell lysates, limiting our 
ability to detect potential transport proteins. A cleaner experiment would be to fractionate the cells into cytoplasmic and nuclear compartments and map interactors. We could then identify proteins that could be bringing AURKA into the nucleus and do knockdowns to look at AURKA localization.

Our study in Chapter 2 opens up many areas of future studies for nuclear AURKA functions in gene regulation and binding partners. The global analyses of DNA structure, binding partners, chromatin modifications will help identify new molecular events and processes that AURKA regulates in the nucleus which affect metastasis. The results will help us understand the bigger picture of nuclear AURKA driven biology and how it impacts metastasis, leading to discoveries on how to inhibit those functions and prevent/cure metastasis.

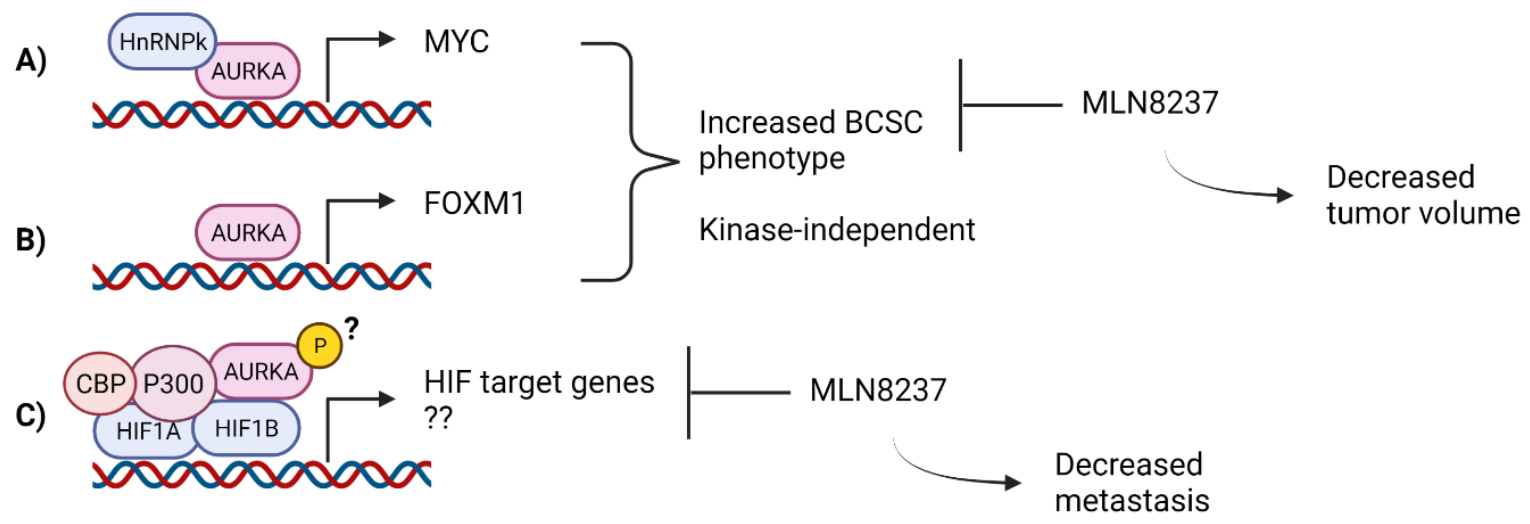

Figure 1. Known Nuclear AURKA Functions. A) Nuclear AURKA and HnRNPk interact, and AURKA transactivates MYC leading to an increased number of breast cancer stem cells. MYC transactivation is kinase-independent, but the treatment with MLN8237 leads to decreased tumor volume. B) Nuclear AURKA transactivates FOXM1 leading to an increased number of breast cancer stem cells. The transactivation of FOXM1 is kinaseindependent, but the treatment with MLN8237 leads to decreased tumor volume. C) Nuclear AURKA transactivates HIF target genes via interaction with HIFs and cofactors $P 300 / C B P$. It is not known if this transcriptional regulation is kinase-dependent. Treatment of MLN8237 leads to decreased metastasis. 


\section{References}

1. Pankova K, Rosel D, Novotny M, Brabek J. The molecular mechanisms of transition between mesenchymal and amoeboid invasiveness in tumor cells. Cell Mol Life Sci. 2010;67(1):63-71.

2. Friedl $\mathrm{P}$, Wolf $\mathrm{K}$, Lammerding J. Nuclear mechanics during cell migration. Curr Opin Cell Biol. 2011;23(1):55-64.

3. Zheng F, Yue C, Li G, He B, Cheng W, Wang X, et al. Nuclear AURKA acquires kinaseindependent transactivating function to enhance breast cancer stem cell phenotype. Nat Commun. 2016;7:10180.

4. Yang N, Wang C, Wang Z, Zona S, Lin SX, Wang X, et al. FOXM1 recruits nuclear Aurora kinase $A$ to participate in a positive feedback loop essential for the self-renewal of breast cancer stem cells. Oncogene. 2017;36(24):3428-40.

5. Kang Y, Siegel PM, Shu W, Drobnjak M, Kakonen SM, Cordon-Cardo C, et al. A multigenic program mediating breast cancer metastasis to bone. Cancer Cell. 2003;3(6):53749.

6. Andrzejewski S, Klimcakova E, Johnson RM, Tabaries S, Annis MG, McGuirk S, et al. PGC-1alpha Promotes Breast Cancer Metastasis and Confers Bioenergetic Flexibility against Metabolic Drugs. Cell Metab. 2017;26(5):778-87 e5.

7. Rankin EB, Giaccia AJ. Hypoxic control of metastasis. Science. 2016;352(6282):17580.

8. Chen A, Sceneay J, Godde N, Kinwel T, Ham S, Thompson EW, et al. Intermittent hypoxia induces a metastatic phenotype in breast cancer. Oncogene. 2018;37(31):4214-25. 9. Bos R, van der Groep P, Greijer AE, Shvarts A, Meijer S, Pinedo HM, et al. Levels of hypoxia-inducible factor-1alpha independently predict prognosis in patients with lymph node negative breast carcinoma. Cancer. 2003;97(6):1573-81 .

10. Gruber G, Greiner RH, Hlushchuk R, Aebersold DM, Altermatt HJ, Berclaz G, et al. Hypoxia-inducible factor 1 alpha in high-risk breast cancer: an independent prognostic parameter? Breast Cancer Res. 2004;6(3):R191-8.

11. Generali D, Berruti A, Brizzi MP, Campo L, Bonardi S, Wigfield S, et al. Hypoxiainducible factor-1alpha expression predicts a poor response to primary chemoendocrine therapy and disease-free survival in primary human breast cancer. Clin Cancer Res. 2006;12(15):4562-8.

12. Wang W, He YF, Sun QK, Wang Y, Han XH, Peng DF, et al. Hypoxia-inducible factor 1alpha in breast cancer prognosis. Clin Chim Acta. 2014;428:32-7.

13. Dupuy F, Tabaries S, Andrzejewski S, Dong Z, Blagih J, Annis MG, et al. PDK1Dependent Metabolic Reprogramming Dictates Metastatic Potential in Breast Cancer. Cell Metab. 2015;22(4):577-89.

14. Koizume S, Miyagi Y. Diverse Mechanisms of Sp1-Dependent Transcriptional Regulation Potentially Involved in the Adaptive Response of Cancer Cells to Oxygen-Deficient Conditions. Cancers (Basel). 2015;8(1). 
15. Yamashita K, Discher DJ, Hu J, Bishopric NH, Webster KA. Molecular regulation of the endothelin-1 gene by hypoxia. Contributions of hypoxia-inducible factor-1, activator protein-1, GATA-2, AND p300/CBP. J Biol Chem. 2001;276(16):12645-53.

16. Liao H, Hyman MC, Lawrence DA, Pinsky DJ. Molecular regulation of the PAI-1 gene by hypoxia: contributions of Egr-1, HIF-1alpha, and C/EBPalpha. FASEB J. 2007;21(3):935-49.

17. Sanchez-Elsner T, Ramirez JR, Sanz-Rodriguez F, Varela E, Bernabeu C, Botella LM. A cross-talk between hypoxia and TGF-beta orchestrates erythropoietin gene regulation through SP1 and Smads. J Mol Biol. 2004;336(1):9-24.

18. Salnikow K, Aprelikova O, Ivanov S, Tackett S, Kaczmarek M, Karaczyn A, et al. Regulation of hypoxia-inducible genes by ETS1 transcription factor. Carcinogenesis. 2008;29(8):1493-9.

19. Pawlus MR, Wang L, Hu CJ. STAT3 and HIF1alpha cooperatively activate HIF1 target genes in MDA-MB-231 and RCC4 cells. Oncogene. 2014;33(13):1670-9.

20. Huang LE. Carrot and stick: HIF-alpha engages c-Myc in hypoxic adaptation. Cell Death Differ. 2008;15(4):672-7.

21. Dengler VL, Galbraith M, Espinosa JM. Transcriptional regulation by hypoxia inducible factors. Crit Rev Biochem Mol Biol. 2014;49(1):1-15.

22. Xia X, Kung AL. Preferential binding of HIF-1 to transcriptionally active loci determines cell-type specific response to hypoxia. Genome Biol. 2009;10(10):R113.

23. Luo Z, Lin C, Shilatifard A. The super elongation complex (SEC) family in transcriptional control. Nat Rev Mol Cell Biol. 2012;13(9):543-7.

24. Kozyreva VK, Kiseleva AA, Ice RJ, Jones BC, Loskutov YV, Matalkah F, et al. Combination of Eribulin and Aurora A Inhibitor MLN8237 Prevents Metastatic Colonization and Induces Cytotoxic Autophagy in Breast Cancer. Mol Cancer Ther. 2016;15(8):1809-22.

25. Lu L, Han H, Tian Y, Li W, Zhang J, Feng M, et al. Aurora kinase A mediates c-Myc's oncogenic effects in hepatocellular carcinoma. Mol Carcinogen. 2015;54(11):1467-79.

26. Rozwadowska N, Kolanowski T, Wiland E, Siatkowski M, Pawlak P, Malcher A, et al. Characterisation of nuclear architectural alterations during in vitro differentiation of human stem cells of myogenic origin. PLoS One. 2013;8(9):e73231. 


\section{Appendix}

Figure publication and licensing rights from BioRender. 


\section{Confirmation of Publication and Licensing Rights}

July 26th, 2021

Science Suite Inc.

Subscription:

Agreement number: Journal name:

\author{
Student Plan \\ HO22R82WWB \\ Dissertation
}

To whom this may concern,

This document is to confirm that Kristina Marinak has been granted a license to use the BioRender content, including icons, templates and other original artwork, appearing in the attached completed graphic pursuant to BioRender's Academic License Terms. This license permits BioRender content to be sublicensed for use in journal publications.

All rights and ownership of BioRender content are reserved by BioRender. All completed graphics must be accompanied by the following citation: "Created with BioRender.com".

BioRender content included in the completed graphic is not licensed for any commercial uses beyond publication in a journal. For any commercial use of this figure, users may, if allowed, recreate it in BioRender under an Industry BioRender Plan.

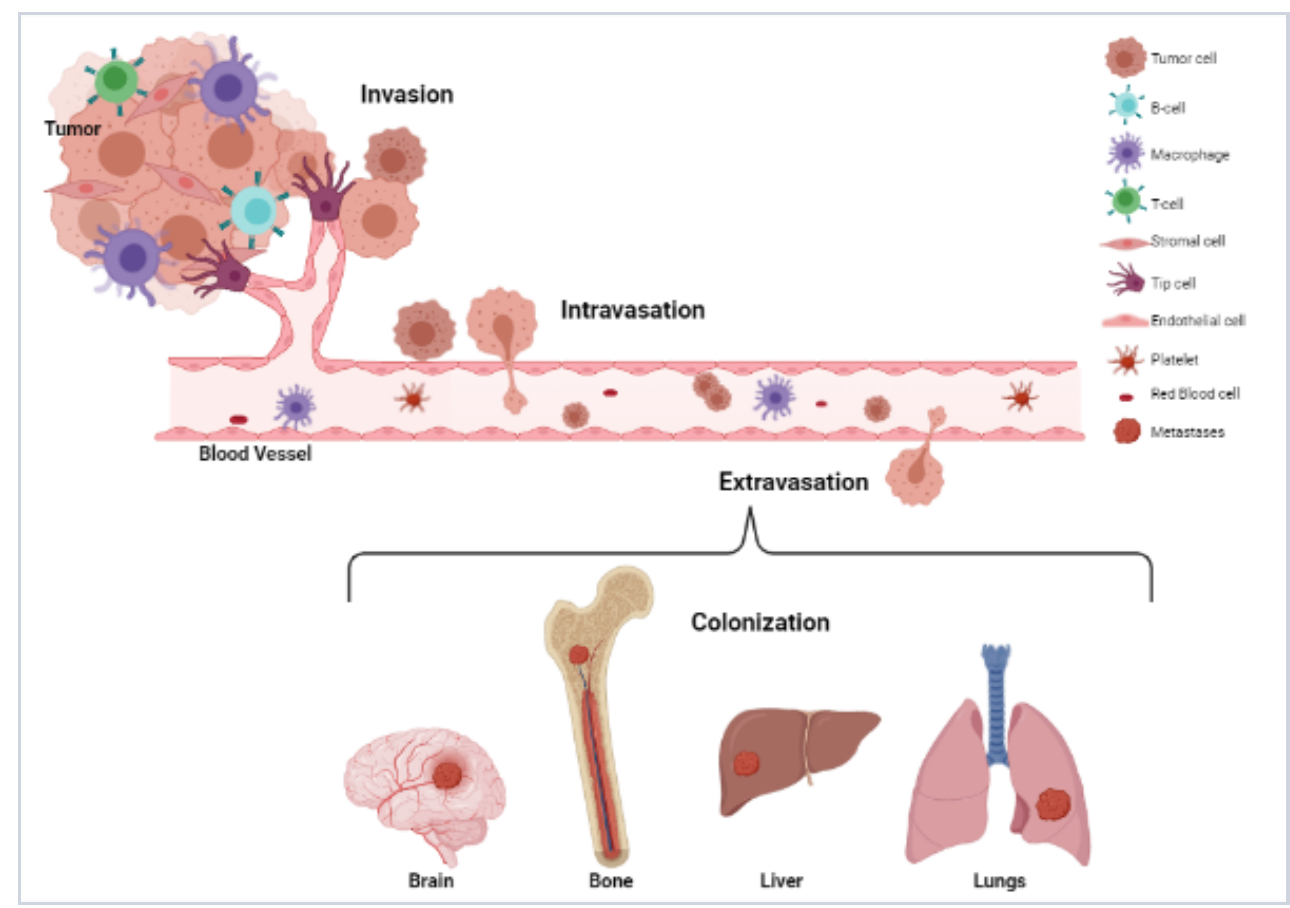

For any questions regarding this document, or other questions about publishing with BioRender refer to our BioRender Publication Guide, or contact BioRender Support at support@biorender.com. 


\section{Confirmation of Publication and Licensing Rights}

July 26th, 2021

Science Suite Inc.

Subscription:

Agreement number: Journal name:

\author{
Student Plan \\ JH22R832GX \\ Dissertation
}

To whom this may concern,

This document is to confirm that Kristina Marinak has been granted a license to use the BioRender content, including icons, templates and other original artwork, appearing in the attached completed graphic pursuant to BioRender's Academic License Terms. This license permits BioRender content to be sublicensed for use in journal publications.

All rights and ownership of BioRender content are reserved by BioRender. All completed graphics must be accompanied by the following citation: "Created with BioRender.com".

BioRender content included in the completed graphic is not licensed for any commercial uses beyond publication in a journal. For any commercial use of this figure, users may, if allowed, recreate it in BioRender under an Industry BioRender Plan.

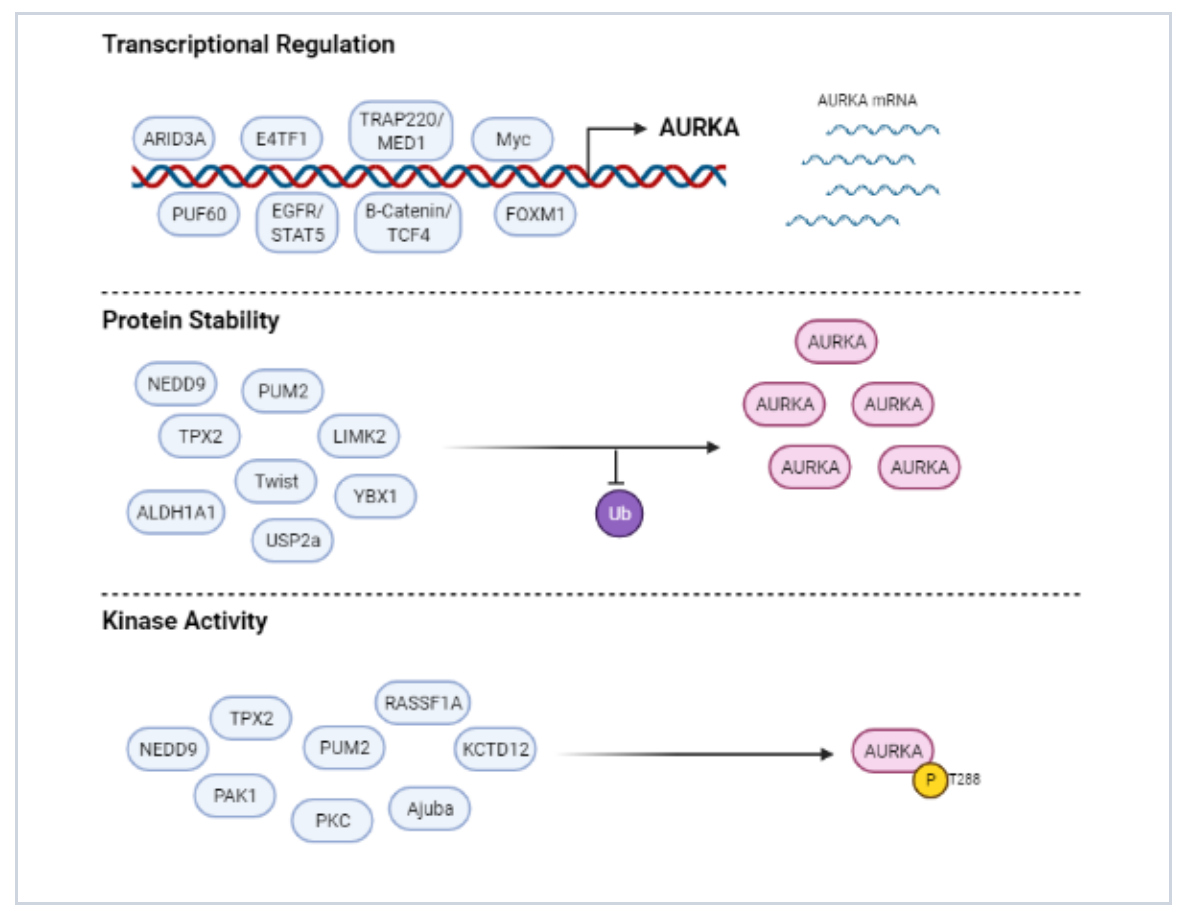

For any questions regarding this document, or other questions about publishing with BioRender refer to our BioRender Publication Guide, or contact BioRender Support at support@biorender.com. 


\section{Confirmation of Publication and Licensing Rights}

July 26th, 2021

Science Suite Inc.

Subscription:

Agreement number: Journal name:

\author{
Student Plan \\ EV22R83G6G \\ Dissertation
}

To whom this may concern,

This document is to confirm that Kristina Marinak has been granted a license to use the BioRender content, including icons, templates and other original artwork, appearing in the attached completed graphic pursuant to BioRender's Academic License Terms. This license permits BioRender content to be sublicensed for use in journal publications.

All rights and ownership of BioRender content are reserved by BioRender. All completed graphics must be accompanied by the following citation: "Created with BioRender.com".

BioRender content included in the completed graphic is not licensed for any commercial uses beyond publication in a journal. For any commercial use of this figure, users may, if allowed, recreate it in BioRender under an Industry BioRender Plan.

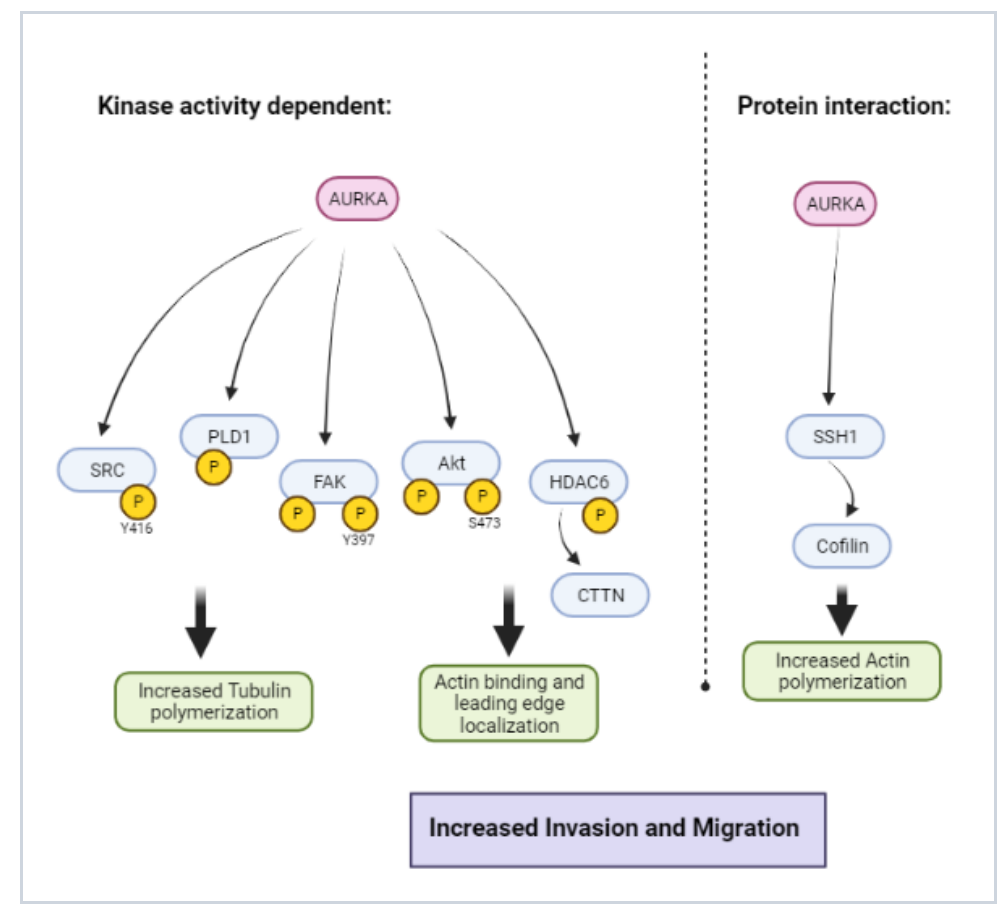

For any questions regarding this document, or other questions about publishing with BioRender refer to our BioRender Publication Guide, or contact BioRender Support at support@biorender.com. 


\section{Confirmation of Publication and Licensing Rights}

July 26th, 2021

Science Suite Inc.

Subscription:

Agreement number:

Journal name:

\author{
Student Plan \\ CW22R83IKW \\ Dissertation
}

To whom this may concern,

This document is to confirm that Kristina Marinak has been granted a license to use the BioRender content, including icons, templates and other original artwork, appearing in the attached completed graphic pursuant to BioRender's Academic License Terms. This license permits BioRender content to be sublicensed for use in journal publications.

All rights and ownership of BioRender content are reserved by BioRender. All completed graphics must be accompanied by the following citation: "Created with BioRender.com".

BioRender content included in the completed graphic is not licensed for any commercial uses beyond publication in a journal. For any commercial use of this figure, users may, if allowed, recreate it in BioRender under an Industry BioRender Plan.

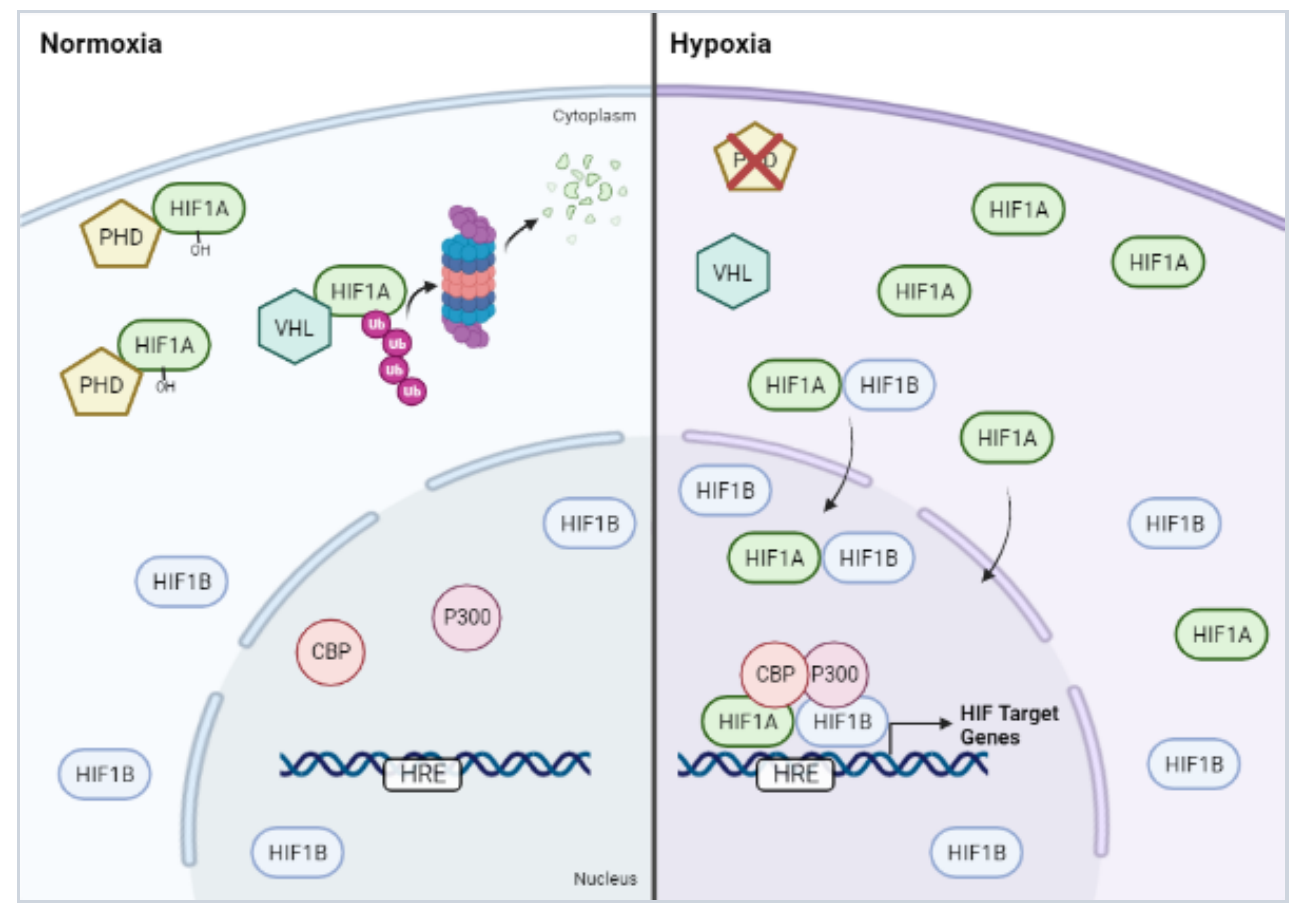

For any questions regarding this document, or other questions about publishing with BioRender refer to our BioRender Publication Guide, or contact BioRender Support at support@biorender.com. 


\section{Confirmation of Publication and Licensing Rights}

July 26th, 2021

Science Suite Inc.

Subscription:

Agreement number: Journal name:

\author{
Student Plan \\ TV22R83KMW \\ Dissertation
}

To whom this may concern,

This document is to confirm that Kristina Marinak has been granted a license to use the BioRender content, including icons, templates and other original artwork, appearing in the attached completed graphic pursuant to BioRender's Academic License Terms. This license permits BioRender content to be sublicensed for use in journal publications.

All rights and ownership of BioRender content are reserved by BioRender. All completed graphics must be accompanied by the following citation: "Created with BioRender.com".

BioRender content included in the completed graphic is not licensed for any commercial uses beyond publication in a journal. For any commercial use of this figure, users may, if allowed, recreate it in BioRender under an Industry BioRender Plan.

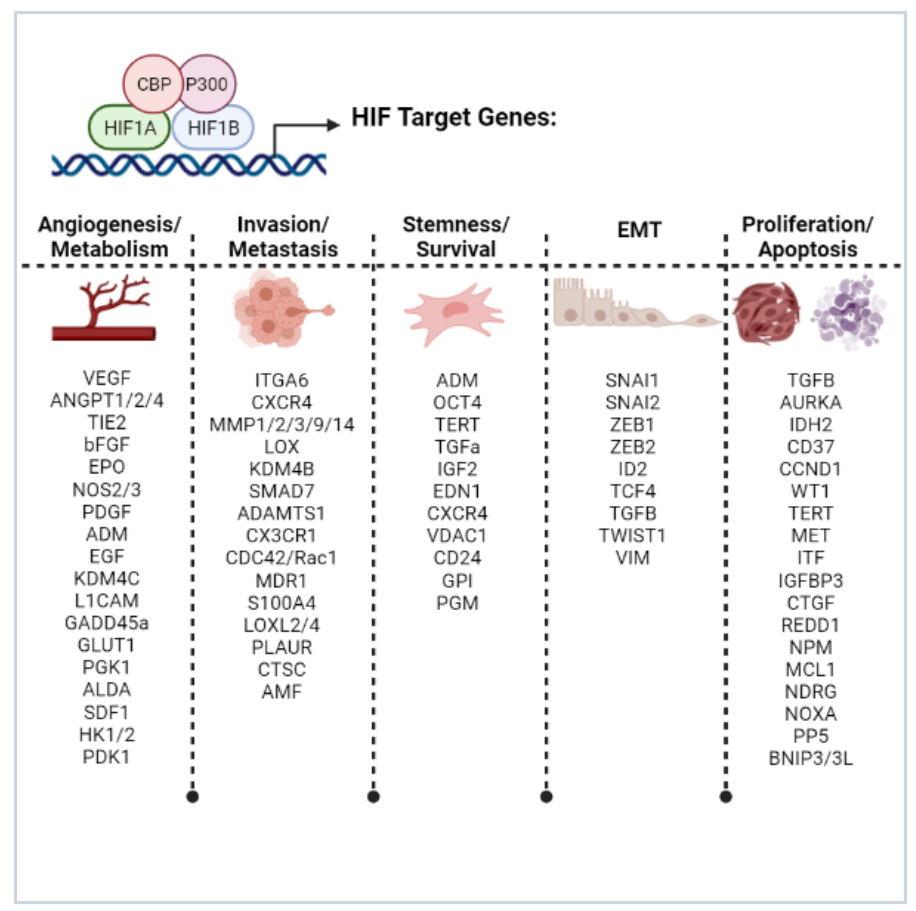

For any questions regarding this document, or other questions about publishing with BioRender refer to our BioRender Publication Guide, or contact BioRender Support at support@biorender.com. 


\section{RENDER}

\section{Confirmation of Publication and Licensing Rights}

July 26th, 2021

Science Suite Inc.

Subscription:

Agreement number: Journal name:

\author{
Student Plan \\ BH22R83S9U \\ Dissertation
}

To whom this may concern,

This document is to confirm that Kristina Marinak has been granted a license to use the BioRender content, including icons, templates and other original artwork, appearing in the attached completed graphic pursuant to BioRender's Academic License Terms. This license permits BioRender content to be sublicensed for use in journal publications.

All rights and ownership of BioRender content are reserved by BioRender. All completed graphics must be accompanied by the following citation: "Created with BioRender.com".

BioRender content included in the completed graphic is not licensed for any commercial uses beyond publication in a journal. For any commercial use of this figure, users may, if allowed, recreate it in BioRender under an Industry BioRender Plan.

A)

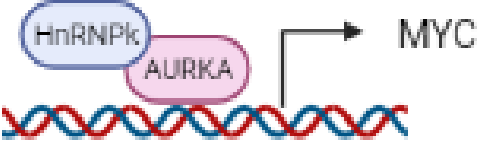

B)
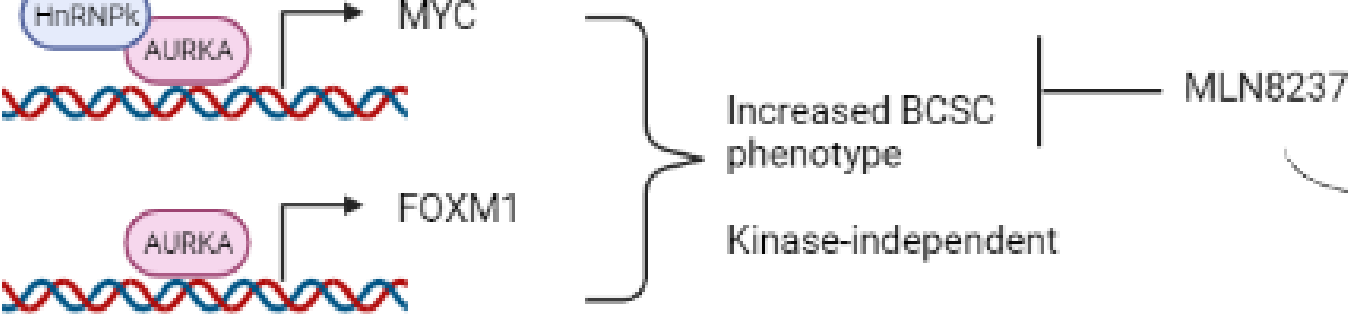

Kinase-independent

Decreased tumor volume

C)
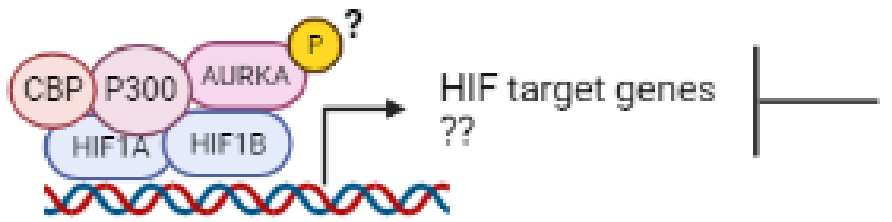

\section{MLN8237}

Decreased

metastasis

For any questions regarding this document, or other questions about publishing with BioRender refer to our BioRender Publication Guide, or contact BioRender Support at support@biorender.com. 